\title{
Protocols for Monitoring Habitat Restoration Projects in the Lower Columbia River and Estuary
}
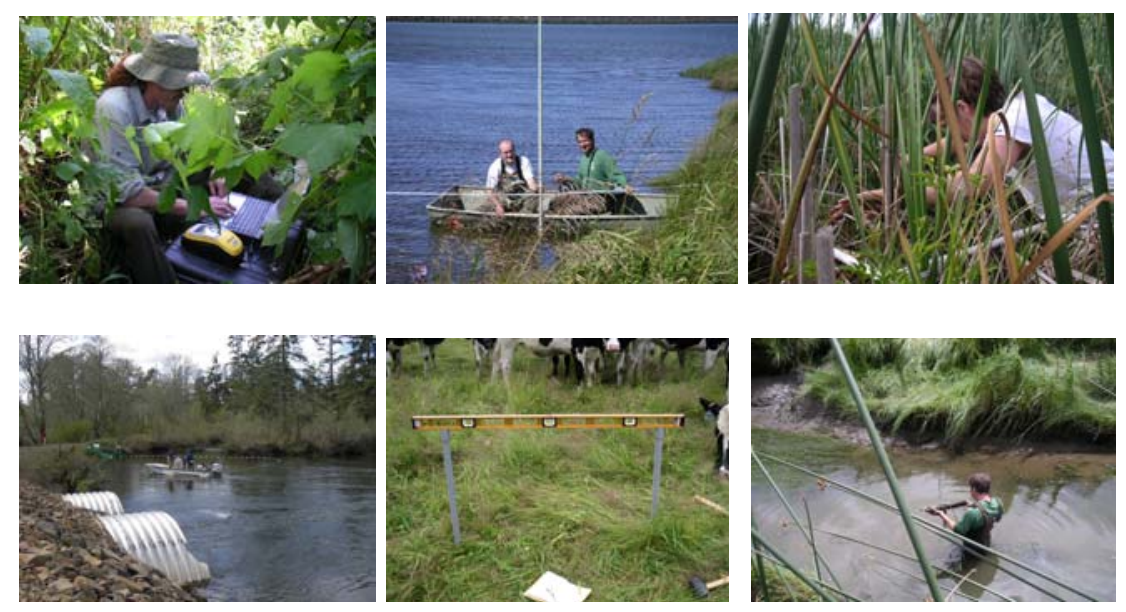

G. C. Roegner

H. L. Diefenderfer

A. B. Borde

R. M. Thom

E. M. Dawley

A. H. Whiting

S. A. Zimmerman

G. E. Johnson

Final Report

April 25, 2008

Prepared for the U.S. Army Corps of Engineers

Portland District, Portland, Oregon

Under a Related Services Agreement with the U.S. Department of Energy

Contract DE-AC05-76RL01830
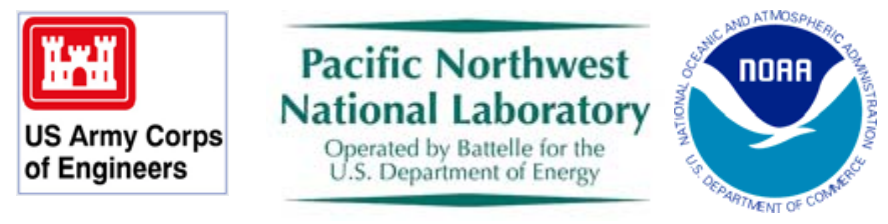


\title{
DISCLAIMER
}

This report was prepared as an account of work sponsored by an agency of the United States Government. Neither the United States Government nor any agency thereof, nor Battelle Memorial Institute, nor any of their employees, makes any warranty, express or implied, or assumes any legal liability or responsibility for the accuracy, completeness, or usefulness of any information, apparatus, product, or process disclosed, or represents that its use would not infringe privately owned rights. Reference herein to any specific commercial product, process, or service by trade name, trademark, manufacturer, or otherwise does not necessarily constitute or imply its endorsement, recommendation, or favoring by the United States Government or any agency thereof, or Battelle Memorial Institute. The views and opinions of authors expressed herein do not necessarily state or reflect those of the United States Government or any agency thereof.

\author{
PACIFIC NORTHWEST NATIONAL LABORATORY \\ operated by \\ BATTELLE \\ for the \\ UNITED STATES DEPARTMENT OF ENERGY \\ under Contract DE-AC05-76RL01830
}

\begin{abstract}
Printed in the United States of America Available to DOE and DOE contractors from the Office of Scientific and Technical Information,

P.O. Box 62, Oak Ridge, TN 37831-0062; ph: (865) 576-8401 fax: (865) 576-5728 email: reports@adonis.osti.gov
\end{abstract}

Available to the public from the National Technical Information Service, U.S. Department of Commerce, 5285 Port Royal Rd., Springfield, VA 22161 ph: (800) 553-6847 fax: (703) 605-6900

email: orders@ntis.fedworld.gov

online ordering: http://www.ntis.gov/ordering.htm

Also available at http://www.pnl.gov/publications/ 


\section{Protocols for Monitoring Habitat Restoration Projects in the Lower Columbia River and Estuary}

G. Curtis Roegner ${ }^{1}$

Heida L. Diefenderfer ${ }^{2}$

Amy B. Borde ${ }^{2}$

Ron M. Thom ${ }^{2}$

Earl M. Dawley ${ }^{3}$

Allan H. Whiting ${ }^{4}$

Shon A. Zimmerman ${ }^{2}$

Gary E. Johnson ${ }^{2}$

Final Report

April 25, 2008

Prepared for the U.S. Army Corps of Engineers

Portland District, Portland, Oregon

Under a Related Services Agreement

with the U.S. Department of Energy

Contract DE-AC05-76RL01830

Pacific Northwest National Laboratory

Richland, Washington 99352

National Oceanographic and Atmospheric Administration, National Marine Fisheries Service

2

Pacific Northwest National Laboratory

National Marine Fisheries Service (retired)

Columbia River Estuary Study Taskforce

(now with P.C. Trask and Associates) 



\section{Abstract}

This document describes a set of protocols developed by the National Marine Fisheries Service of the National Oceanographic and Atmospheric Administration, Pacific Northwest National Laboratory, and the Columbia River Estuary Study Taskforce with the support of the U.S. Army Corps of Engineers. These protocols are designed for researchers and managers monitoring the effectiveness of actions to restore degraded wetland habitat in the lower Columbia River and estuary (CRE). The intent is to promote a standard set of monitoring protocols to assess and compare habitat restoration projects in the region.

The goal of many restoration activities in the CRE is to repair the connectivity and function of wetland habitats, and thereby to allow juvenile salmon to regain benefit from these important rearing and refuge areas. To do this effectively, researchers and managers require the means to 1) evaluate the results of individual restoration activities, 2) compare results among projects, and 3) determine the long-term and cumulative effects of habitat restoration on the overall estuary ecosystem. To help achieve this, we have developed a standardized set of monitoring protocols. We limited the number of metrics to a proposed "core" set and selected measurement methods that are straightforward and economical to use. By "core," we mean an optimum suite of metrics that can adequately detail the results of restoration, depending on the goals of the restoration action and financial and logistical limitations of comprehensively monitoring ecological change over extended temporal and spatial scales. We selected core metrics based on the following criteria: 1) correspond to commonly held restoration project goals; 2) are applicable to all sites; 3) characterize controlling factors, ecosystem structure, and ecosystem function; 4) are relevant to both present and future investigations; and 5) are practical in terms of level of effort.

In this document, we summarize the types of restoration strategies being planned and implemented in the CRE. We then propose a set of metrics and statistical design for restoration monitoring activities based on commonly shared ecological goals. Finally, we provide specific protocols for this set of estuary monitoring metrics. Monitoring protocols are provided for hydrology (water surface elevation); water quality (temperature, salinity); elevation (topography); landscape features (remote sensing); plant community (composition and cover); vegetation plantings (success); and fish community (species, temporal presence, size/age structure).

\section{Preface}

This research was conducted under the auspices of the U.S. Army Corps of Engineers' (Corps) Anadromous Fish Evaluation Program (AFEP; study code EST-P-04-04), and funded by Congress through the Columbia River Fish Mitigation Project. The study is implemented and overseen by the Corps' Portland District, with Blaine Ebberts and Doug Putman as the Corps' Biological Technical Lead and Program Manager, respectively. The protocols benefited from feedback and discussions by scientists at workshops on Columbia River estuary restoration project monitoring convened in June 2004 and February 2007. The study was conducted jointly by the Pacific Northwest National Laboratory (operated 
by Battelle for the U.S. Department of Energy), the National Marine Fisheries Service, and the Columbia River Estuary Study Taskforce. We invite comments on this document. Our intent is to achieve a widely adopted standard set of metrics and protocols for monitoring the effectiveness of restoration projects in the Columbia River estuary. This document replaces the version released in April 2006. Please send comments or questions to Blaine Ebberts (blaine.d.ebberts@usace.army.mil; 503-808-4763).

Suggested citation: Roegner, G.C., H.L. Diefenderfer, A.B. Borde, R.M. Thom, E.M. Dawley, A.H. Whiting, S.A. Zimmerman, and G.E. Johnson. 2008. Protocols for Monitoring Habitat Restoration Projects in the Lower Columbia River and Estuary. PNNL-15793. Report by Pacific Northwest National Laboratory, National Marine Fisheries Service, and Columbia River Estuary Study Taskforce submitted to the U.S. Army Corps of Engineers, Portland District, Portland, Oregon. 


\section{Acknowledgments}

We thank Blaine Ebberts and Doug Putman of the U.S. Army Corps of Engineers for supporting the development of these protocols, beginning in 2004 with a process that included workshops, literature review, field testing, and writing and a first draft released for review in 2006. During this process, many individuals with expertise on the Columbia River have contributed their knowledge or reviewed the document, which could not have taken the present form without their assistance. We are particularly grateful to George Kral of Ash Creek Forest Management in Tigard, Oregon, for permitting the republication of his methods for monitoring revegetation.

The following individuals responded to the invitation by the authors to attend a meeting on June 23, 2004, for the purpose of involving restoration project managers in identifying minimum monitoring indicators and appropriate methods. The meeting was convened by the Lower Columbia River Estuary Partnership, U.S. Army Corps of Engineers, Pacific Northwest National Laboratory, and National Marine Fisheries Service at the offices of the Estuary Partnership in Portland, Oregon. The contributions of the following participants were invaluable foundations for this document: Michael Anderson, Taunja Berquam, Matt Burlin, Tim Counihan, Todd Cullison, Blaine Ebberts, Craig Haskell, Joe Hymer, Jason Karnezis, Scott McEwen, Michelle Michaud, Dave Sahagian, Ian Sinks, Kathryn Sobocinski, Janelle St. Pierre, Robert Warren, Jack Wiles, and Greg Williams.

Following release of the 2006 working draft, we implemented the protocols at field test sites, and we are grateful for cooperation by the land owners and managers: the Columbia Land Trust and the Port of Astoria. In addition to our own field testing, we received valuable comments from others who implemented the draft protocols in the course of their work: Laura Brophy, Lori Lilly, Micah Russell, and Ian Sinks. Many individuals assisted us in field testing, including Jimmie Cotton, Kate Hall, April Rouse, Micah Russell, and Kathryn Sobocinski. Following field testing, the following individuals provided additional feedback on the draft revised protocols at a meeting convened on February 8, 2007: Rita Beaston, Laura Brophy, Matt Burlin, Suzi Cloutier, Robert Ellis, Kas Guillozet, Joe Krieter, Jill Leary, Lori Lilly, Margaret Magruder, Scott McEwen, Doug Putnam, and Kathryn Sobocinski. We also received valuable review comments on the most recent version of the document from Krista Jones and Nikki Sather. 


\section{Contents}

Abstract .iii

Preface iii

Acknowledgments.

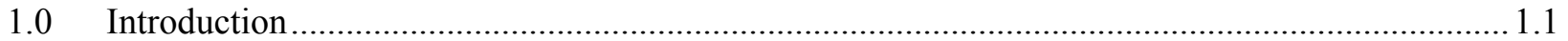

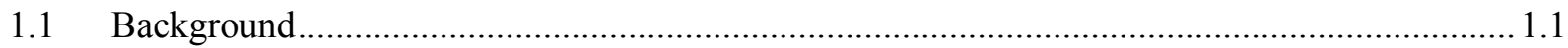

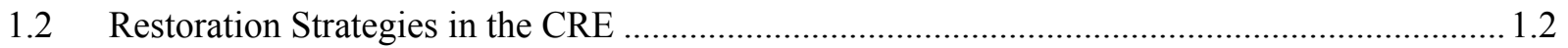

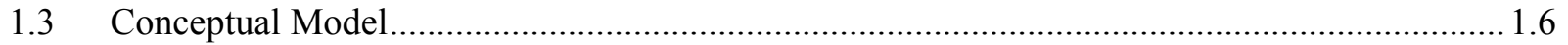

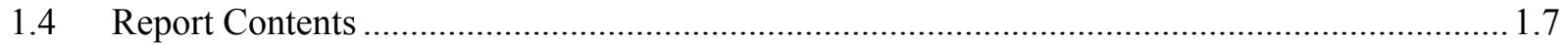

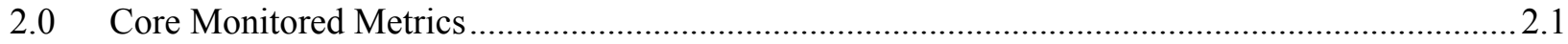

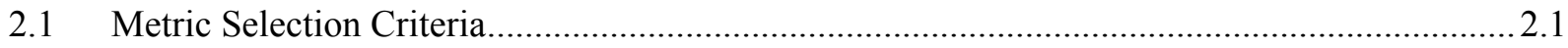

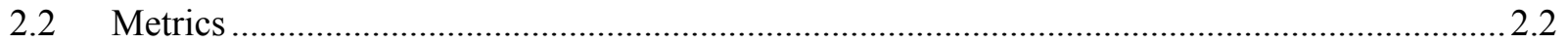

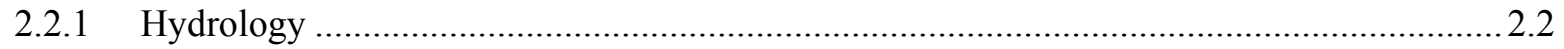

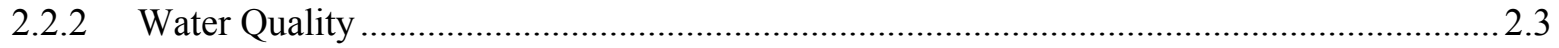

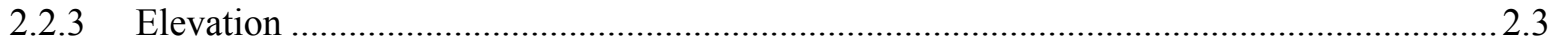

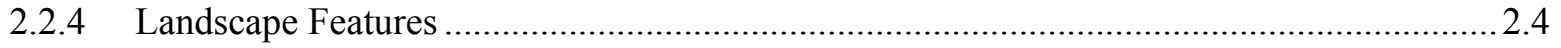

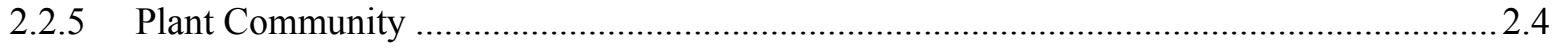

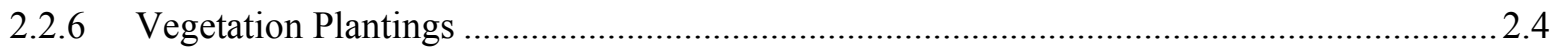

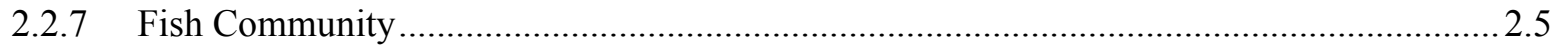

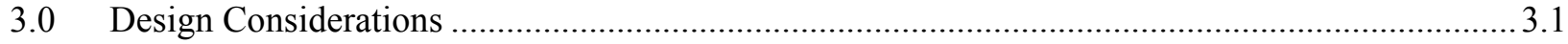

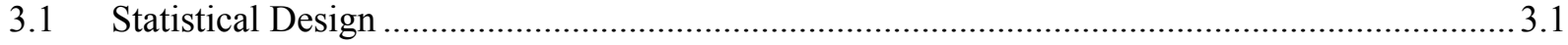

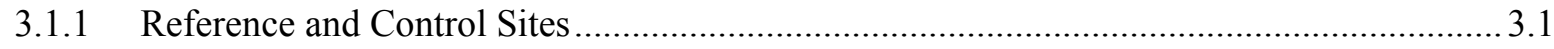

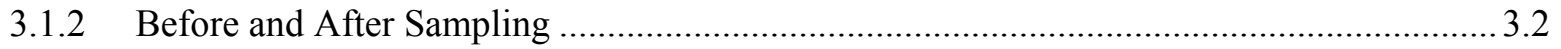

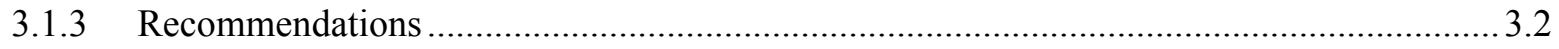

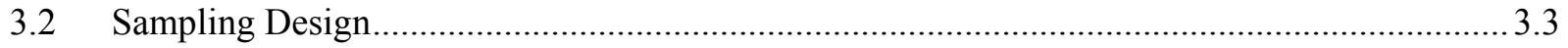

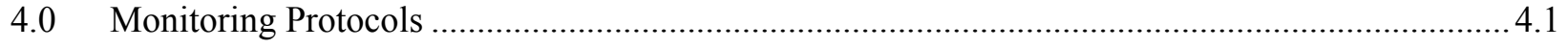

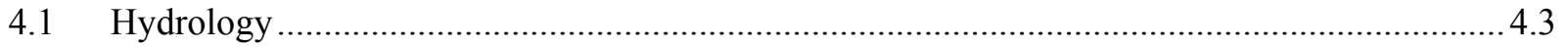

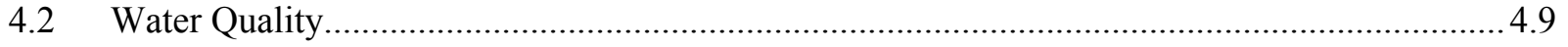

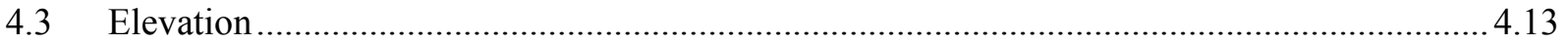

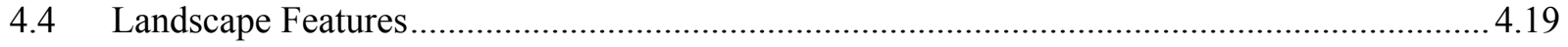

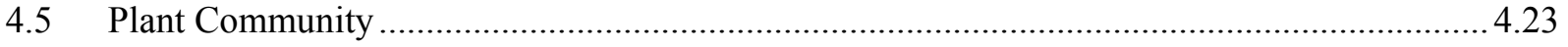

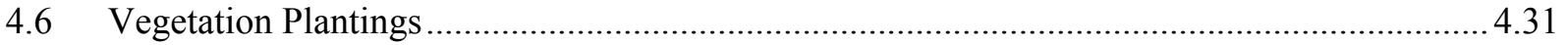

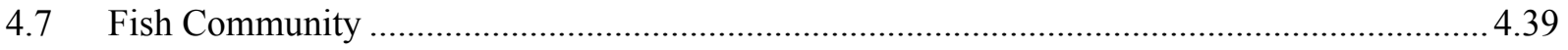

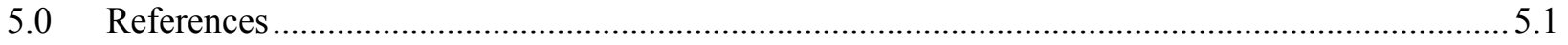




\section{Figures}

Figure 1.1. Habitat Restoration, Enhancement, and Protection Projects 1.3

Figure 1.2. Columbia River Estuary Conceptual Model Applied to Estuary RME Action Effectiveness Research for Tidal Reconnection Projects.

Figure 4.1. Deployment Options for Data Logging Instruments.

Figure 4.2. Water Level Variations Surrounding a Tide Gate Removal at Kandoll Farm, 2005.

Figure 4.3. Exposure-Elevation Plot for Pre- and Post-Restoration Periods at Kandoll Farm Restoration Site, 2005

Figure 4.4. Time Series of Mean Daily Temperature $(+\mathrm{sd})$ for Reference and

Restoration Sites Surrounding Tide Gate Removal, Grays River system, 2005

Figure 4.5. Channel Cross-Sections at Kandoll Farm, 2005-2007

Figure 4.6. Before and After Photo Points at a Culvert Installation on Kandoll Farm

Figure 4.7. Example of Baseline and Transect Sampling Design in Herbaceous Area .

Figure 4.8. Example of Sampling Design in Forested Wetland 4.26

Figure 4.10. Percent Cover of Dominant Flora, Kandoll Farm 2005 4.30

Figure 4.11. Example of a Woody Vegetation Planting Site Showing Location of Sample Area, Baseline, Transects, and Sample Plots

Figure 4.12. Time Series of Relative CPUE for Salmonids Sampled at Restoration and Reference Sites, Grays River System 2006 and 2007

Figure 4.13. Size-Frequency of Juvenile Salmonids Captured in Restoration and Reference Sites, Grays River system $2007 .$.

Figure 4.14. Fish Community Structure and Diversity Indices, Grays River System, 2007

\section{Tables}

Table 1.1. Restoration Strategies, Examples of Project Types, and Targeted Ecosystem Benefits for the CRE

Table 2.1. Summary of Core Metrics for Lower Columbia River and Estuary Restoration Projects ....... 2.3

Table 3.1. The Sequence of Sampling Events

Table 4.1. Average Percent Cover of the Dominant Plant Species at Two Sampling

Locations on a Restoration Site before and after a Restoration Action.

Table 4.2. Example weighted similarity index 4.30

Table 4.3. Plant Vigor Categories. 


\subsection{Introduction}

The recovery of salmonid stocks requires restoration of estuarine habitats supporting the diversity of life history patterns that historically mitigated for environmental variability (NOAA 2004; Bottom et al. 2005). Research on salmon distribution patterns in the lower Columbia River and estuary (CRE), as well as other West Coast estuarine systems, indicates use of tidal freshwater and estuarine habitats by diverse stocks of subyearling and yearling salmonids (e.g., Reimers and Loeffel 1967; Healey 1980; Levy and Northrote 1982; Shreffler et al. 1990, 1992; Levings et al. 1991; Levings 1994; Sommer et al. 2001; Tanner et al. 2002; Roegner et al. 2005). Much of this historically abundant habitat has been isolated, degraded, or destroyed (Thomas 1983; Burke 2004). The goal of many restoration activities is to repair connectivity and function of these habitats, to thereby allow fish to regain benefits from these important rearing and refuge areas. However, researchers and managers require the means to 1) evaluate the effectiveness of individual restoration activities (Roni et al. 2002), 2) compare projects (Neckles et al. 2002; Williams and Orr 2002), and 3) determine the long-term and cumulative effects of habitat restoration on the overall ecosystem (Steyer et al. 2003; Diefenderfer et al. 2005a). This can best be achieved with a standardized set of research and monitoring metrics. The purpose of this document is to provide protocols for monitoring the effectiveness of habitat restoration projects in the CRE.

A review of the literature uncovered many relevant examples of restoration monitoring theory and design (e.g., Simenstad et al. 1991; Callaway et al. 2001; Hillman 2004; Rice et al. 2005), yet none concisely outlined procedures particular to the CRE (Diefenderfer et al. 2005a). The intent of this manual, therefore, is to provide the rationale and procedures for standardized metrics specific to the tidal waters of the Columbia River estuary. The ultimate goal for results using these methods, which may be fully realized decades from now, is to compile a compatible time series database of physical and biological metrics collected from many individual restoration projects. This database will enable evaluation of the effectiveness of individual restoration projects, as well as the cumulative effects of many restoration projects, on improving salmon habitat in the CRE. Protocols for the metrics are provided herein.

\subsection{Background}

The lower Columbia River and estuary have been highly modified by human activities that converted tidal wetlands into agricultural and commercial uses. Construction of dikes, docks, and roads, installation of tide gates, and alterations such as dredging and filling have destroyed habitat and disconnected large areas of emergent and forested wetlands from tidal inundation. This has resulted in the loss of $70-90 \%$ of the productive wetlands in the estuarine and tidal freshwater regions of the lower Columbia including important spawning and rearing habitat (Thomas 1983; Simenstad et al. 1992; Weitkamp 1994; Kukulka and Jay 2003a, b) for several Evolutionarily Significant Units of salmonids (ESUs; Waples 1991).

The incentive for many restoration activities in the CRE involves increasing habitat for rearing and migrating juvenile salmonids listed as threatened or endangered under the Endangered Species Act. Salmon stocks most likely to directly benefit from restoration activities in the CRE are the wild and hatchery-reared ocean type Chinook salmon, chum salmon, and stream-type coho salmon from lower river tributaries (reviewed in Diefenderfer et al. 2005a). However, migrants from tributaries throughout 
the Snake, and Upper- and Mid-Columbia River systems are thought to have utilized estuarine habitat in the early 1900s, prior to extensive dam construction and loss of shallow water and wetland habitat (Rich 1920; Weitkamp 1994; Lichatowich and Mobrand 1995; Burke 2004; Bottom et al. 2005). While most individuals from the surviving ESUs of upriver stocks currently migrate rapidly through the estuary to the ocean, some individuals of those groups (usually the smallest and latest migrants) display a protracted migration to and through the estuary and presumably gain enhanced growth and survival prior to ocean entry (Dawley et al. 1986; Diefenderfer et al. 2005a). Thus, while the greatest use of estuarine habitats is expected from fish originating in lower river tributaries, threatened and endangered salmon from upriver tributaries are also expected to benefit from increased habitat opportunity.

There is growing momentum to reverse land use patterns and specifically to reconnect historical wetland areas to the influence of tidal inundation. The challenge we face is how to evaluate the effects of various restoration projects on wetland function, given that the goals, scales, resources, and managing partnerships of projects vary greatly. To this end, there has been a regional movement in the Pacific Northwest and elsewhere to standardize measurement metrics and techniques that will facilitate comparison between restoration studies over time (Callaway et al. 2001; Neckles et al. 2002; Johnson et al. 2008; Hillman 2004; Rice et al. 2005). Standardized metrics are required to provide the best possible input to managers making decisions regarding habitat restoration in the CRE.

\subsection{Restoration Strategies in the CRE}

Various types of restoration are occurring throughout the CRE region in an effort to recover lost habitats (Figure 1.1). These activities fall under five broad strategies summarized in Table 1.1 (Johnson et al. 2003). The protocols provided herein are applicable to restoration, ${ }^{1}$ enhancement, and creation activities, detailed below. In addition, conservation and protection activities ongoing in the CRE include acquisition of land or development rights, regulations on land use such as zoning designations and protection ordinances, and financial incentives for landowners to manage land for conservation. Improved management techniques being encouraged through such means include riparian setbacks as well as agricultural practices such as manure management, the addition of riparian buffer strips, integrated pest management, and off-stream livestock watering techniques.

- Restoration - Restoration activities are designed to return degraded habitat to a state closer to the historical ecological condition. The most common restoration approaches in the CRE are tidal reconnection through dike breaching, dike removal, culvert upgrades, or culvert installations. The selected monitoring metrics of this manual are specifically chosen to track ecosystem changes resulting from this type of restoration treatment.

- Enhancement - Habitat enhancement is the improvement of a targeted ecological attribute and/or process. Enhancement projects in the CRE include tide gate or culvert replacement, riparian plantings and fencing, invasive species removal, and streambank stabilization.

\footnotetext{
${ }^{1}$ Unless noted otherwise, the term "restoration" refers collectively to all strategies applied in the CRE.
} 


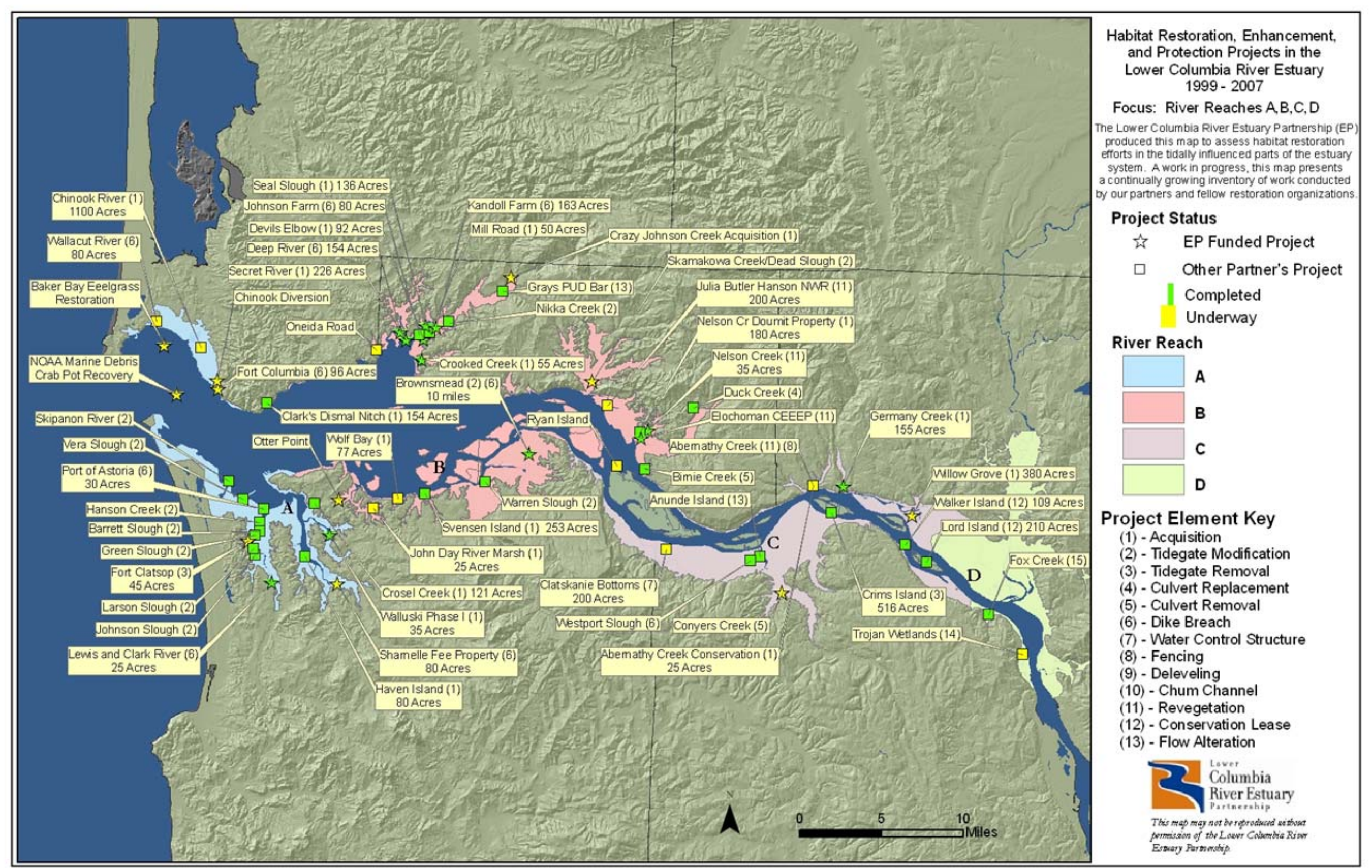




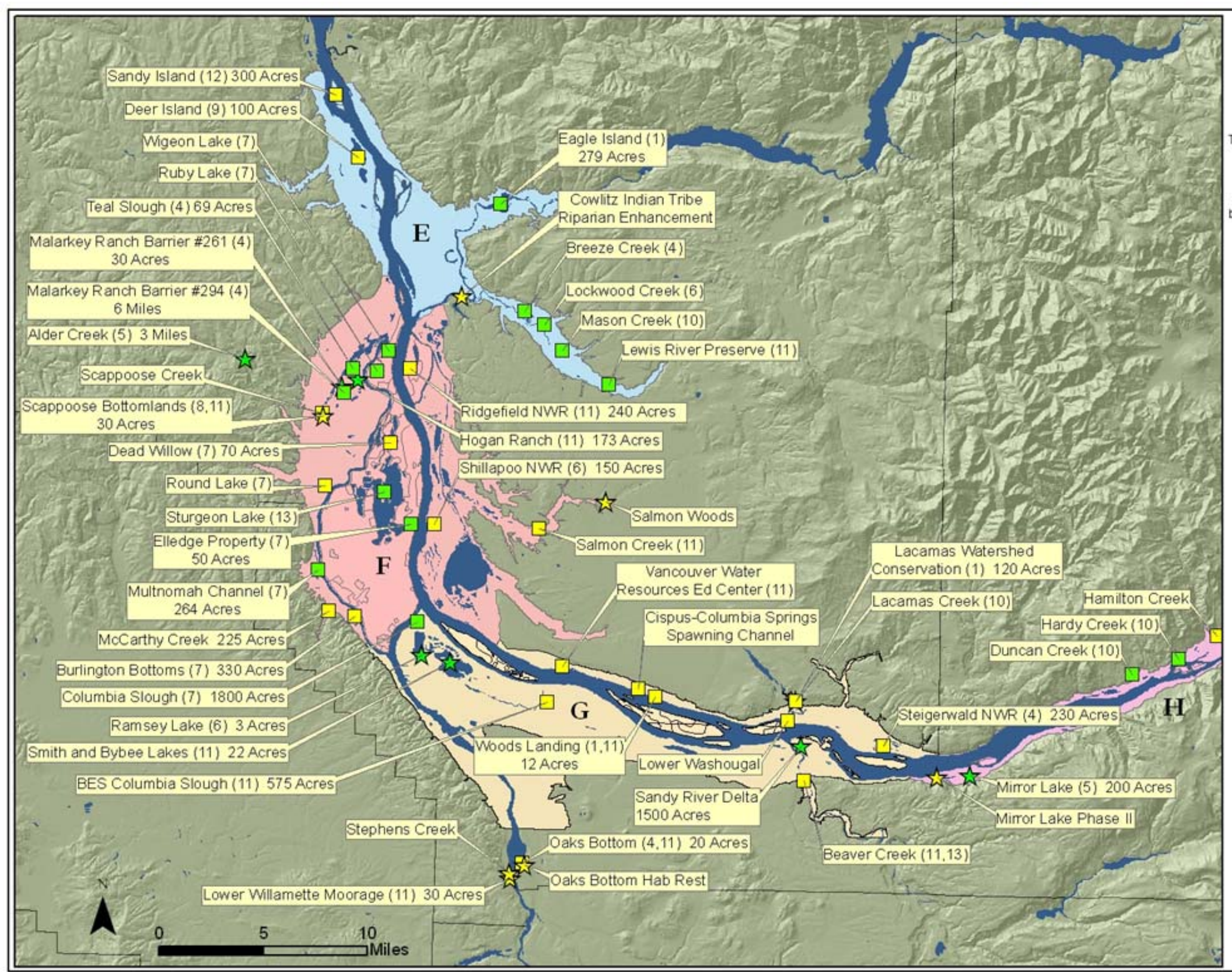

Habitat Restoration, Enhancement, and Protection Projects in the

Lower Columbia River Estuary 1999 - 2007

Focus: River Reaches E,F, G,H

The Lower Columbia River Estuary Partnership (EP) produced this map to assess habitat restoration
efforts in the tidally influenced parts of the estuary systern. A work in progress, this map presents a continually growing irventory of work conducted

\section{Project Status}

is EP Funded Project

$\square \quad$ Other Partner's Project

Completed

Underway

\section{River Reach}

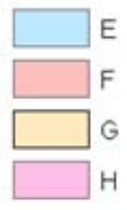

\section{Project Element Key}

(1) - Acquisition

(2) - Tidegate Mocification

(3) - Tidegate Removal

(4) - Culvert Replacement

(5) - Culvert Removal

(6) - Dike Breach

(7) - Water Control Structure

(8) - Fencing

(9) - Deleveling

(10) - Chum Channel

(11) - Revegetation

(12) - Conservation Lease

(13) - Flow Alteration

$P 2$ Columbia

7 River Estuary

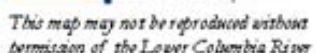
Aermision of tho Laver Colberbia Ring Estraty Parsinutiof 
- Creation - Habitat creation involves constructing or placing habitat features where they did not previously exist in order to foster development of a functioning ecosystem. Examples include tidal channel excavation and the placement of dredge material intended to create marsh or other habitat.

Table 1.1. Restoration Strategies, Examples of Project Types, and Targeted Ecosystem Benefits for the CRE (adapted from Johnson et al. 2003)

\begin{tabular}{|c|c|c|}
\hline Strategy & Project Type & Targeted Ecosystem Benefit \\
\hline \multirow[t]{4}{*}{ Restoration } & Tide gate removal & $\begin{array}{l}\text { Restores partial or full hydrologic connection to slough habitat improving } \\
\text { water quality, access to lost habitat types and processes, and potential } \\
\text { removal of invasive plant species. }\end{array}$ \\
\hline & Dike breaching & $\begin{array}{l}\text { Provides similar benefits as tide gate removal, this application requires } \\
\text { significant earth moving activities to allow tidal energy to influence } \\
\text { historic slough signatures and can involve tidal channel excavation. }\end{array}$ \\
\hline & $\begin{array}{l}\text { Culvert } \\
\text { upgrades/culvert } \\
\text { installation }\end{array}$ & $\begin{array}{l}\text { Provides similar benefits to above restoration activities through the } \\
\text { improvement of water quality, access to lost habitat types and processes, } \\
\text { and potential removal of invasive species. }\end{array}$ \\
\hline & Elevation adjustment & $\begin{array}{l}\text { Restores elevation of site to level that will support appropriate wetland } \\
\text { vegetation. }\end{array}$ \\
\hline \multirow[t]{5}{*}{ Enhancement } & Riparian plantings & $\begin{array}{l}\text { Promotes water temperature reduction, contaminant removal, connection } \\
\text { of terrestrial habitat corridors, sediment reduction, and water storage; } \\
\text { future source of large woody debris input. }\end{array}$ \\
\hline & $\begin{array}{l}\text { Tide gate/culvert } \\
\text { replacement }\end{array}$ & $\begin{array}{l}\text { Promotes water temperature reduction, dissolved oxygen availability, } \\
\text { increased habitat access. }\end{array}$ \\
\hline & $\begin{array}{l}\text { Invasive species } \\
\text { removal }\end{array}$ & Increases opportunities for native species propagation. \\
\hline & $\begin{array}{l}\text { Bioengineered stream- } \\
\text { bank stabilization }\end{array}$ & Reduces sediment load, diffuses hydrologic energy. \\
\hline & Riparian fencing & Protects riparian zones from disturbances. \\
\hline \multirow[t]{2}{*}{ Creation } & Material placement & $\begin{array}{l}\text { Mimics habitat function and complexity through the placement of material } \\
\text { at a given elevation. }\end{array}$ \\
\hline & $\begin{array}{l}\text { Tidal channel } \\
\text { modification }\end{array}$ & Increases tidal flows and mimics tidal channel structure. \\
\hline \multirow[t]{4}{*}{ Conservation } & Land conservation & $\begin{array}{l}\text { Limits land use impacts harmful to salmon habitat such as sediment, } \\
\text { contaminants, nutrient loading. }\end{array}$ \\
\hline & Easements & $\begin{array}{l}\text { Benefits ecological features through legal protection of critical areas, } \\
\text { potentially allowing for complimentary restoration strategies to take place. }\end{array}$ \\
\hline & Riparian fencing & Deters livestock from degrading stream-side areas. \\
\hline & Manure management & Minimizes the inputs of nutrients and bacteria into stream corridor. \\
\hline \multirow[t]{2}{*}{ Protection } & Land acquisition & $\begin{array}{l}\text { Preserves existing intact ecological features, functions, and processes at } \\
\text { site scale and/or enables the application of additional strategies without } \\
\text { human land use constraints. }\end{array}$ \\
\hline & Land use regulations & $\begin{array}{l}\text { Limits or prohibits potentially harmful land use activities on or adjacent to } \\
\text { the land surrounding the site, thereby protecting habitat-forming processes } \\
\text { and features. }\end{array}$ \\
\hline
\end{tabular}




\subsection{Conceptual Model}

A conceptual model representing the existing ecological condition of a restoration project site and its landscape can be used to forecast alternative future conditions based on different restoration planning scenarios and environmental conditions (Fischenich 2008). Development of a conceptual model is also a useful tool for identifying which metrics to monitor. During restoration planning phases, conceptual models often serve to enhance communication between parties involved with the project. Five types of conceptual models commonly used in ecosystem restoration planning are described in Diefenderfer et al. (2005b): landscape, ecosystem, ecosystem performance, ecosystem services, and subsystem.

Conceptual models should help identify features of the site that require study. For example, if a site is predicted to recover to a tidal marsh, elevation relative to water level is critical. In order to assure that elevation is correct, some elevation measurements are required in addition to collection of water level data proximal to the site. If elevation is too low or too high relative to the water level, the effectiveness of the restoration action toward satisfying the project goal would be poor. Further, monitoring of water level relative to marsh development may help provide an explanation if the marsh is not developing as expected.

It is important that each project document knowledge of ecosystem structures and processes at the site, relationships between the site and landscape, and expected changes following the implementation of restoration actions (Diefenderfer et al. 2003). An effective vehicle to do this documentation is the conceptual model. Understanding such information is foundational to determining the relative success of a restoration project (Thom 1997; Thom 2000). Simple conceptual models depict environmental factors or processes occurring in an ecosystem and represent the magnitude and direction of their relationships and interactions. Examples of factors and processes include 1) anthropogenic stressors, such as passage barriers; 2) controlling factors, such as topography; 3) ecosystem structures, such as emergent marshes; 4) ecosystem processes, such as sediment trapping; and 5) ecosystem functions, such as providing salmonid rearing habitat. Key landscape factors that may influence system performance, or be influenced by the restoration project, include land use, roads, boats, air- or water-borne contamination, domestic or wild animals, fishing, and water diversion. Examples of a Columbia River Estuary Conceptual Model adapted from Thom et al. (2004) and applied to both status and trends and action effectiveness monitoring in the estuary can be found in Johnson et al. (2008, Appendix B, www.salmonrecovery.gov/research_reports_pubs/research/). A simple example of a conceptual model can be found online in Diefenderfer et al. (2003). A general conceptual model for action effectiveness of a tidal reconnection project is shown in Figure 1.2. 


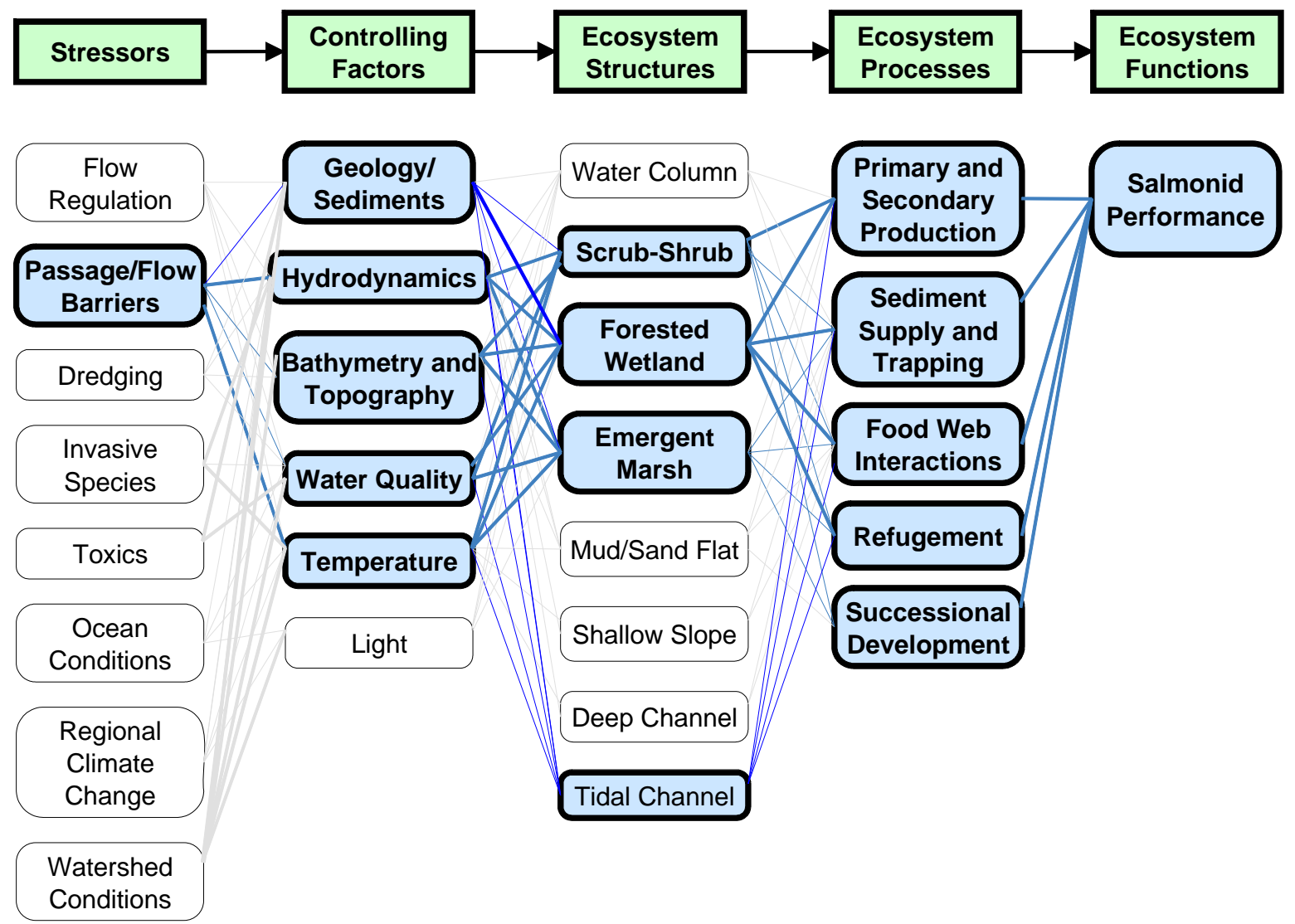

Figure 1.2. Columbia River Estuary Conceptual Model Applied to Estuary RME Action Effectiveness Research for Tidal Reconnection Projects. (Adapted from Johnson et al. 2008).

\subsection{Report Contents}

In the following sections, we propose a set of metrics for restoration monitoring activities based on commonly shared ecological goals (Section 2), discuss design considerations (Section 3), and provide specific protocols for this set of estuary monitoring metrics (Section 4). References are listed in Section 5. 


\subsection{Core Monitored Metrics}

The CRE comprises a unique continuum of wetland ecosystems strongly influenced to varying degrees by river flow, tidal amplitude, and salinity. Unlike streams in nontidal upland regions, semidiurnal and spring-neap variation in water level in the CRE imposes a structuring force on both geophysical features and biota, especially as distance to the mouth of the river decreases. Water elevation fluctuations, keyed to site topography, directly determine periods of inundation and salinity intrusion (Kukulka and Jay 2003a, b) and this in turn structures plant communities and fish habitat use (Thomas 1983; Fox et al. 1984; Small et al. 1990). The tidal cycle controls the magnitude and duration of bidirectional current velocities that cause sedimentation/erosion and the evolution of geomorphological features like tidal channels and levees (Hume and Bell 1993). Tidal currents additionally affect the spatiotemporal distribution of water quality parameters such as salinity and temperature, and the transport of organic and inorganic materials that affect organism abundance and growth (Roegner 1998). Many restoration projects in the $\mathrm{CRE}$ will be tidal reconnections; our metrics reflect this and were specifically chosen to measure changes in hydrology due to restoration activities and physical and biological responses of the floodplain wetlands.

\subsection{Metric Selection Criteria}

The decision-making process culminating in the suggested core monitoring metrics was based on several interrelated criteria. First, metrics need to be diagnostic of some relevant ecosystem function and also to correspond to commonly held goals among the restoration projects in the CRE (Thom and Wellman 1996). Second, we followed NRC (1992) guidelines that at least three classes of monitoring attributes be tracked: one for controlling factors (e.g., tidal regimes), one for structural factors (e.g., vegetation growth), and one for functional factors (e.g., fish community structure). Third, metrics should be potentially applicable to all sites with measurements that result in comparable datasets relevant to both present and future investigations (Tegler et al. 2001). Finally, measurements and data analysis must be practical in terms of funding, manpower, and processing requirements (Callaway et al. 2001).

This last factor necessitates limiting the number of metrics to a "core" set and selecting measurement methods that are straightforward and economical to use. By "core," we mean a suite of metrics that can adequately detail the effectiveness of restoration while acknowledging the financial and logistical limitations of comprehensively monitoring ecological change over an extended temporal and spatial scale. Ideally, all projects in the region would perform the core physical measurements, which we view as encompassing the fundamental forces on, and responses to, changes in the affected systems. However, we recognize that funding even these core metrics may be financially infeasible. In this case, an even smaller set of metrics may be usefully employed as part of a broader, extensive sampling effort (see Johnson et al. (2008) and Johnson and Diefenderfer (2008)). Project goals for the biological variables (e.g., fish use or vegetation cover) may vary between studies.

We also encourage researchers to make additional measurements, especially process-related derivations of the core metrics (e.g., fish growth rate, primary productivity, and material flux). The relevance of various metrics such as these to the CRE is being investigated at this time, as described in the 
series of reports from this project: Diefenderfer et al. (2005a), Diefenderfer et al. (2006), Johnson (2007), Johnson and Diefenderfer (2008). Structure and process-oriented indicators of the effects of CRE wetland ecosystems range from materials flux to large woody debris to sediment accretion rates. Those under review include salmonid growth, residence time, and prey; organic matter and nutrient fluxes; hydraulic geometry; swamp and marsh macrophyte productivity; species diversity and distribution; and hydrological and flood storage modeling. Research and monitoring on higher order metrics such as these will help to reduce fundamental uncertainties in existing knowledge of the ecosystem of the lower Columbia and thereby improve restoration project design and future monitoring.

The selection of relevant core metrics according to the above criteria was based on 1) a review of pertinent literature; 2) a meeting with local restoration managers (Diefenderfer et al. 2005a Appendix A), and 3) past iterations of this document based on our field results. We strove to keep the protocols useful not only to scientists but to all staff and volunteers who potentially will be involved in restoration monitoring. Thus, the format and level of detail in the protocols reflect the larger purpose of standardizing data collection on restoration projects in the CRE; that is, the development of a regional database consistent enough to permit estuary-wide analyses. As discussed above, we are concentrating on projects implementing tidal reconnection, a key ecological driver for a whole array of structural and functional attributes in the CRE. We found many relevant frameworks describing metrics important for monitoring restoration activities of potential salmonid habitat (although none were tailored specifically for the CRE). We relied extensively on papers by Simenstad et al. (1991), Simenstad and Cordell (2000), Zedler (2001), Johnson et al. (2004), Hillman (2004), and Rice et al. (2005) to derive an initial set of potential metrics. These were augmented and expanded during meetings with regional restoration managers and monitoring practitioners in June 2004 and February 2007.

\subsection{Metrics}

Table 2.1 outlines the set of core monitored metrics, their collection method, sampling frequency, and indicator category. We recommend a combination of data logging instruments, on-site survey and sampling methods, and remote sensing techniques.

\subsubsection{Hydrology}

Hydrology is a main controlling factor of wetland evolution in the CRE, and it influences habitat structure and processes as well as ecological functions (Sanderson et al. 2000; Rice et al. 2005).

Measuring water level variation is especially crucial for tidal reconnection restoration projects. Tidal forcing determines such processes as sedimentation/erosion, tidal channel development, inundation periods, and salinity intrusion. We advocate the use of automated data logging pressure sensors set to hourly frequency, which will record tidal, event-scale, and seasonal water elevation variation. This method of data collection generates a time-series of measurements that can be compared between habitats and across seasons. Sensors can be "stand alone" or integrated into a water quality instrumentation package (below). 
Table 2.1. Summary of Core Metrics for Lower Columbia River and Estuary Restoration Projects

\begin{tabular}{|c|c|c|c|}
\hline $\begin{array}{l}\text { Indicator } \\
\text { Category }\end{array}$ & Monitored Metric & Collection Method & $\begin{array}{l}\text { Sampling } \\
\text { Frequency }\end{array}$ \\
\hline \multicolumn{4}{|c|}{ Physical } \\
\hline Hydrology & $\begin{array}{l}\text { surface water } \\
\text { elevation }\end{array}$ & data-logging instrument & hourly \\
\hline Water Quality & temperature, salinity & data-logging instrument & Hourly \\
\hline \multirow[t]{2}{*}{ Habitat } & landscape features & photography, GIS & annually \\
\hline & elevation & ground survey & annually \\
\hline \multicolumn{4}{|c|}{ Biological } \\
\hline \multirow[t]{4}{*}{ Plants } & species composition & \multirow[t]{4}{*}{ ground survey } & \multirow[t]{4}{*}{ annually } \\
\hline & percent cover & & \\
\hline & elevation & & \\
\hline & planting success & & \\
\hline \multirow[t]{3}{*}{ Fish } & species composition & \multirow[t]{3}{*}{ ground survey } & \multirow{3}{*}{$\begin{array}{l}\text { monthly- } \\
\text { seasonally }\end{array}$} \\
\hline & size structure & & \\
\hline & temporal presence & & \\
\hline
\end{tabular}

\subsubsection{Water Quality}

Water quality parameters such as temperature, salinity, dissolved oxygen, $\mathrm{pH}$, and turbidity play deterministic roles influencing species abundance and distribution in the CRE (OWEB 1999; Johnson et al. 2003). Most organisms have specific tolerances for water parameter ranges or rates of change (fluctuations). For example, temperature is a good predictor of juvenile salmon abundance and condition (OWEB 1999) and salinity is a main determinant of vegetation patterns (Thom et al. 2002). Oxygen concentration and $\mathrm{pH}$ can control the distribution of many organisms. Turbidity can limit the depth distribution of submerged aquatic vegetation. While all these parameters, and others such as specific dissolved constituents, are important and worthy of monitoring, we recommend temperature and salinity (in saline and brackish regions) as our core water quality metrics based on importance and methodological consistency. We advocate the use of automated data logging multiprobe instruments for measuring time series of water quality parameters. Additional transect surveys with conductivitytemperature-depth (CTD) probes can provide vertical and horizontal spatial scale perspectives useful for augmenting the spatially fixed time series data (Callaway et al. 2001).

\subsubsection{Elevation}

Hydrologic reconnection usually results in substantial alteration of geomorphic features such as location and sinuosity of tidal creeks, changes in the extent and slope of intertidal regions, and substrate characteristics (Cornu and Sadro 2002; Williams and Orr 2002). These landscape changes in turn affect (and are affected by) the composition, distribution, and abundance of biota, which often have distinct habitat requirements in wetland areas (Sanderson et al. 2000). Establishing the time course of bathymetric 
and topographic change at a restoration site is crucial for evaluating the progress of the restoration effort. It is helpful if detailed topographic or bathymetric surveys are conducted by professional surveyors during the restoration planning phase. This information can be useful to predict restoration outcomes, identify areas that may require elevation increases or decreases to achieve desired species composition, plan invasive species management, and identify areas appropriate for plantings. Limited elevation surveys recommended in this manual include channel cross-sections, vegetation plots, vegetation community boundaries, water-level instruments, and sediment accretion stakes. These techniques have wellestablished methodologies and should be coordinated with biological surveys described below.

\subsubsection{Landscape Features}

Large-scale alterations of landforms and vegetation patterns often accompany wetland restoration activities (Tanner et al. 2002; Williams and Orr 2002). The measurement of spatial changes in biogeophysical features, such as evolution of tidal channel complexity, alteration in intertidal area, and succession of vegetation communities, is best accomplished by remote sensing using aerial imagery (e.g. Wright et al. 2000). Many technologies are available, including real color and near infrared aerial photography, hyperspectral imagery, digital aerial photography, high-resolution satellite imagery, and Light Detection and Ranging (LiDAR). Ground truthing imagery is necessary to ensure accurate analysis.

Repeated measures over time are best analyzed using GIS to quantify the progress of restoration.

\subsubsection{Plant Community}

Plant community composition and cover can change rapidly following reconnection to a tidal hydrologic regime (Cornu and Sadro 2002; Roman et al. 2002) especially if the reconnection fosters salinity intrusion (Thom et al. 2002). Vegetation patterns confer both structural elements and ecological processes to wetland ecosystems, and may increase ecosystem capacity for foraging salmonids (Sommer et al. 2001; Tanner et al. 2002). We recommend that measurement of changes in vegetation community structure be accomplished at both landscape-scale (described above) and through transect or ground survey techniques.

\subsubsection{Vegetation Plantings}

Some restoration projects include revegetation in riparian zones or across broader areas, which may be used to achieve a variety of objectives such as accelerating reestablishment of native plants, suppressing invasive plants, providing environmental conditions such as shade, or affecting the biota through, for example, salmonid prey production (Simenstad and Thom 1996; Naiman et al. 2005). The effectiveness of plantings can be assessed by tracking plant survival and growth. It is important to determine a criterion for success to ensure that the project goals are being achieved, and this criterion will dictate specific monitored metrics. Typical metrics include a quantitative count (for density) and measurement of height (for growth) and qualitative estimation of condition (for survival) (Simenstad and Thom 1996; Erwin 1990). 


\subsubsection{Fish Community}

The incentive for many restoration activities in the CRE involves increasing rearing and refuge habitat for juvenile salmonid ESUs listed as threatened or endangered under ESA (Thom et al. 2005). It is generally acknowledged that documenting "realized function" (Simenstad and Cordell 2000) is difficult because of the migratory nature of salmonids, while determining habitat capacity and opportunity are less problematic (Tanner et al. 2002). For minimum effectiveness monitoring, fish sampling should permit the evaluation of changes in community structure in restored locations compared with before-treatment and reference areas. Measurements of fish density (individuals $/ \mathrm{m}^{2}$ ) provide the most robust comparative value. We advocate conducting the most intense sampling effort logistically possible across sites, habitat types, and time. Additionally, it is highly desirable to determine higher order metrics ("realized function" attributes), such as residence time, growth, and survival, which necessitate measuring metrics such as prey availability, prey consumption, age assessment, genetic stock identification, parasite load, and markrecovery data (e.g., Roegner et al. 2005). 


\subsection{Design Considerations}

\subsection{Statistical Design}

Monitoring data from individual restoration projects throughout the estuary will be important both for assessing project-specific outcomes and for analyzing changes in the broader estuary ecosystem. The roles of project monitoring data in the estuary-wide statistical design for ecosystem restoration in response to the biological opinion (NOAA 2007) are detailed in the document Research, Monitoring, and Evaluation for the Federal Columbia River Estuary Program (Johnson et al. 2008). The program incorporates both intensive monitoring of a small number of restoration projects and extensive monitoring of a smaller number of metrics at a larger number of projects (e.g., Trexler and Busch 2003). Through the efforts of the Estuary Partnership and BPA, a suite of reference sites is being established and monitored to allow comparison to restoration projects (see Borde et al. 2007); paired reference sites specific to a project are also recommended in Johnson et al. (2008).

\subsubsection{Reference and Control Sites}

The definitions of reference and control sites are used variously in the literature, so key elements distinguishing them are reiterated here, following Downes et al. (2002) and consistent with Johnson et al. (2008). Reference sites represent "the state of an environment undisturbed by human activity," while control sites are "as similar as possible in all respects to the impact location, except for the presence of the putative impact." One apparent source of confusion in the literature arises from the fact that the "impact" under consideration in ecological restoration is expected to be of a positive nature. Thus, for example, in the case of hydrological reconnection of floodplain areas to the main stem Columbia, a typical control site would be a diked pasture, while a typical reference site would be a tidal wetland. The best possible design is to monitor both control and reference sites relative to the restoration site; however this will rarely be possible with limited monitoring funds. For most projects in the CRE we therefore advocate concentrating on monitoring reference sites in conjunction with restoration sites. Conditions at restoration sites can be assessed in respect to the trajectory of their development against the "target" states represented by the reference sites (Johnson et al. 2008).

The selected reference site should be spatially situated near the restoration site and subjected to similar large-scale climatic and environmental conditions, but be independent of activities affecting the restoration site to the extent possible. Ideally it represents a natural, minimally modified, or target condition and would be chosen to measure specific habitats or processes, such as tidal channels or marsh communities. It is widely recognized that choosing the reference site in regions that have been highly modified is challenging. The Estuary Partnership's set of reference sites should be consulted. Within each hydrogeomorphic reach of the CRE, regional reference sites are being monitored to provide a range of "target" conditions for restoration activities.

In general, for projects in the CRE, the goal will be the return of the restored site to close approximation of its natural, undisturbed condition. Therefore, the key information needed to evaluate progress toward this goal is some measure of the similarity of the restored site to either pre-disturbance conditions or the conditions existing at nearby reference site(s) that are a reasonable approximation of 
pre-disturbance conditions. Because quantitative data on site conditions prior to disturbances are rarely available, reference site(s) are the only viable option. However, qualitative comparisons to information on pre-disturbance conditions, using old photographs, land surveys, topographic surveys, etc., can be useful in concluding whether the site is actually returning to its former condition.

\subsubsection{Before and After Sampling}

The ability to detect ecological change due to restoration in a naturally varying environmental system is problematic (Osenberg et al. 1994). For restoration monitoring in the estuary, we considered two basic sampling designs, the Before After Control Impact ("BACI," Green 1979) and the Accident Recovery ("Recovery," Skalski et al. 2001). BACI incorporates before and after sampling at control and restoration ("impact") sites, while the Recovery method incorporates after-only sampling at reference and restoration sites. Because the original BACI design is susceptible to confounding project effects with other factors causing site-by-time interactions, the use of the modified Before After Control Impact Paired Series (BACIPS) has recently been recommended for restoration monitoring (Osenberg et al. 2006). The essential difference between BACIPS and the Recovery method is that BACIPS estimates the effect of the restoration based on the amount of effect, while Recovery assesses the endpoint relative to target conditions. As Osenberg et al. (2006) suggest: "A combination of both approaches is likely ideal - we would like to know how much of an effect we have produced (effect-size-based outcomes) and if that change is 'sufficient' (endpoint-based outcomes)."

One measure of restoration "success" or performance is for values of post-restoration parameters (the monitored attributes) to converge with those of the reference site (Kentula et al. 1992; Simenstad and Thom 1996; Raposa 2002). The Recovery model tests the "parallelism hypothesis" (Skalski et al. 2001): how a treatment site recovers in comparison to a relatively undisturbed reference site, as opposed to comparison to "before" conditions at a control (cf. Miller and Simenstad 1997; Skalski et al. 2001; Hood 2002a; Thom et al. 2002; Steyer et al. 2003). This analytical method is discussed in more detail and diagrammed in Johnson et al. (2008, Figure 5). While the Recovery model does not require multiple data collection times before implementation of restoration actions, before data is highly desirable for documenting the initial response of the system to the restoration process as well as to assess interannual or seasonal variability in the reference and restoration sites (Skalski et al. 2001). See Hillman (2004) for further discussion of these types of statistical comparisons.

Within either the BACIPS or the Recovery sampling design, two primary data collection categories are likely to be employed in the CRE, depending on the parameter of interest: survey type measurements and time series type measurements. In contrast to the time series measures described above, survey type measurements are "snap shots" in the temporal frame and can include aerial photos, topographic surveys, vegetation surveys, and fish community sampling. Repeated measures over time are made to evaluate changes in metrics.

\subsubsection{Recommendations}

The choice of sampling design will depend on site-specific circumstances and the availability of funding for before and after project implementation periods. However, whatever the sampling design, it should be determined early in the restoration planning process. We recommend that in all cases the 
following occur during the project planning phase: 1) select a subset of reference sites from the existing suite, if reference sites comparable to target project conditions are being sampled; 2) establish a paired reference site, if possible, and secure access; 3) determine whether monitoring will include a control and if so, select the location and secure access. The Recovery design is recommended for all restoration projects, using either a subset from the existing suite of restoration sites, a paired site, or both. If a control site is also selected, then use of the BACIPS design in addition to the Recovery design is also recommended, on a modular basis, i.e., for those metrics to which such analysis is applicable.

In general, we recommend a sequence of sampling events such as that listed in Table 3.1. Monitored parameters are sampled simultaneously at two (or more) locations (reference versus restoration) before and after the restoration action (before versus after). All sampling techniques and sampling periods should be identical between reference and restoration sites, to the extent possible. These paired measurements are to be made before and after the restoration activity. The spatial and temporal replication of the measurements is dependent on the monitoring metric, the size of the restoration area, and logistics (Table 3.1). It should be emphasized that the ecological processes associated with a given restoration activity, such as breaching a dike, evolve for many years post-implementation. A long-term monitoring commitment ( 5 to 10 years) is thus necessary for selected projects to adequately document the ecosystem response in relation to natural variation (Zedler 1988; Larsen et al. 2003; NOAA 2004). In forested wetlands, conditions may not converge for many decades.

\subsection{Sampling Design}

Generally, resources for restoration monitoring are too limited to permit random sampling of any parameter across an entire restoration site at a sufficient density to draw statistically defensible conclusions. Therefore, we recommend that most field sampling be concentrated on transects proximal to expected changes - for example, near a culvert replacement or a dike breach. This intensive monitoring at a small spatial scale can be complemented through mapping using an aerial photo and ground truthing methods (Erwin 1990) or other remotely sensed information such as LiDAR data to characterize aspects of the restoration site in its entirety. The use of georeferenced surveys wherever possible will permit the integration of hydrology, vegetation, fish, elevation, and other data at multiple scales. To maximize possibilities for integrating data the following design is recommended (see Protocol 5: Plant Species Composition and Cover, Figure 4.7):

- channel cross-sections surveyed along vegetation sampling baselines;

- elevation data collected at vegetation plots;

- data logging sensors deployed year-round to acquire water level and temperature information near where the vegetation baseline crosses the restored channel;

- and fish collection efforts located in the same channels.

In summary, wherever possible, the location of data logging instrumentation, elevation and vegetation transects, and fish surveys should be spatially linked so that changes in multiple metrics can be evaluated for a single site. This is especially important for documenting how changes in physical parameters such as tidal elevation and channel morphology affect biological metrics such as vegetation and fish communities. 
The specific elements of such sampling designs relevant to each metric are described in more detail in each of the following protocols.

Table 3.1. The Sequence of Sampling Events

\section{A. Before Restoration Activity}

1. Aquire and process available restoration and reference site data (Protocol 4)

a. Locate elevation and tidal benchmarks from website (Protocol 3).

b. Acquire digital aerial photograph of site (Protocol 4)

c. Create and ground truth vegetation community map.

d. Acquire LiDAR or topographic survey and local bathymetry (if available)

2. Select field sampling areas

a. Choose reference and restoration sampling areas.

b. Choose survey transect locations.

3. Ground survey (at reference and restoration sites)

a. Deploy and maintain water elevation and water quality data loggers at surveyed locations (Protocol 1-3)

b. Conduct cross-section/sediment accretion survey (Protocol 3)

c. Conduct vegetation-elevation/fish community survey (Protocol 3, 5-7).

4. Time Series (Before, if time permits)

a. Maintain data loggers.

b. Repeat 3b-c

B. After Restoration Activity

1. Repeat Steps 1b-c and 3a-c to acquire "After" data set.

2. Evaluate change in hydrology and water quality (Protocols 1 and 2)

3. Determine change in physical features (Protocols 3 and 4)

4. Compute vegetation structure analysis (Protocol 5).

5. Evaluate planting success, if applicable (Protocol 6).

6. Compute fish community structure analysis (Protocol 7).

7. Repeat B 1-6 at designated frequencies. 


\subsection{Monitoring Protocols}

Seven monitoring protocols are described in detail in this section: hydrology, water quality, elevation, landscape features, plant community, vegetation plantings, and fish community. For each protocol, we describe purpose, goal, design, equipment needed, site selection, sampling periodicity, sampling protocol, calculations and analysis, and site-specific contingency considerations, if any. Examples are provided from field research and monitoring at the Kandoll Farm or Vera Slough restoration sites. While selected literature or other additional information sources are provided with each protocol, these represent only a small fraction of the number of related protocols and the number of examples of published research using similar methods that are available. Hillman (2004) and Brophy (2007) provide thorough explanations of monitoring approaches in Northwest freshwater and estuarine environments, respectively. Among the most recent references generally applicable to most of the protocols herein, we recommend Callaway et al. (2001), Neckles et al. (2002), and Rice et al. (2005).

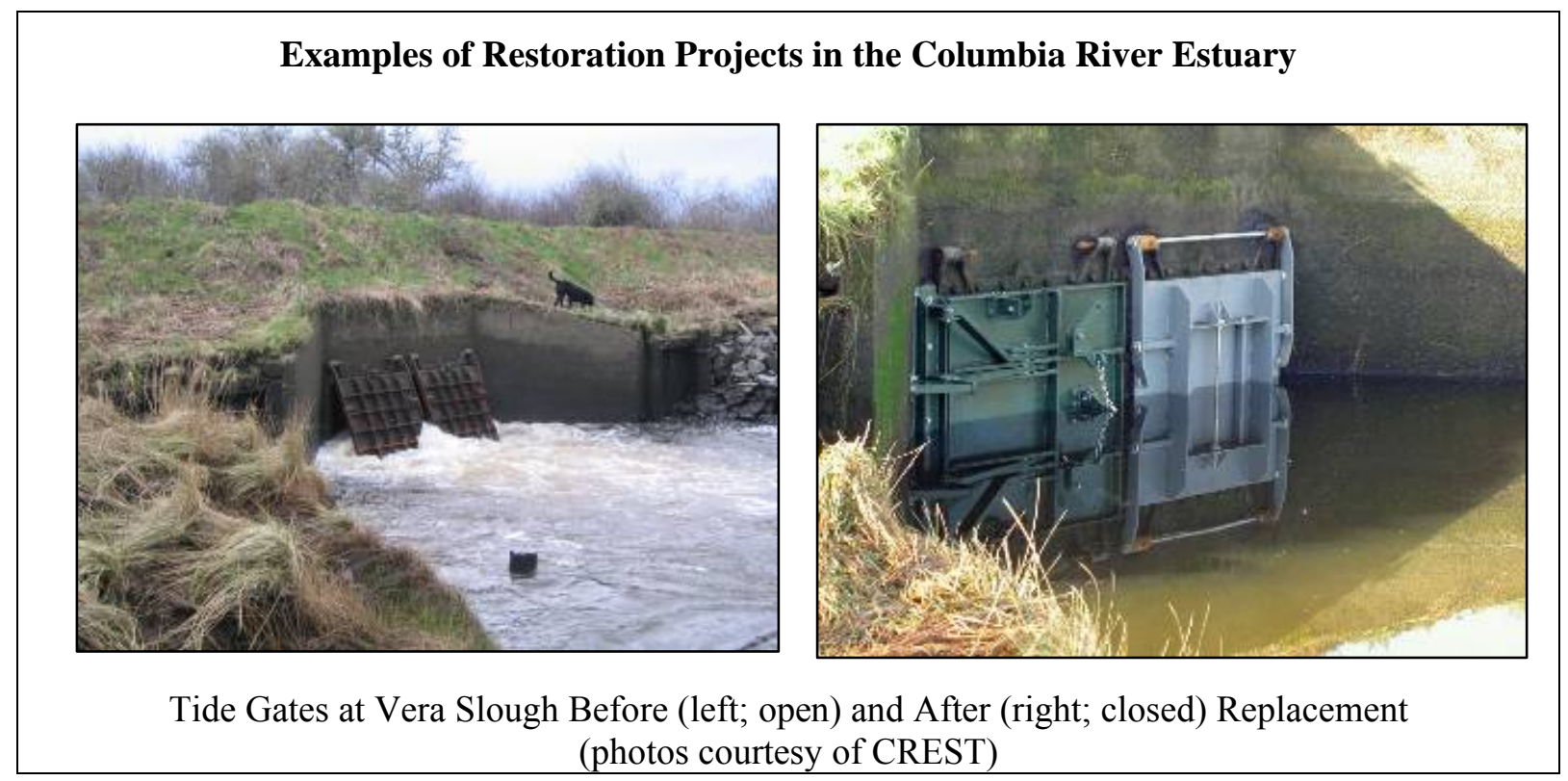



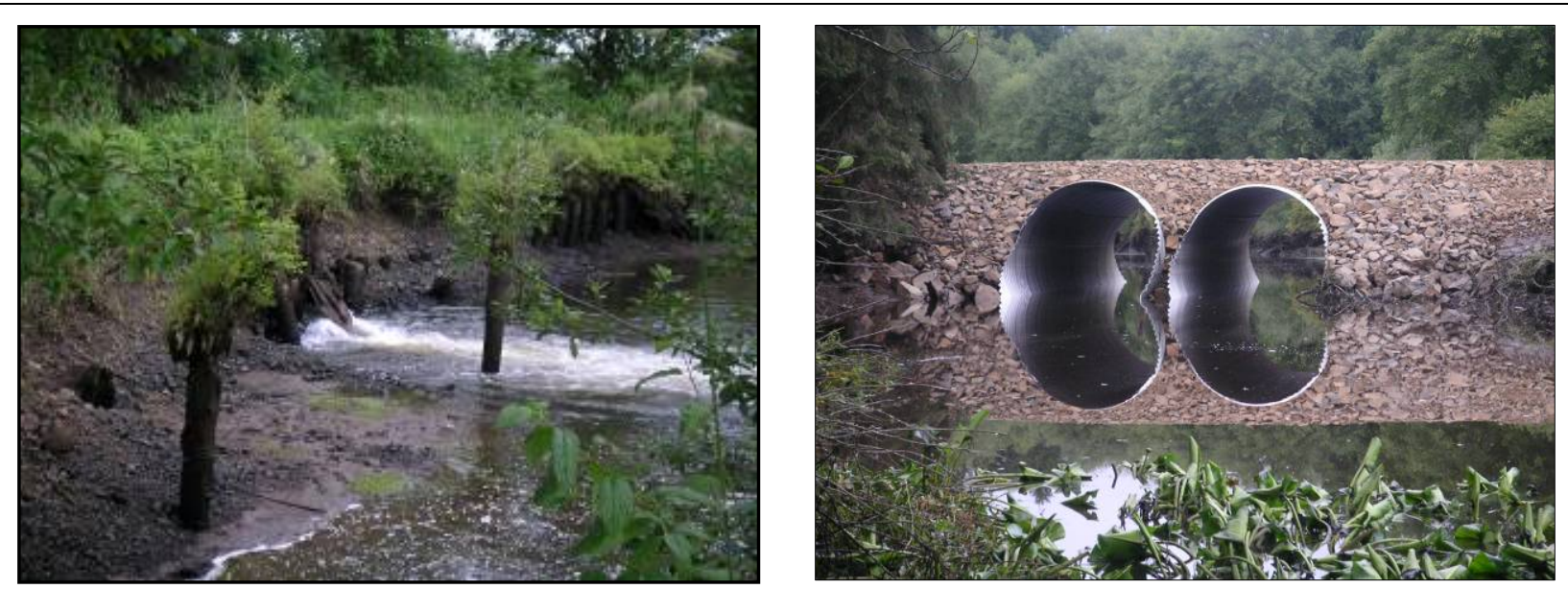

Tide Gate at Kandoll Farm before (left) and Culverts after (right) Replacement 


\subsection{Hydrology}

\section{PURPOSE}

Water-level variation in wetlands is a function of river flow and tidal fluctuations. This variation largely drives wetland evolution in the CRE, with tidal fluctuations probably being the most deterministic for wetland restoration (Cornu and Sadro 2002). A key measure is change in tidal elevation within a restoration project due to tidal reconnection. The extent, period, and duration of tidal forcing will cause changes in aerial exposure, circulation patterns in tidal creeks (including the distribution of water quality parameters such as salinity, temperature, and DO), sedimentation/erosion patterns and tidal creek evolution, and the distribution of vegetation and fishes. In general, restoration sites on the Columbia estuary are not close enough to existing NOAA water-level stations for the data to reflect water levels at the site, thus measurement in the field will

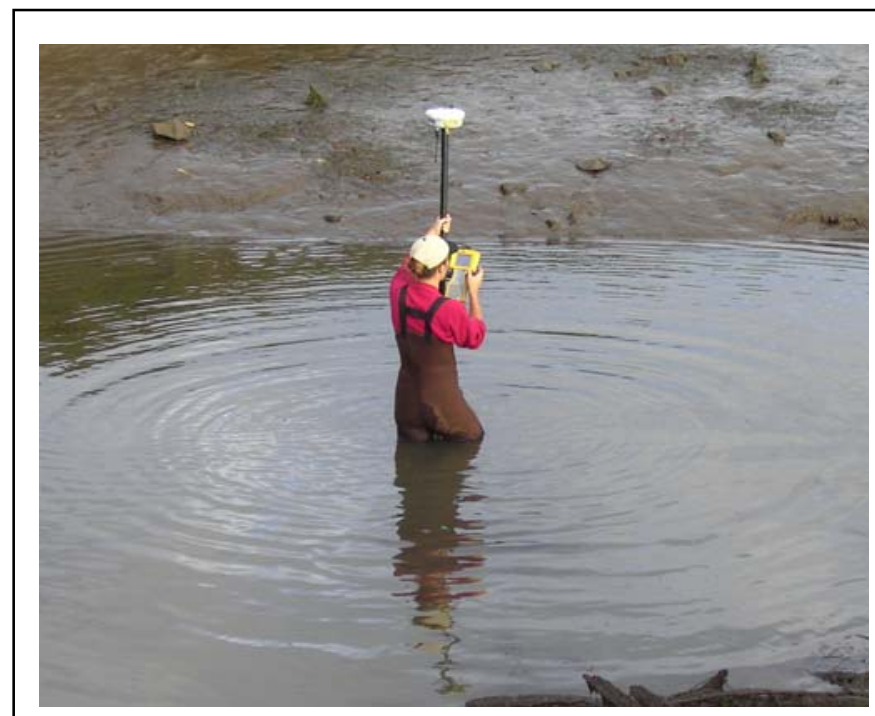

Recording GPS position of depth sensor. be necessary.

Water-level data should be properly georeferenced to local topographic data (Protocol 3: Elevation) that is related to an established vertical elevation datum (e.g., North American Vertical Datum 1988 [NAVD88] or mean lower low water [MLLW] if applicable, see Additional Information in Protocol 3: Elevation). Water-level information and topographic information combined can be used to determine inundation periods and vegetation response (Protocol 3: Elevation and Protocol 5: Plant Species Composition and Cover). In addition, tidal stage parameters for the site (i.e., MLLW) can be computed from each recording station. Elevation is thus a priority metric and is best measured with automated data logging pressure sensors. Current technology now offers multiple parameter probes that combine measurements like depth with others such as temperature and salinity (see Protocol 2: Water Quality). Although we present separate protocols for hydrology and water quality, for most purposes a single instrument will perform both sets of measurements.

\section{GOAL}

Measure the pattern of hydrology with respect to a known reference point to determine the timing, frequency, and duration of tidal inundation in reference and restored sites. 


\section{DESIGN}

Recovery and/or BACIPS time series design should be used to evaluate changes in water elevation caused by the restoration activity. At a minimum, two instruments would be deployed, one at the reference and the other at the restoration site. Where logistically possible, prerestoration (baseline) measurements are desirable to evaluate natural variations in the system. Comparing ranges and fluctuations of the reference and restoration time series gives a measure of the effectiveness of the restoration project. In addition, if atmospheric pressure correction data is not locally available, an additional instrument will need to be deployed that is exposed to air to collect this. Comparisons to conditions in the nearest river channel can also be informative if an additional instrument can be deployed there.

\section{EQUIPMENT}

A. Field: Continuous water level recorders (pressure transducer) or multiple parameter probe (see Protocol 2: Water Quality), laptop computer and data logger launching/downloading software (or waterproof shuttle), monumenting equipment (t-post, surveying equipment), hammer, GPS, and extra batteries.

B. Lab: Data logger software, calibration and maintenance manual

\section{SITE SELECTION}

Primary site for data loggers in both restoration and reference sites is near the mouth of the tidal reconnection site (but within the hydrological constriction). These positions would ideally be located where other monitoring activities take place (i.e., channel cross-section). Additional instruments, if available, should be placed upstream of the reconnection to evaluate extent of hydrological reconnection, especially to gauge for lags in period and reductions in tidal amplitude.

\section{SAMPLING PERIODICITY}

A. Preferred sample frequency is $1 \mathrm{hr}$. Try to initiate logging on the hour to simplify alignment with other time series data.

B. Download/change batteries at $<$ six-month intervals during spring and autumn to limit data loss and maximize recovery opportunities due to seasonal variation in daylight and tidal amplitude.

C. Note that while tidal parameters may be predicted after a 2 to 3 month period of field data, waterlevel sensors record river flow events as well as tide; combined effects of extreme events (storms) may not be easily predictable yet can have strong impacts on wetland development.

\section{SAMPLING PROTOCOL}

Automated instruments require proper placement to ensure comparable monitoring. Data loggers should be secured subtidally with sensors positioned at least 25 to $50 \mathrm{~cm}$ below the anticipated lowest tide level and at least $10-20 \mathrm{~cm}$ above the substrate to prevent sedimentation or excessive abrasion in high- 
velocity areas. Remember that hydrologic reconnections that increase tidal amplitudes may convert subtidal areas to intertidal zones.

Instruments can be attached directly to existing structures such as pilings, although it is prudent to encase them in a protective plastic sleeve (PVC) to minimize any metal-to-metal contact that can cause corrosion. The sleeve can be simply the length of the sensor and attached by cable ties, or as shown below to allow for deployment and retrieval at higher water levels (Figure 4.1).

For each deployment, the height of the sensors relative to known elevation point needs to be determined to relate water-level fluctuations to topography. To accomplish this, the vertical elevation of a surveyed point (usually the top of the post structure) must be determined (see Protocol 3: Elevation). During deployment, measure the distance from the sensor to the top of the permanent attachment post. This will tie the sensor position to the actual elevation. Note: add length of instrument body to measurement if the measured distance is from the top of the instrument and the sensor is at the bottom.

A measurement from the sensor to the water level at the time of deployment and retrieval provides a means of verifying the water-level data during post-processing. Additionally, record the location of the data logger with a GPS and periodically visit data loggers as required by factory user's manual to check for fouling or damage. When removing or redeploying the data logger, record the vertical position on piling or post so that it can be replaced at the same position. Waterproof "shuttles" are now available with the capability to download and re-launch water level-loggers in the field, reducing time lapses in the data. Where required, be sure to calibrate sensors before each deployment.

Water-level data is affected by atmospheric pressure, and therefore the data collected in the field needs to be corrected for atmospheric pressure. One method to do this is to deploy an additional sensor at the site, above water. Generally, this will be required unless atmospheric pressure is available from another source (e.g., NOAA weather station) within a 10-mile radius of the site (as per recommendations at www.onsetcomp.com). 


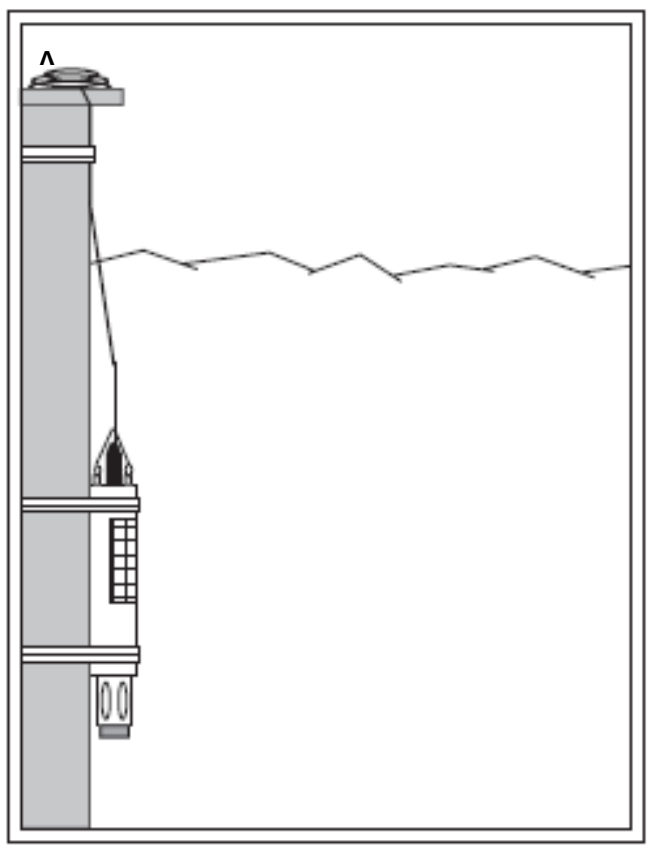

Figure 4.1a. Deployment Options for Data Logging Instruments: A. Attachment to pile.

\section{B I $\quad$ Optional Deployment Steps: \\ 1) Sensor is cable tied inside 1" PVC (white in diagram) so the sensor tip is just above the bottom of the PVC. \\ 2) 2" ABS (black) is attached by 3 " hose clamps to a T-post. The bottom hose clamp (red) is placed through holes drilled in the $A B S$ and left loose in order to slide down over the T-post. The top hose clam is tightened securely around the T-post. \\ 3) The PVC is then placed in the ABS and attached at the top to the T-post by a cable tie (blue). When sensor is retrieved the cable tie at the top of the PVC is removed and the PVC pipe is taken out of the ABS from the top.}

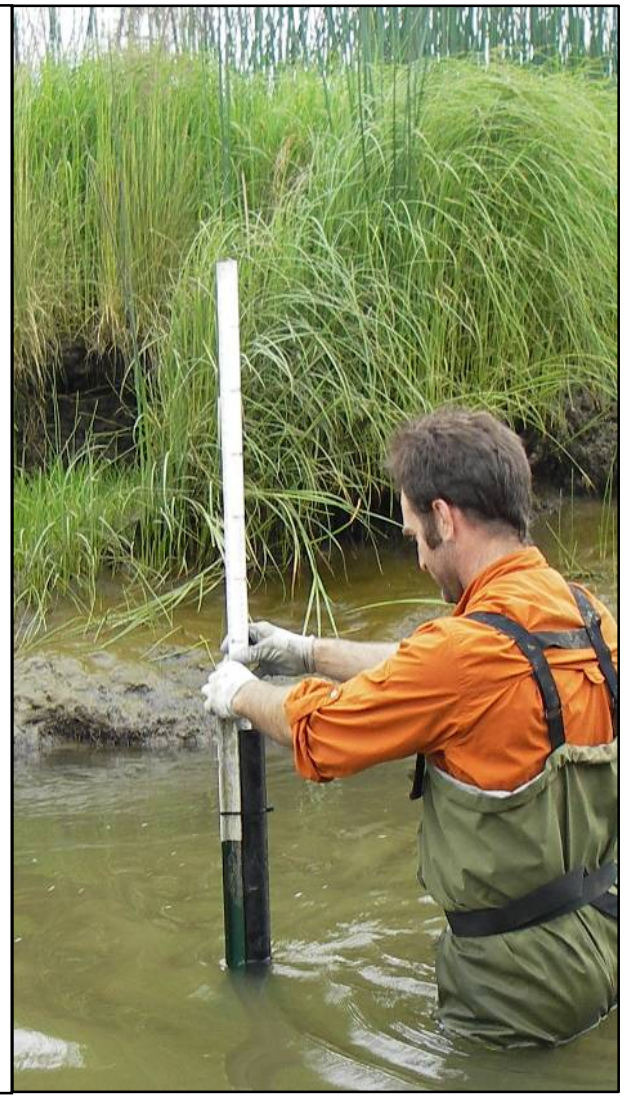

Figure 4.1b. Deployment Options for Data Logging Instruments: B. Insertion in PVC pipe. 


\section{CALCULATIONS \& ANALYSIS}

A. Primary output from data loggers is a time series of water levels. These relative heights should first be corrected for atmospheric pressure following guidelines specific to the data logger. Next, they should be converted into elevation relative to the standard topographic datum (NAVD88) using field-surveyed elevation data; this references hydrology to site topography and also facilitates comparison between sites. Data storage requirements quickly increase with 1-hr interval data collection, and data management and archiving can require a substantial time investment.

B. Data should be presented to contrast water level fluctuation at reference and restored sites preand post-restoration (Figure 4.2).

C. Inundation period ( $\%$ of time inundated) can be calculated for any elevation within the site and used to generate an exposure-height curve, which relates percent inundation by vertical height (Figure 4.3). Be aware that calculated inundation periods vary according to seasonal changes in tidal amplitude and river flow, and results are affected by the time period used for the calculations.

D. Percent inundation data can be integrated with topographic surveys to create percent inundation maps in GIS.
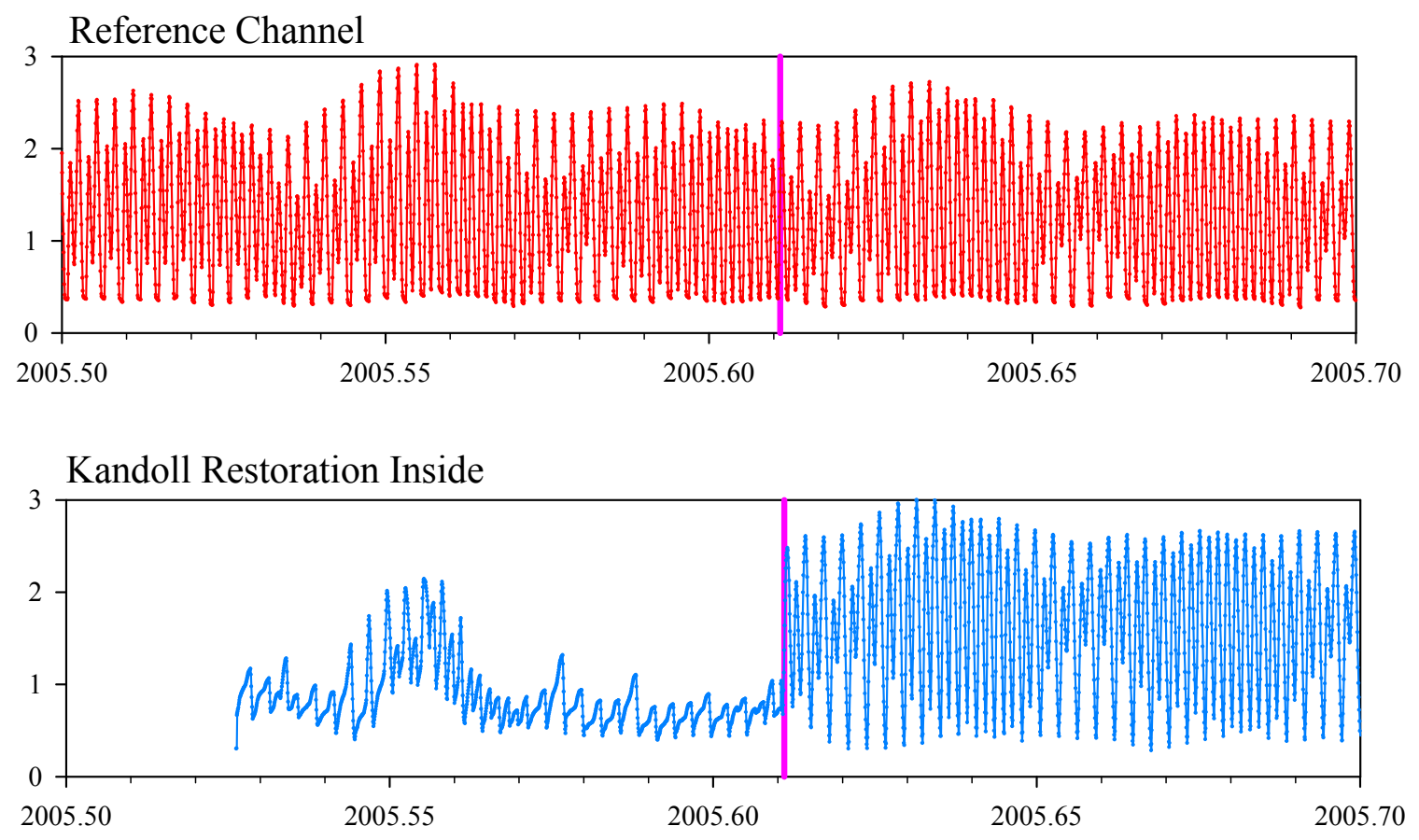

Figure 4.2. Water Level Variations Surrounding a Tide Gate Removal at Kandoll Farm, 2005. A. Reference hydrograph. B. Restoration hydrograph. The timing of the tide gate removal is indicated by pink vertical line. Tide gate removal resulted in reestablishment of the semidiurnal tidal pattern. 


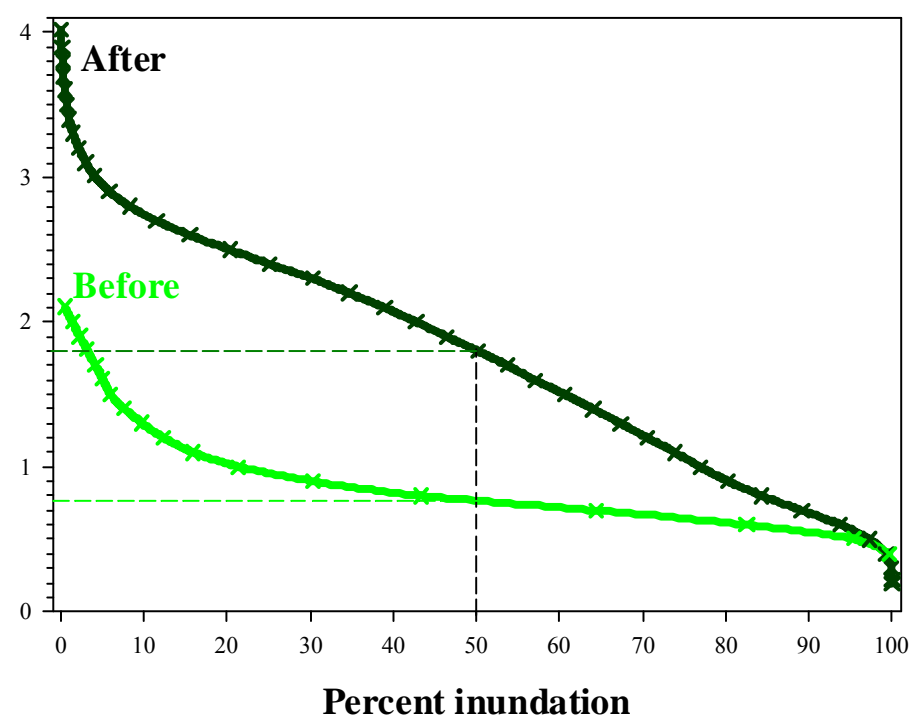

Figure 4.3. Exposure-Elevation (hypsographic curve) Plot for Pre- and Post-Restoration Periods at Kandoll Farm Restoration Site, 2005

\section{SITE-SPECIFIC CONTIGENCY CONSIDERATIONS}

A. Observe bank conditions of the water body where equipment is deployed; assess its potential for slope failure that can place risk to equipment and affect data quality.

B. Ensure probes' metallic elements are not in close proximity to any other metallic structure as this can cause electrolysis and instrument malfunction (especially in saline areas).

C. Forecast tidal fluctuations and set up maintenance schedule accordingly so that equipment can be deployed and retrieved safely.

D. Review first sets of data carefully and use to make inferences of unexpected site conditions.

E. Data loggers should be from the same vendor when possible to facilitate data downloads and consistency with inherent variability of readings.

\section{ADDITIONAL INFORMATION}

For planning purposes, real-time and predicted water-level data is available at http://tidesonline.nos.noaa.gov/. In addition, tidal prediction software is available that provides more options for graphic and data outputs.

Climate (atmospheric pressure) correction data: http://www.ncdc.noaa.gov/oa/ncdc.html 


\subsection{Water Quality}

\section{PURPOSE}

Organisms have varying tolerances to water quality parameters such as temperature, salinity, turbidity, $\mathrm{pH}$, and dissolved oxygen (OWEB 1999). Measuring variations in pre- and post-restoration water quality conditions are a direct measure of changes in habitat opportunity (Callaway et al. 2004), and are important for explaining floral and faunal changes that may accompany hydrologic reconnection. Increased circulation due to tidal reconnection may reduce excessive temperature and help maintain suitable DO levels. Increased salinity intrusion on a restored site can also determine vegetation community structure. As with water elevation (Protocol 1: Hydrology), we advocate the use of autonomous data logging equipment to measure water quality parameters. Some water level loggers also record temperature and/or salinity. While DO is an important metric, data collection is often problematic, therefore the minimum recommended core metric is temperature in tidal freshwater regimes, and temperature and salinity in estuarine habitats.

\section{GOAL}

To measure time series of water quality parameters at reference and restoration sites and relate to biotic changes.

\section{DESIGN}

The design follows Protocol 1: Hydrology. A Recovery and/or BACIPS time series design should be used to evaluate changes in water quality caused by the restoration activity. At a minimum, two instruments would be deployed, one at the reference and the other at the restoration site. Position the latter in a reach near the site of the hydrological reconnection, which would ideally be located where other monitoring activities take place (i.e., fish abundance). Where logistically possible, pre-restoration (baseline) measurements are desirable to evaluate natural variation in the system. Comparing ranges and fluctuations of the reference and restoration time series gives a measure of the effectiveness of the restoration project.

\section{EQUIPMENT}

A. Field: data loggers, laptop computer, and data logger launching/downloading software, data logger attaching/anchoring equipment (stakes, cable ties), hammer, GPS, camera, or field notebook for documenting data logger location, and extra batteries.

B. Lab: data logger calibration and maintenance manual, data logger output software.

\section{SITE SELECTION}

A. Install data loggers in both reference and restoration sites. Additional instruments, if available, should be placed upstream of the reconnection to evaluate the extent of hydrological reconnection. 
B. Choose locations that are representative of the overall reach and with some assurance of repeatability under changing conditions from the restoration treatment (e.g., increased water-level fluctuations and velocities).

\section{SAMPLING PERIODICITY}

A. Preferred sample frequency is $1 \mathrm{hr}$. Try to initiate logging on the hour to simplify alignment with other time series data.

B. Download/change batteries at $<$ six-month intervals during spring and autumn to limit data loss and maximize recovery opportunities.

\section{SAMPLING PROTOCOL}

Attach monitoring probe on secure structure at least $25-50 \mathrm{~cm}$ below the lowest anticipated water levels and 10-20 cm from channel bottom. If possible, install logger at position relative to a known surveyed elevation (Protocol 1: Hydrology) to ensure all data is collected at the same position in the water column. This will provide comparable data sets for the reference and restoration sites. Record GPS location to aid in retrieval. Clean and maintain monitoring probe using factory recommendation and ensure equipment is placed in a consistent location in the water column after download or maintenance.

\section{CALCULATIONS \& ANALYSIS}

A. Primary output from data loggers is time series of parameters, which can be analyzed with methods such as spectral analysis to capture trends in the data. Data should be inspected for data outliers (+/- 3 sd of the mean). Time series from reference and restoration site should be temporally aligned and graphed together.

B. Comparisons between sites can be made with difference time series plots (Reference valueRestoration value). Mean daily maximum values may be used to examine periods where temperatures exceed organism tolerances (Figure 4.4).

\section{SITE-SPECIFIC CONTIGENCY CONSIDERATIONS}

A. Observe bank conditions of the water body where equipment is deployed; assess its potential for slope failure that can place risk to equipment and affect data quality.

B. Ensure probes' metallic elements are not in close proximity to other metallic structure as this can cause

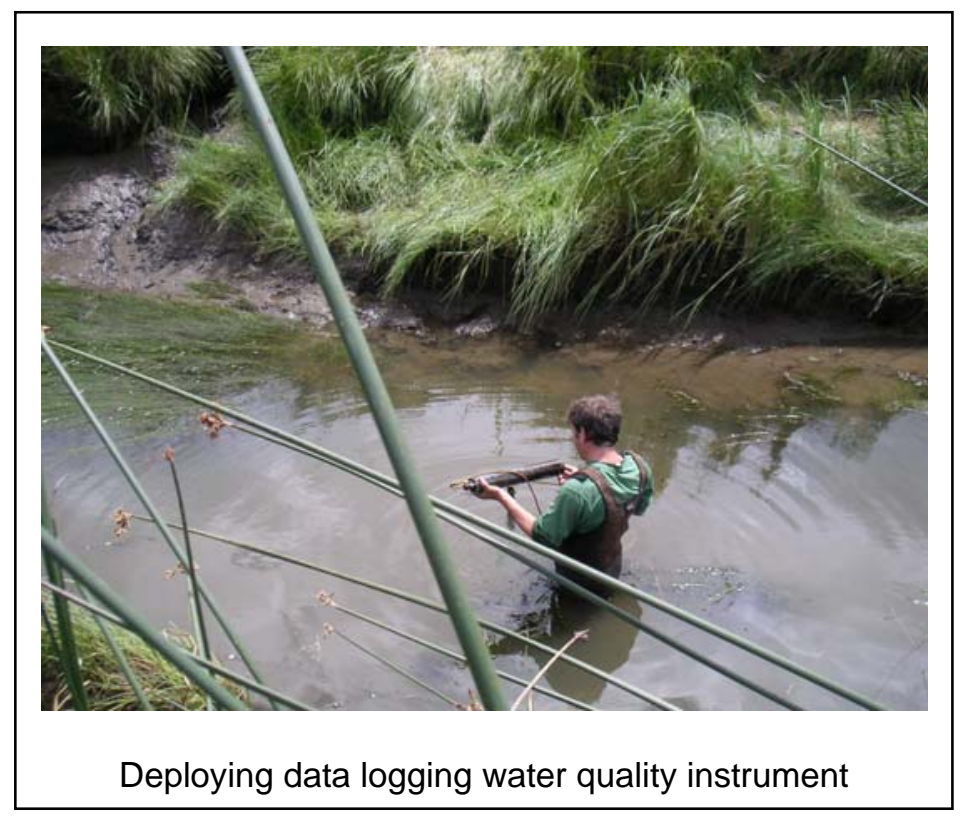


electrolysis and instrument malfunction (especially in saline areas).

C. Forecast in advance tidal fluctuations and set up maintenance schedule accordingly so that equipment can be deployed and retrieved safely.

D. Review first sets of data carefully and use to make inferences of unexpected site conditions.

E. Monitoring probes should be from the same vendor when possible to facilitate data downloads and consistency with inherent variability of readings.
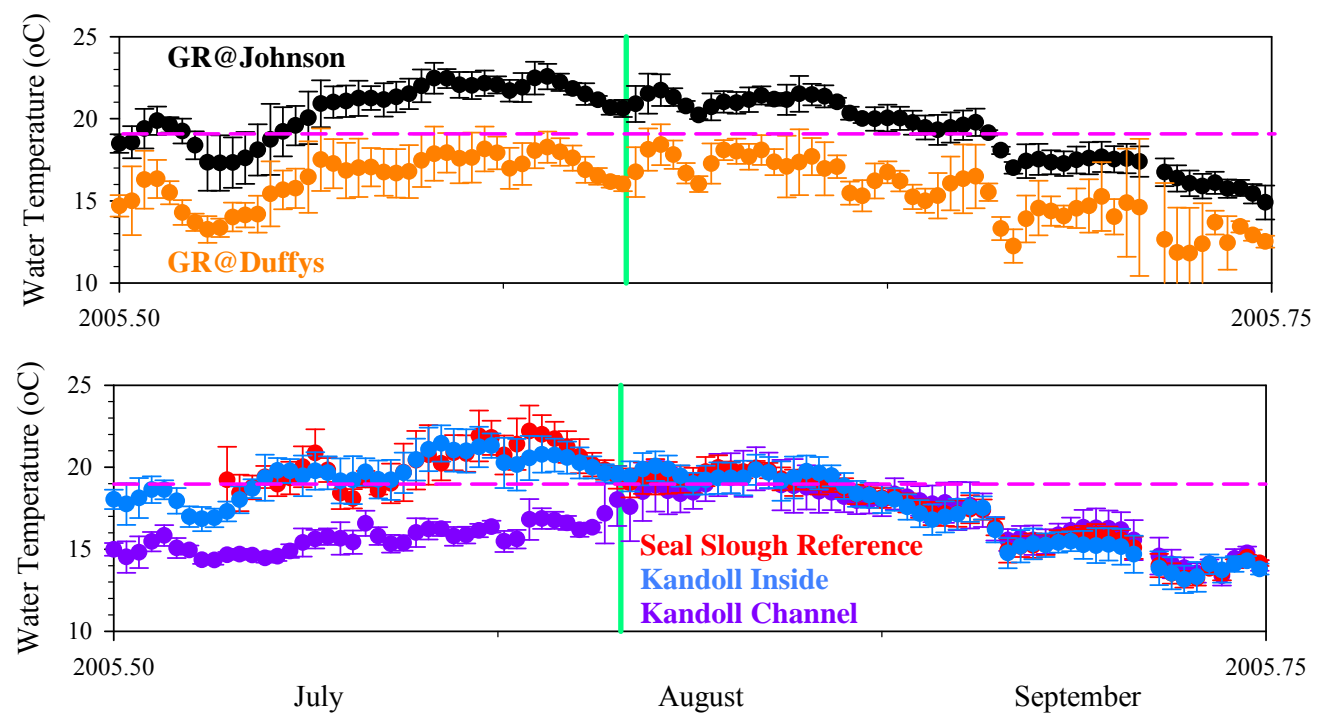

Figure 4.4. Time Series of Mean Daily Temperature $( \pm s d)$ for Reference and Restoration Sites Surrounding Tide Gate Removal, Grays River system, 2005. Upper plot, times series from up- and downstream monitoring stations illustrating strong temperature gradient. Lower plot, time series from stations at Seal Slough reference (red) and within restoration site (blue, purple) monitoring stations. The timing of the tide gate removal indicated by green vertical line. $19^{\circ} \mathrm{C}$ temperature threshold indicated by dashed horizontal line. 


\subsection{Elevation}

\section{PURPOSE}

Wetland elevation is a factor in geomorphological evolution, vegetation succession, and fish habitat use (Rice et al. 2005). Dynamic alterations of channel morphology and vegetation patterns often accompany hydrologic reconnection of sloughs and backwaters with tidal forcing (Zedler 2001; Coats et al. 1995). Establishing the extent and rate of change of elevation at a restoration site is important for evaluating the progress of the restoration effort.

\section{GOAL}

Quantify changes in elevation before and after restoration actions on portions of the site within the area influenced by tidal inundation; link data logging instruments to topography and biotic surveys.

\section{DESIGN}

Accurately monitoring elevation changes in an intertidal area requires a precise elevation survey tied to a benchmark and linked to an established vertical datum (e.g., NAVD88 or MLLW; see Additional Information). However, established survey benchmarks may not be in close proximity to restoration sites and therefore may be of limited utility for determining elevations at a site. Often a site survey is conducted by a certified surveyor as part of the restoration project design. Note that if surveys are not conducted in combination with vegetation surveys or in other specific areas of interest, such as tidal channels, they may not be useful for evaluating vegetation patterns or analyzing channel formation and change. At a minimum, surveys should establish a series of elevation benchmarks at the restoration site with "line-of-site" to the portions of the site where elevation data is critical (e.g., at the location of vegetation transects, channel cross sections, and water depth sensors). An autolevel can then be used to survey elevation differences between the established benchmarks and the areas of interest.

\section{EQUIPMENT}

Field: Autolevel, tripod, stadia rod, meter tape, radio communications, GPS, PVC/rebar and mallet/sledge hammer.

\section{SITE SELECTION}

Sampling station locations may be generated from aerial photography. Elevation measurements should be constrained by the boundaries of expected change and should include the following locations:

A. Fixed points
a. Along vegetation transects
b. Water pressure sensors
c. Cross section end points
d. Sediment accretion stakes. 
B. Site features

a. Natural levees and channels

b. Created features that may be part of the restoration effort (e.g., added soils or excavated areas)

c. Boundaries between vegetation communities

d. Upper and lower elevation range of site.

In addition to taking elevation measurements, channel cross-sections should be measured to determine channel volume and relative changes over time. Channel cross sections should be sited as follows:

a. At the locations of water pressure sensors (proximal to restoration action)

b. Near the expected boundary of post-restoration inundation.

\section{SAMPLING PERIODICITY}

Minimally, sampling should be conducted annually while the system is changing rapidly in the years immediately following restoration.

\section{SAMPLING PROTOCOL}

Elevations should be surveyed at 1) the location of data logging instruments (Protocol 1 \& 2: Hydrology \& Water Quality), 2) at selected channel cross sections, 3) at the location of vegetation transects (Protocol 5: Plant Species Composition and Cover), and 4) at sediment accretion stakes. It is advantageous to use PVC or rebar to permanently mark the endpoints of the transects as defined in Protocol 5 (Plant Species Composition and Cover) and the endpoints of the channel cross sections. Elevations should be measured at the top of the stakes because the ground surface elevation can change over time. Additionally a GPS should be used to determine the location of each stake.

\section{Water-Level Sensors}

The elevation of the water-level sensors is critical to linking the relative water-level changes to a known elevation datum (Protocol 1: Hydrology). This data can be used to predict inundation over areas of known elevations. The elevation of the sediment surrounding the post where the sensor is attached is likely to change over time due to accretion or erosion around the post. Therefore the elevation of the post should be measured by leveling the stadia rod on top of the post. Each time the sensor is deployed, the distance from the top of the post to the sensor must be measured. If the post is ever moved, the elevation must be re-established. 


\section{Channel Cross Sections}

A. Set transect endposts. The endpoints should be marked with a permanent marker (e.g., rebar or PVC) at a distance far enough from the bank to ensure they will not be washed out by erosive forces. The transect endpoint locations should also be recorded using a GPS, preferably with differential correction. If satellite coverage for the GPS is not available due to tree cover then points can be established in areas offset from the original location with measurements of distance, azimuth, and elevation difference.

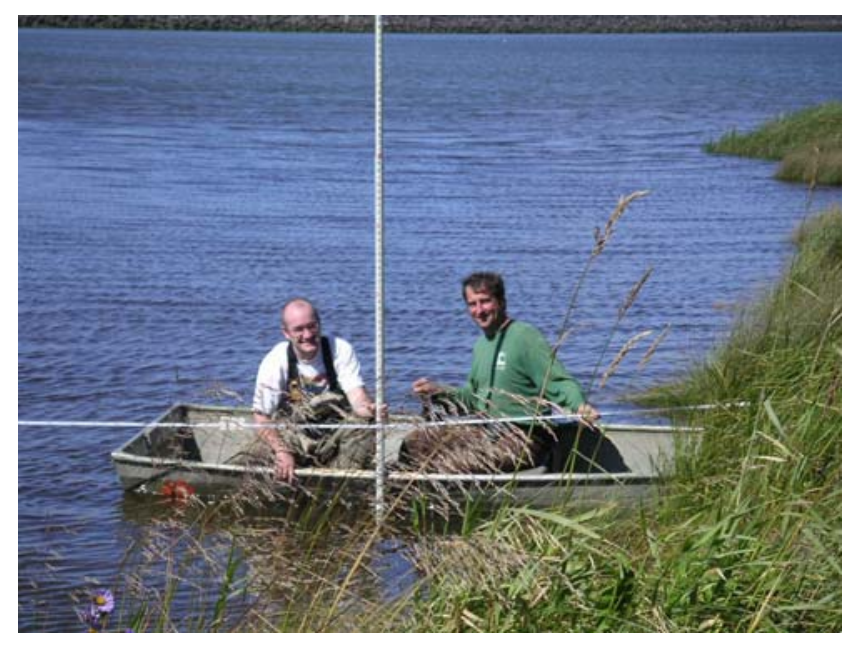

Surveying channel cross section
B. Attach measuring tape to fixed endpoints. Level stadia rod at each predetermined interval and record the interval on the tape and the height measured with the autolevel. The interval can be greater (e.g., 1 to 2 meters) in areas of low slope and smaller ( 0.5 meters) in areas of steeper slope. Hand-held radios are useful when distances make communication difficult.

C. Repeat at each measurement interval. This procedure is useful for determining two-dimensional (2D)

change across an intertidal/tidal creek profile.

\section{Vegetation Transects}

The elevation surveys at vegetation sampling areas are best conducted in a grid using transects along a baseline as outlined in Protocol 5: Plant Species Composition and Cover. If resources are limited, fewer points may be surveyed for elevation than for vegetation, for example: a) the endpoints of the transects, b) borders between plant communities, or c) points representative of certain plant communities. To map elevations in the area of the vegetation transects, the elevations could be measured at three alternative times as follows:

A. Alternative 1: The elevation survey could be conducted at the same time as the vegetation survey by placing the stadia rod at the center of the quadrat before or after vegetation percent cover is determined (see Protocol 5: Plant Species Composition and Cover) and measuring the elevation difference from the established benchmark with the autolevel.

B. Alternative 2: The location of each quadrat location could be marked with flagging in the center of the quadrat and the elevation data can be recorded at a later time by positioning the stadia rod at the location of the flagging. The latter situation carries the risk of the flagging moving or getting lost between the time of the vegetation survey and the elevation survey. 
C. Alternative 3: The meter tapes could be repositioned and the original locations of the quadrats remeasured. This alternative has the highest amount of potential error because it is highly unlikely that the exact position of the quadrats would be located.

\section{Sediment Accretion Stakes}

Sediment accretion stakes are an economical means for measuring the erosion or deposition of sediment, a typical result of hydrological reconnection projects.

A. Sediment accretion stakes should be set prior to restoration in an area likely to be inundated and should be measured once before hydrological reconnection. Pre-restoration measurements may be averaged or plotted for comparison to post-restoration measurements.

B. Sediment accretion stakes can be made from 1" schedule 40 sunlight-resistant PVC conduit (gray). If possible, the stakes should be driven into the ground at least $1.0 \mathrm{~m}$ deep to ensure their stability against hydrological forces following restoration. Stakes are placed one meter apart. The tops of the stakes must be leveled. This is accomplished by laying a construction level between them.

C. To measure sediment accretion, a meter stick is set across the top of the sediment accretion stakes. A second meter stick is held vertically with the 0 -end touching the sediment surface and is read to the lower edge of the resting meter stick. This is done at $10-\mathrm{cm}$ intervals between the stakes. Measurements should be made to the nearest millimeter.

D. It is useful but not necessary to measure the elevation of the top of one sediment stake by leveling the stadia rod on top of the post.

\section{CALCULATIONS AND ANALYSIS}

Data should be entered into a GIS and in a spreadsheet.

A. Difference plots. Subtract before from after elevations (or time series): positive values indicate accretion and negative values erosion.

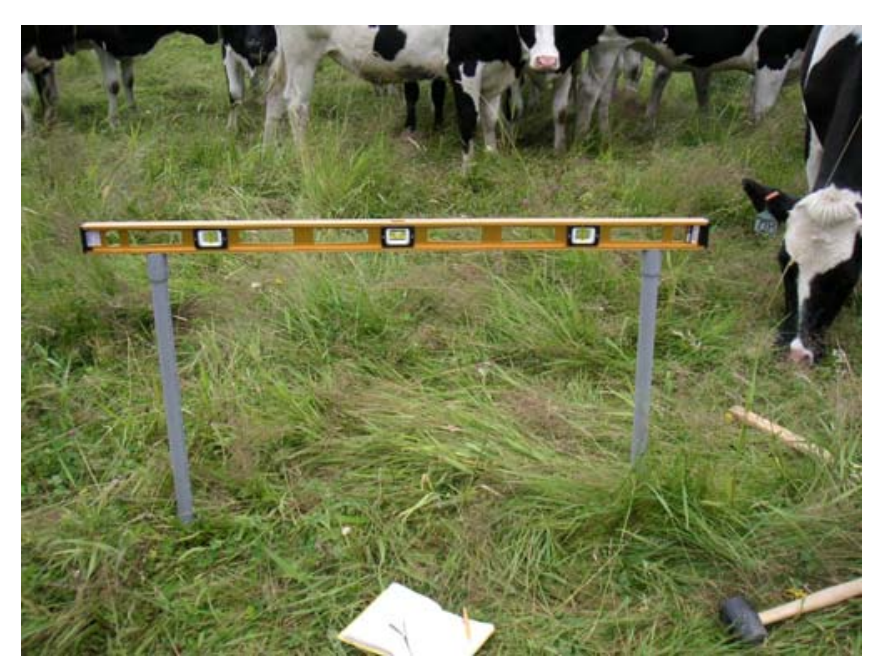

Leveling sediment accretion stakes
B. Elevations and vegetation can be plotted to show the means and ranges of elevation for species or communities. This information can be used prior to restoration to predict vegetation colonization post-restoration.

C. Channel condition metrics calculated from above.

- Change in cross-sectional area of tidal channel at selected transects (Figure 4.5). 
- Change in channel gradient (elevation change per unit horizontal distance, $\mathrm{dz} / \mathrm{dx}$ ).

- Wetted width: width of water surface perpendicular to flow (modeled from water elevation data). Water elevation analysis as described in Protocol 1: Hydrology.

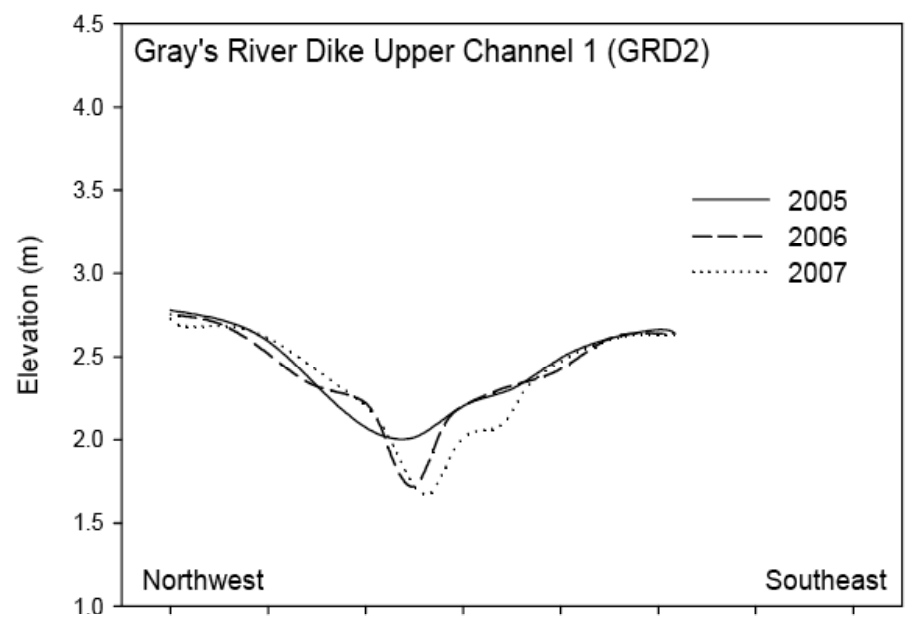

Figure 4.5. Channel Cross-Sections at Kandoll Farm, 2005-2007

\section{ADDITIONAL ANALYSIS TOOLS}

A. For topographic surveys we advocate use of a "total station," which is a combination transit and electronic distance measuring device. Elevation and position data are logged internally and can easily be transferred to mapping software for analysis and display. Although simple 2D (distance and elevation) transects across areas of interest can be made, this system can also generate 3D maps from regular or random grids of data points. Such maps can be digitized and overlain on aerial photography images to produce digital elevation maps and change analysis can be used to measure changes to landforms over time.

B. The total station system consists of an electronic instrument stabilized on a leveled tripod and a reflecting mirror affixed to the end of a graduated stadia rod. The instrument uses infrared light to measure the distance and angle from instrument to reflector, then calculates the relative position and elevation. Two benchmarks are required for a total station to provide accurate information. The users manual should be consulted for calibration and other procedures specific to the instrument employed. Similar to the autolevel method, the total station requires line of sight to points of interest and operation typically requires two people.

C. In addition, real-time kinematic (RTK) GPS technology is a useful means of establishing benchmarks and can be used for elevation surveys. Two GPS receivers are linked via a radio connection: the base unit is stationary and the mobile unit (rover) is used to make position and elevation measurements. This technique is advantageous in that measurements are made rapidly 
and only one individual is required. One drawback is that there may be satellite reception problems in areas of heavy tree or shrub cover. In addition, surveyed elevations using an RTK and NOAA's Online Positioning User Service (OPUS) processing may differ from traditional field surveys using local benchmarks (see Additional Information). NOAA's height modernization program is designed to improve vertical control throughout the US, and while the Columbia River region has no definite update plan, efforts are underway in Oregon to implement the program.

D. For bathymetry, surveys can be conducted in shallow water $(<1 \mathrm{~m})$ using the techniques described for topographic surveys. For deeper water areas, a GPS-referenced sonar will be required.

\section{ADDITIONAL INFORMATION}

Two types of vertical datums relate elevations in the Columbia River Estuary. Tidal datums, including mean lower low water (MLLW), are based on data collected at tidal benchmarks over a 19-year period. Fixed geodetic datums, such as North American Vertical Datum-1988 (NAVD88), are based on a fixed set of constants and are generally used for terrestrial elevation surveys. The Columbia River Datum (CRD) is a fixed datum; however NOAA has linked the CRD to a tidal datum for eight locations on the River (Stolz et al. 2005). The corrections between these datums are available at selected sites in the Columbia River, but interpolation of the corrections between sites should be done cautiously and is not recommended for locations away from the main channel of the River (e.g. up tributaries and sloughs). Tidal benchmarks information and datum correction information is available at http://tidesandcurrents.noaa.gov/.

Survey Procedures: http://www.usace.army.mil/usace-docs/engmanuals/em1110-1-1005/toc.htm

Real Time Kinematic (RTK) GPS: http://geodesy.noaa.gov/OPUS/

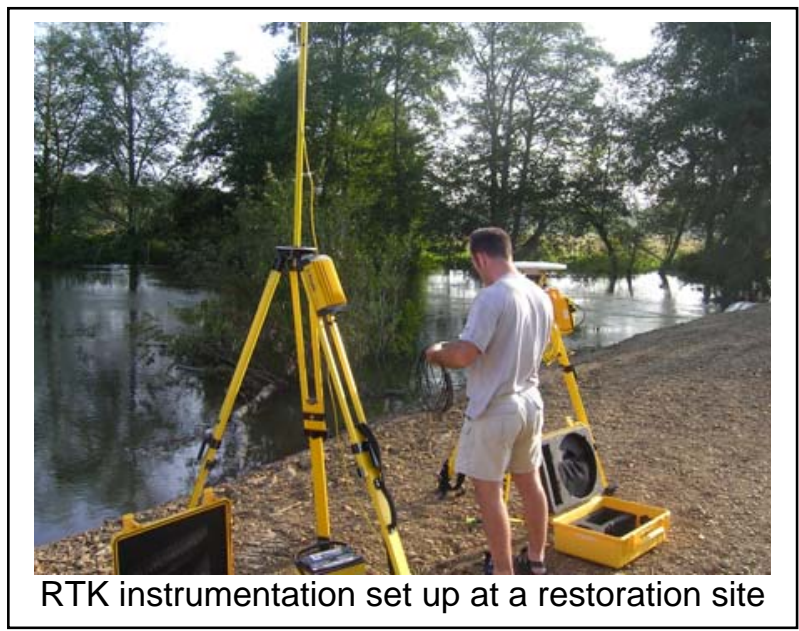

LiDAR: http://pugetsoundlidar.ess.washington.edu/ 


\subsection{Landscape Features}

\section{PURPOSE}

Aerial photography and photo points are key tools for conducting quantitative measurements and qualitative assessments of landscape features at monitored sites. It is important to document the spatial changes in geomorphological features (such as tidal channel evolution or intertidal area) and vegetation communities (for example agricultural meadow versus emergent marsh) at a site scale to complement less extensive statistical sampling. Full color or near infrared aerial photographs are often publicly available through governmental agencies and provide a low-cost alternative for evaluating environmental change without image-analysis software and remote sensing expertise. If funds and expertise are available, hyperspectral or multispectral satellite imagery or digital aerial photography can provide additional information.

\section{GOAL}

To quantify project-wide changes in landform and vegetation patterns accompanying restoration.

\section{DESIGN}

\section{Imagery}

Prior to restoration, aerial photos should be analyzed to identify hydrological barriers, to establish baseline vegetation conditions, and to make preliminary selections of sampling transects (Protocols 3 and 5: Elevation and Vegetation), locations for data logging instruments (Protocols 1 and 2: Hydrology and Water Quality), and reference sites. Photos documenting historical conditions (i.e., prior to land use changes) are also useful for project design. After restoration actions are implemented, new aerial photographs must be acquired in order to assess changes in geomorphological features and vegetation communities.

A. Specifications. The three sources of aerial imagery are publicly available (free of charge), commercially available (with a fee), or contractually flown data specific to a site (individually contracted). Further, a variety of types of imagery useful to site-scale restoration project monitoring are available including orthorectified black and white or color aerials, stereo-paired aerials, digital multispectral orthorectified aerials (including infrared), and satellite imagery. Aerial imagery requires sufficient detail to identify features of interest (e.g., $1 \mathrm{~m}$ resolution) and should be full color and/or near infrared to distinguish plant communities and vigor. Tidal stage, time of day, and seasonality are also important factors to consider. For example, low

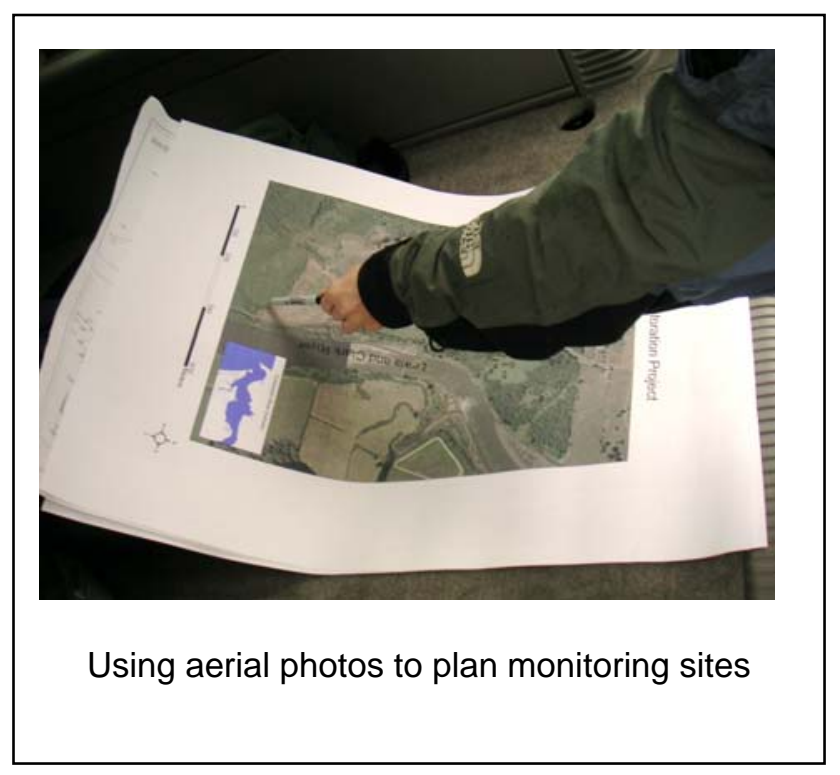


water at spring tide can expose landforms and vegetation, while high water can document the extent of tidal inundation or channel development. Morning or afternoon increases light contrast. Late summer season maximizes vegetation growth and has a better chance of favorable weather in the Pacific Northwest. These conditions should be as similar as possible in all imagery, yet this may be difficult due to weather conditions and other factors. Recommendations depend on the main purpose of analyses.

B. Interpretation. Interpretation of the acquired imagery can be conducted "manually" by digitizing polygons, lines, or points using a GIS platform. This method requires ground-truth data to evaluate the photos and determine where features should be delineated. Key elements of ground-truthing imagery include collection of GPS data with corresponding photos of the vegetation and geomorphological features at each point, line, or polygon.

C. Analysis. GIS techniques may be employed to quantify changes in landforms and vegetation patterns. For example, polygons of vegetation classes can be developed from interpretation of the imagery and can be evaluated to determine the area of each classification and the change in area over time. Additionally, tidal channel delineations can be evaluated to assess the amount of marsh area that is accessible via the channels, channel order, and channel sinuosity.

\section{Photo Point Monitoring}

The essence of photo point monitoring is consistency. Photo point monitoring requires little more than a camera, compass, measuring and marking tools, and a map. Some important considerations include exact replication of the center point of the photograph, angle, and degree of zoom (Figure 4.6). A reference stake placed in the frame of the photo can provide scale and a consistent feature in all photos. In addition, bringing photos from prior years into the field makes it easier to replicate the exact frame. Photo points are best permanently marked with PVC or rebar. Using the same camera also increases consistency.
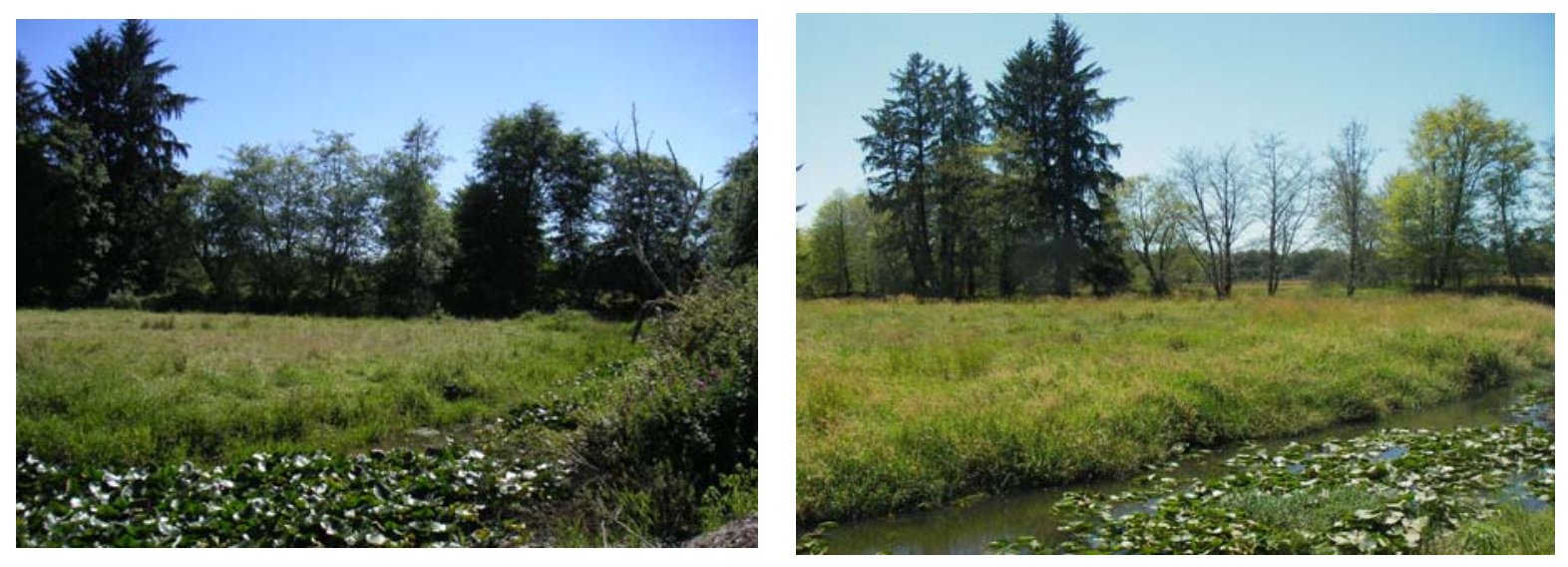

Figure 4.6. Before and After Photo Points at a Culvert Installation on Kandoll Farm 


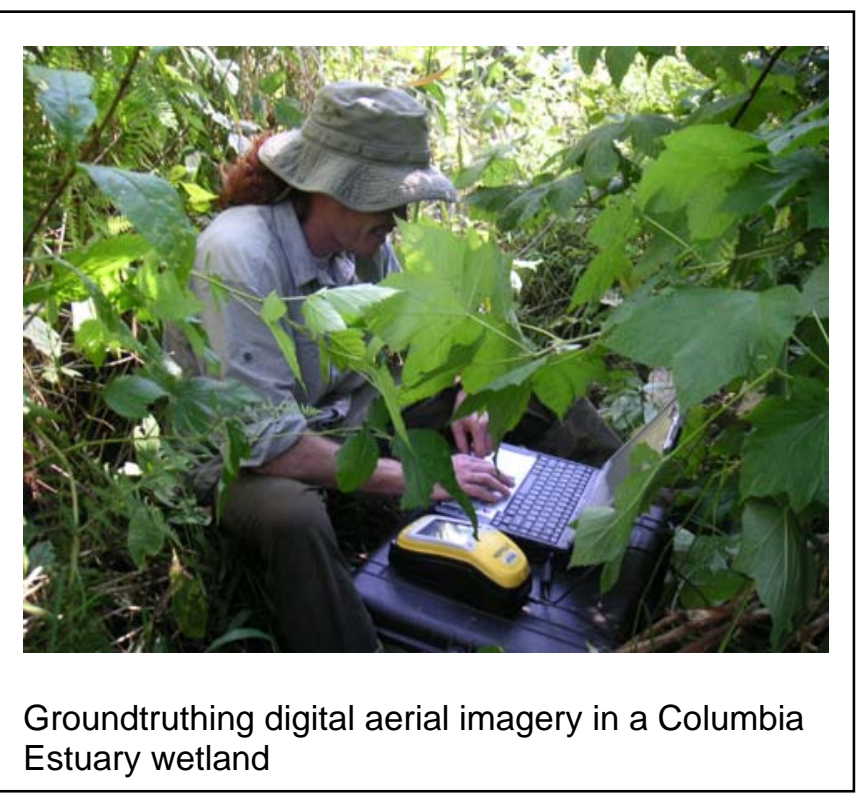

\section{EQUIPMENT}

A. If publicly available aerials are insufficient, overflights of target sites may be arranged through commercial venders. Ideally, large areas of the CRE can be acquired during one flight, thus maximizing coverage and providing cost efficiencies.

B. Desktop analysis requires GIS.

C. Camera, map, compass, stakes for marking and for reference in photo, GPS.

\section{SITE SELECTION}

Imagery should include the restoration

and reference sites in their entirety and collected concurrently. Photo points should be located at vantage points offering views of expected areas of change.

\section{SAMPLING PERIODICITY}

The frequency of imagery acquisition is often a balance between sampling objectives and costs. For example, publicly available imagery is often flown at long intervals relative to restoration project development (e.g., once every 5 years). More frequent acquisition may be necessary to document periods with high rates of change such as the period immediately following implementation of restoration actions. Photo point periodicity depends on sampling objectives, i.e., comparing seasonal differences or annual variability.

\section{SAMPLING PROTOCOL}

Step 1. Before

A. Obtain aerial photos of reference and restoration sites.

B. Examine photos for hydrologic barrier locations.

C. Assess vegetation patterns and channel locations.

D. Plan location of random or stratified sampling grid.

E. Collect GPS coordinates and corresponding photographs to ground truth landform and vegetation patterns.

Step 2. After

A. Repeat A-E above.

B. Compare before and after images of reference and restoration sites for changes in landforms and vegetation using GIS. 


\section{CALCULATIONS \& ANALYSIS}

GIS-based measurements:
A. Site area
B. Width, sinuosity, density, and total edge of tidal channels
C. Area and configuration of landforms and broad vegetation communities.

\section{ADDITIONAL ANALYSIS TOOLS}

A. Digital imagery coupled with ground truthing may be analyzed using GIS to quantify the progress of restoration. With multispectral imagery and ground-truth data, algorithms can be developed to identify pixel values in an image using image analysis software. The pixel values are then applied to the whole image to get a classified representation of the site. This kind of image classification provides a spatially explicit method of determining broad vegetation categories and the location of tidal channels that is not subjective and is repeatable in subsequent years.

B. In addition, LiDAR information available for selected areas of the estuary can identify landscape features at a very high resolution. Examples of such features include topography, drainage signatures, and large woody debris. These data sets are important to correlate with monitoring attributes related to water elevation, passage barriers, and tidal channel edge.

\section{ADDIONAL INFORMATION:}

Imagery:

Aerials from multiple years for Oregon, including most of the CR estuary:

http://www.oregon.gov/DAS/EISPD/GEO/data/doq.shtml

Source for aerial imagery (recent and historic) and satellite imagery:

http://edcsns17.cr.usgs.gov/EarthExplorer/

Aerials available for purchase from Washington Department of Natural Resources: http://www.dnr.wa.gov/BusinessPermits/Topics/Maps/Pages/orthophotography.aspx Photo Points:

Oregon Watershed Enhancement Board (OWEB) photo point monitoring protocol: http://www.oregon.gov/OWEB/docs/pubs/PhotoPoint_Monitoring_Doc_July2007.pdf

Hall (2002). 


\subsection{Plant Community}

\section{PURPOSE}

Tidal reconnections can result in substantial changes in the species abundance and distribution of vegetation (Cornu and Sadro 2002; Roman et al. 2002; Thom et al. 2002). Vegetation is recognized as a key indicator of ecological conditions in a restored environment (Zedler et al. 2001; Rice et al. 2005), and floristic measurements can be used to document plant succession following the implementation of restoration actions. Native estuarine and tidal freshwater plant communities have both structural and functional effects on estuarine ecosystems, although we concentrate here only on structural elements. We encourage measurements of functional benefits (i.e., primary productivity); while equally important, these are often more labor intensive to measure. To measure vegetation changes, we advocate georeferenced surveys that can be integrated with hydrology (Protocol 1), elevation (Protocol 3), and landscape-scale GIS data (Protocol 4).

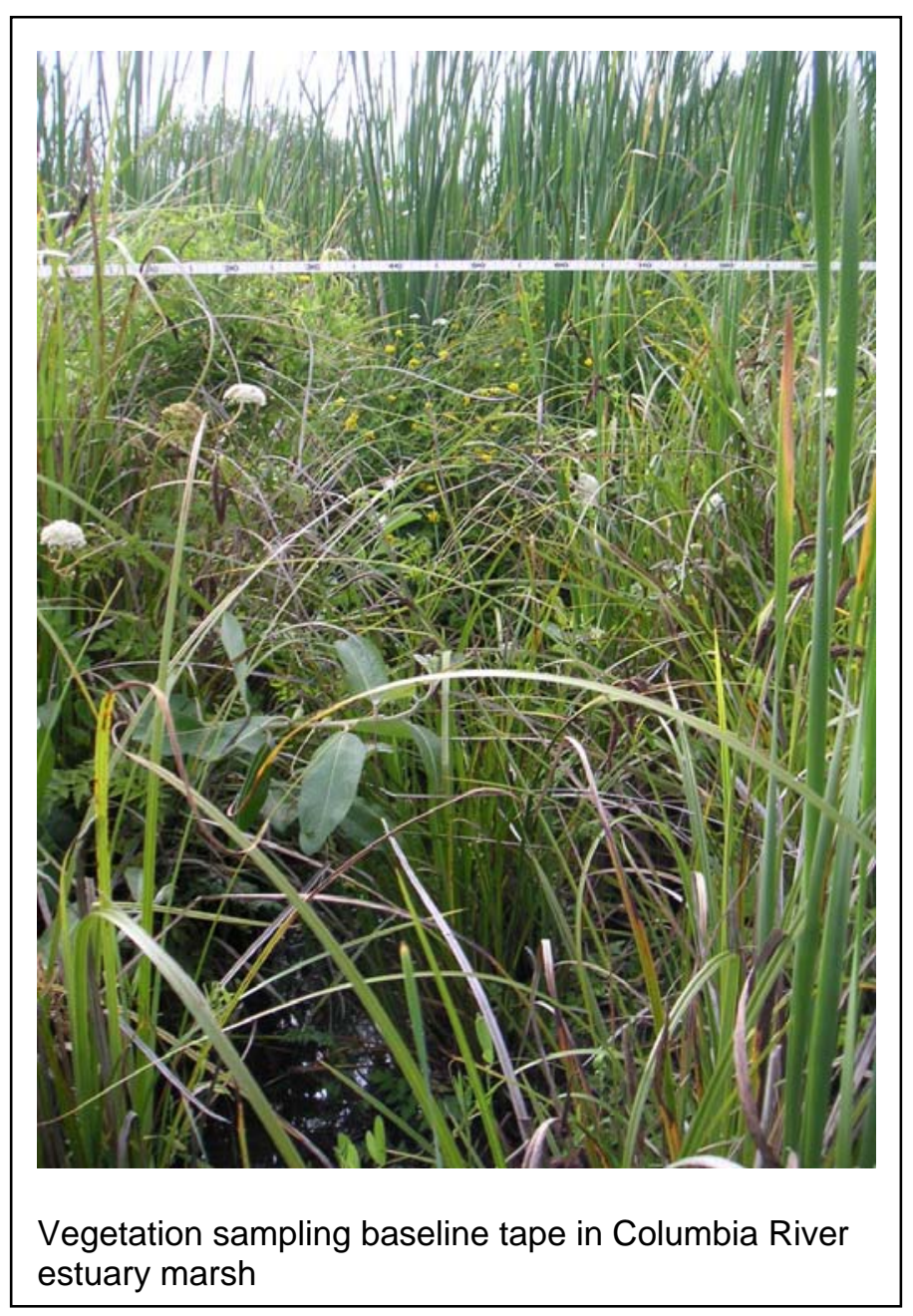

\section{GOAL}

Measure changes in vegetation species composition and distribution to assess successional trajectories toward reference estuarine plant communities following reconnection to tidal influence.

\section{DESIGN}

Vegetation monitoring at restoration sites in Pacific Northwest estuaries is typically designed to quantify changes in species percent cover (e.g., Frenkel and Morlan 1990; 1991; Thom et al. 2002). Measurements are usually made along transects. We recommend sampling be concentrated on transects proximal to expected changes, for example, near a culvert replacement or dike breach. For comparability, vegetation sampling on reference sites is best conducted at portions of the site with similar hydrology, for example, at similar distances from channels. Information derived from measuring Landscape Features (Protocol 4) can complement this vegetation monitoring by mapping plant communities at the site scale. Sampling designs such as "systematic sampling from a random start" permit appropriate data analysis; transects are established at set intervals along an established 'baseline' with plots spaced equally on each 
transect with a randomly selected starting point (Figure 4.7). A subset of plots may be fixed (i.e., sampled repeatedly), to track trends, while others are randomized anew for each sampling event to assess status. The location of the baseline is determined in part by site conditions, with the aim of stratifying major vegetation assemblages by elevation. Elevation gradients affect vegetation distribution at various distances from both the main channels and the riverine shore; while soil surveys and groundwater monitoring can provide additional information for stratification, these data sources may not be available. If a considerable elevation gradient is present at the site, multiple baselines may be required to encompass the different plant communities present at different elevations.

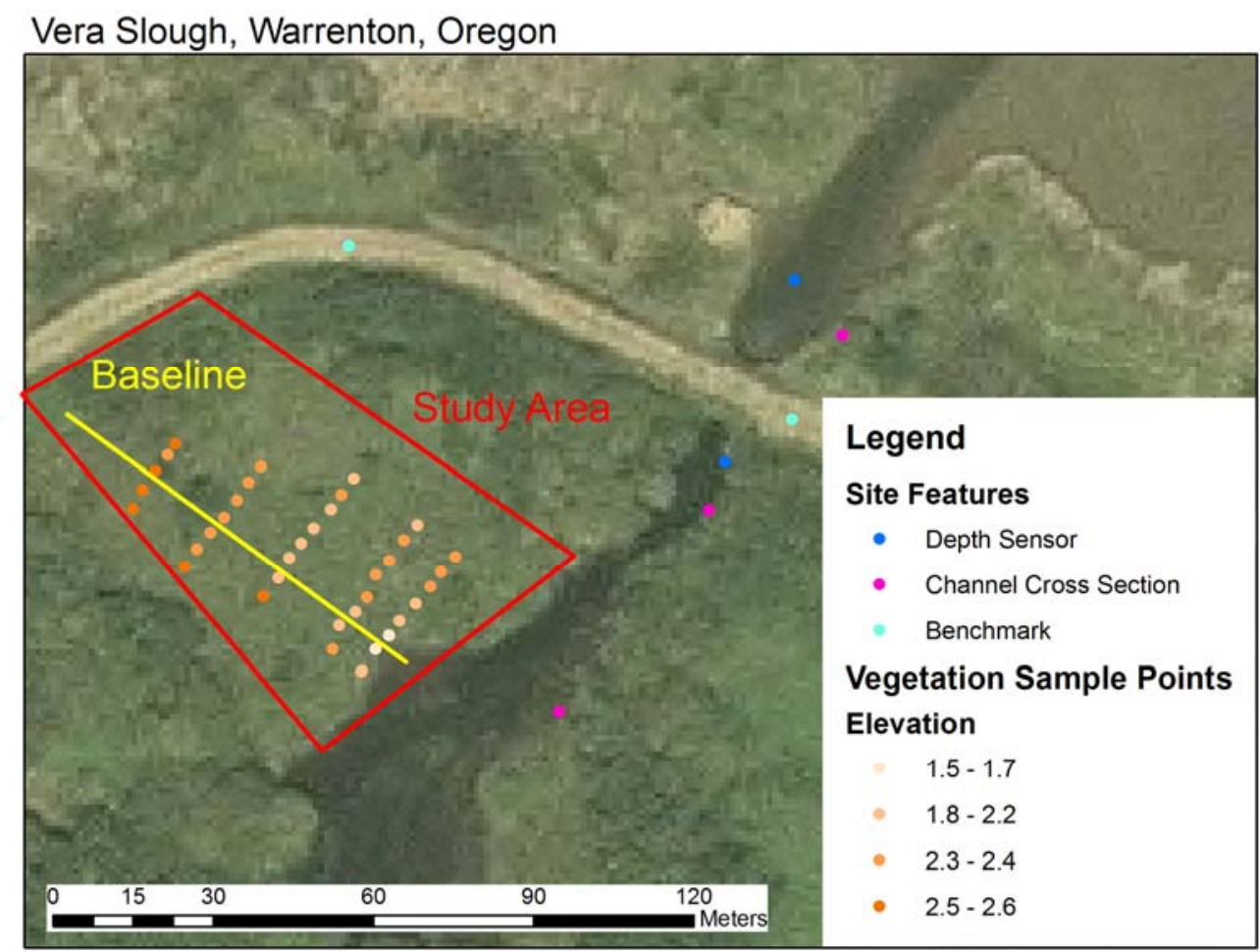

Figure 4.7. Example of Baseline and Transect Sampling Design in Herbaceous Area

Vegetation along transects is sampled in plots with plot size and shape depending on the type of dominant vegetation at the site: $1 \mathrm{~m}^{2}$ plots are used for herbaceous plant communities (Thom et al. 2002), belt transects for shrubs (Havens et al. 2003), and large circular plots are used for forested wetlands. When multiple plant communities are present at a site, the sampling design selects smaller herbaceous plots from both within and outside of larger plots to represent a greater portion of the study area and improve precision. While the 10 -meter-diameter tree plot size recommended here is smaller than some comparable methods (Havens et al. 2003), it approximates line-of-sight in Columbia River swamps and for this reason is highly efficient, enabling a greater number of plots to be sampled and increasing precision. 


\section{EQUIPMENT}

A. Field: $1 \mathrm{~m}^{2}$ quadrat, 100-meter tapes, site map, rebar or PVC stakes, mallet or hammer, plant identification book(s), bags for unidentified plant collection, GPS. Additional tools for forested wetland and shrub-scrub communities: diameter tape, calipers, increment borer, clinometer, 10meter tape, meter stick.

B. Lab: Aerial photos, GIS (if available).

\section{SITE SELECTION}

A. General site selection considerations,

i. A sampling site is selected proximal to the proposed restoration action (e.g., dike breach). At the reference site, a sampling site similar to the restoration sampling site is selected, particularly with respect to proximity to channel, channel size, and the width of the area sampled, allowing comparison between the two sites. If multiple plant communities are present (along elevation gradients), the sampling may need to be stratified by plant community.

B. For herbaceous communities;

ii. A linear baseline is established that is oriented perpendicular to the elevation gradient and that runs through the entire sampling site (Figure 4.7). This baseline transect should be representative of the vegetation community within an elevation gradient at the site and proximal to the proposed restoration action (e.g., dike breach). Multiple baselines can be chosen to systematically represent different vegetation communities.

iii. Next, several transects are established at intervals perpendicular to the baseline. The position of the first transect is chosen at random from all possible points along the baseline (systematic sampling with a random start). The additional transects are equally spaced relative to the first transect (e.g., 5 transects at 20-m intervals along a 100-m baseline).

iv. Finally, on each transect, monitoring plots $\left(1 \mathrm{~m}^{2}\right)$ are established at equally spaced intervals depending on size of site. As with the positioning of transects along the baseline, the plots are spaced relative to the first plot, which is positioned at random along the transect and thus avoids a grid pattern. Typically 5 to 10 plots per transect are sufficient to adequately sample the cover of the vegetation.

C. For forested wetland and shrub-scrub communities;

v. First the length of the focal channel to be sampled is determined (e.g., 300 meters) and a random number between 0 and the length of the channel is chosen as the start point for placement of the first transect. Transects cross the channel encompassing the riparian area on both sides (e.g., 50 $\mathrm{m}$ on each side of the channel). Remaining transects are located parallel to the first and systematically spaced (e.g., 5 transects at 50-m intervals). See Figure 4.8.

vi. Next, monitoring plots (10-m diameter circles) are established at equally spaced intervals along each transect starting $10 \mathrm{~m}$ from the channel bank (Figure 4.9). Very high numbers of plots may 
be required to achieve high precision in some of these communities (e.g., 695 tree plots for alpha $=0.05$ and precision $=0.05$ in Sitka spruce swamps). Typically, such sampling is not economically feasible for restoration practitioners and a lower precision is accepted for reference purposes (e.g., 6 plots per transect on 5 transects yields 30 plots).

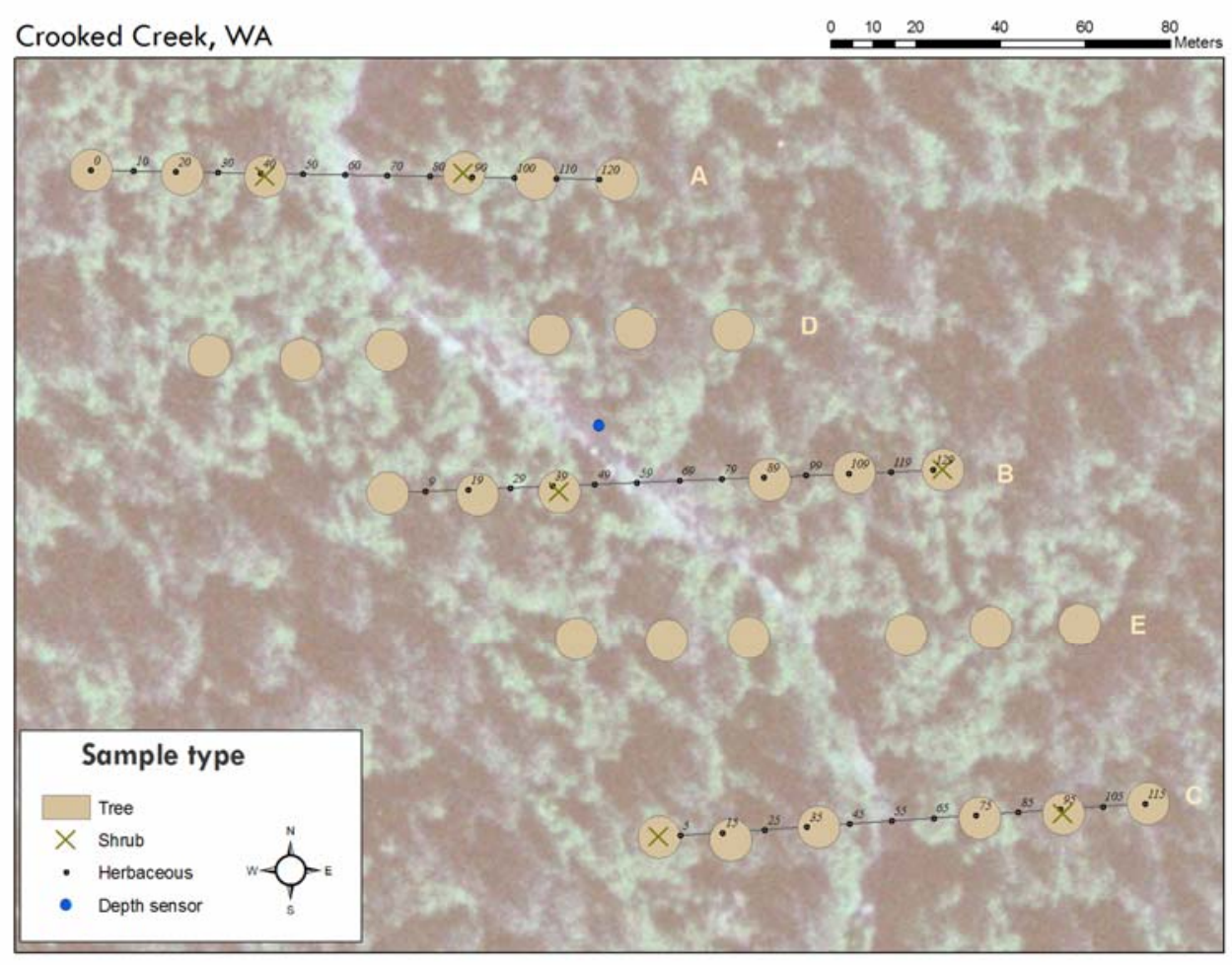

Figure 4.8. Example of Sampling Design in Forested Wetland

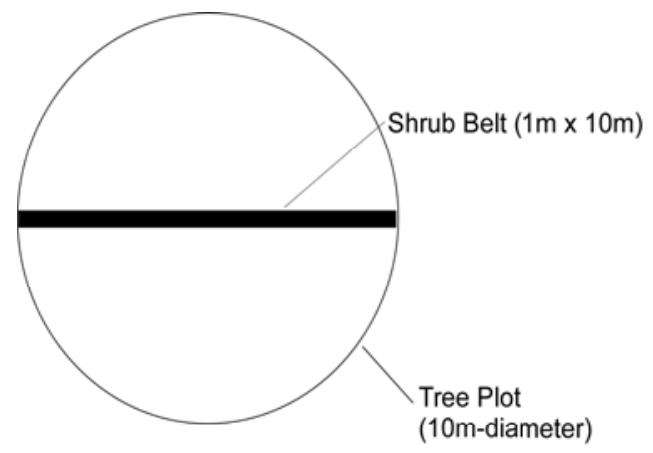

Figure 4.9. Plot Design for Forested Wetlands 


\section{SAMPLING PERIODICITY}

If possible, sampling should occur at least once before restoration treatments and the year following restoration. Subsequent sampling can be conducted at 1- to 3-year intervals for 5 to 10 years to capture the major transition in vegetation communities. With limited resources, it is best to sample vegetation in mid-summer to capture the period of greatest biomass and cover, although sampling in both spring and late summer generally increases the number of species found on the site.

\section{SAMPLING PROTOCOL}

\section{Initial Assessment}

The protocols for sampling are necessarily different for herbaceous, shrub-scrub, and forested wetland communities because of the horizontal and vertical scales appropriate for capturing variation within and between them. The boundaries between plant communities can be mapped using a GPS in the field or from aerial photography with ground truthing (Protocol 4: Landscape Features). This technique is being used in the Columbia estuary Ecosystem Monitoring Program and is most effective when clear elevation gradients are present (Leary et al. 2006).

Step 1. Define the study area boundaries (see example above) based on extent of expected inundation and proximal to the proposed restoration action.

Step 2. Use aerial photos (Protocol 4: Landscape Features) to broadly characterize existing plant communities (e.g., herbaceous, shrub/scrub, forested).

Step 3. Establish baseline(s) based on broad plant communities and elevation strata. Mark baseline endpoints with permanent stakes (e.g., rebar or PVC) and record GPS positions.

\section{Herbaceous Vegetation Communities}

Step 1. Establish transects at intervals along the baseline with a density of approximately 5 transects per 100 meters.

Step 2. Select plots along each transect (5-10 plots per transect are often sufficient). The total number of plots is dependant on the size and homogeneity of the area.

Step 3. In each $1 \mathrm{~m}^{2}$ plot, visually estimate percent cover in 5\% increments, using a "trace" category for species that cover less than 5\% of the area within the quadrat (e.g., 25\% Carex lyngbyei, 50\% Phalaris arundinacea, 20\% Typha latifolia, 5\% Alisma plantago-aquatica, Trace Galium trifidum).

Step 4. Using a random number generator, establish a subset of approximately one-third of the total number of plots to be permanent plots. These plots will be resampled each year. Mark the four corners of each permanent plot with 1.-2. m, $1.9 \mathrm{~mm}$ (3/4-inch) PVC pipe driven to a depth of at least $1 \mathrm{~m}$. Flag the pipe so that it can be easily identified from a distance and record GPS positions.

Step 5. Repeat sampling protocol design at reference site. 


\section{Shrub/Scrub and Forested Vegetation Communities}

The sampling methods for these community types are far less defined in the literature and are still under development by many organizations in the Pacific Northwest at this time. The recommendations here are based on our investigations of Sitka spruce swamps in the vicinity of Grays Bay on the Columbia River. Tree, shrub, and herbaceous layers may be present in these communities and require sampling with different methods. Conditions in these systems are challenging at best, making many measurements difficult and time consuming relative to sampling precision objectives. Each situation needs to be considered individually for hazards and feasibility.

Step 1. Establish transects as described in Site Selection (C) above.

Step 2. Place systematically spaced tree, shrub, and herb plots along each transect.

A. Starting $10 \mathrm{~m}$ from the channel bank, place $10-\mathrm{m}$ circular tree plots along each transect, the number and spacing is dependant on the size and homogeneity of the area. In the Site Selection example above, thirty plots or three plots on each side of the channel on five transects may be sufficient to provide tree cover precision within $20 \%$ of the mean $80 \%$ of the time (i.e., $20-\mathrm{m}$ spacing between 10 -m plot centers).

B. Select a random subset of the tree plots in which to sample the shrub belt. A randomly selected subset of 10 of the 30 tree plots may be sufficient to provide shrub cover precision within $20 \%$ of the mean $80 \%$ of the time.

C. Place $1-\mathrm{m}^{2}$ herbaceous plots systematically spaced from a random start on each transect. In the previous example, 50 plots may be sufficient to provide herbaceous cover precision within $20 \%$ of the mean $80 \%$ of the time.

Step 3. Measure species cover for each plot using the following techniques:

A. Trees: Lay a 10-m tape perpendicular to the transect tape to delineate the 10-m diameter circular tree. Identify all trees in the plot to species and measure diameter at breast height (dbh) with calipers or a dbh tape. (Measurement of dbh is made at $1.4 \mathrm{~m}$ above the duff layer upslope of the tree, not including woody debris).

If the construction of site tables correlating age with height and dbh is desired, 1) core these trees or a randomly selected subset of them with an increment borer and preserve the cores for later ring counts (drinking straws provide a convenient storage method); and 2) measure the angle from the observer's eye to the top of the tree with a clinometer, along with the distance from the observer to the tree for later calculation of height.

B. Shrubs: Lay a 10-m tape perpendicular to the transect tape to delineate a 1-m by 10-m "belt" across the tree plot. Identify all shrubs that are rooted within the belt to species and count number of stems at $1.4 \mathrm{~m}$ height and record by species. If level of effort permits, record stems by diameter class (at dbh) following Peet (1998): 0-1, 1-2.5, 2.5-5, 5-10, 10-15, 15-20, 20-25, 25-30, 30-35, 35-40; stems greater than $40 \mathrm{~cm}$ should be measured. Following Peet (1998) individuals are defined as stems at $0.5 \mathrm{~m}$ : "Multiple stems arising from a common root system are recorded 
separately if they branch below $0.5 \mathrm{~m}$ above ground level (stems branching above $0.5 \mathrm{~m}$ and below $1.4 \mathrm{~m}$ are measured at the narrowest point below the branch)."

C. Herbaceaous: Sample the percent cover of the herbaceous layer on $1 \mathrm{~m}^{2}$ plots as described above in Herbaceous Vegetation Communities, Step 3.

\section{CALCULATIONS \& ANALYSIS}

Data gathered from these protocols can then be used for the following:

A. For herbs, construct a table with a species list containing the mean with standard deviation (SD) and/or $80 \%$ confidence limit for 1) cover of each species over the entire site); 2 cover of each species along each transect; and 3$)$ total vegetation cover $( \pm$ SD) for the entire site (Table 4.1).

B. For shrubs, a table with a species list containing 1) the number of stems of each species over the entire site along with the SD and/or $80 \%$ confidence limit, and 2) the stem density of each species (stems/hectare).

C. For trees, a table with the basal area of each species, percent frequency, density, basal area/hectare (dominance), and relative frequency, relative density, and relative dominance.

D. A species-time $x-y$ plot showing the mean cover of 1 to 3 selected species versus sampling period at the restored site.

E. A bar graph showing the mean cover with SD or $80 \%$ confidence limit bars of the selected species at both the restored and reference sites.

F. Calculation of the similarity of the species composition at the restored site versus the species composition at the reference site and between years using the formula presented in Thom et al. (2002), Table 4.2.

G. Correlation of dominant plant community with elevations, if elevation data are collected (Figure 4.10; see also Leary et al. 2006).

Table 4.1. Average Percent Cover of the Dominant Plant Species at Two Sampling Locations on a Restoration Site (SSE and SSW) before and after a Restoration Action

\begin{tabular}{llcccc}
\hline Scientific Name & Common Name & SSE 2005 & SSE 2006 & SSW 2005 & SSW 2006 \\
\hline Juncus effusus & Soft rush & 0.88 & 1.51 & 14.2 & 3.92 \\
Phalaris arundinacea & Reed canary grass & 27.1 & 57.0 & 33.1 & 56.3 \\
Ranunculus repens & Creeping buttercup & 21.5 & 13.7 & 6.78 & 1.85 \\
Rubus discolor & Himalayan blackberry & 0.00 & 0.00 & 16.8 & 3.42 \\
Trifolium pratense, T. & Red clover, white & 19.4 & 0.28 & 0.00 & 0.00 \\
repens, T. dubium & clover, sm. hopclover & & & & \\
n/a & Mixed Grass & 49.7 & 22.5 & 4.19 & 3.13 \\
\hline
\end{tabular}


Table 4.2. Example Weighted Similarity Index. This assesses the similarity of the vegetation cover between baseline conditions in 2005 and post-restoration conditions in 2006 at two restoration sites (SSE and SSW), and compares baseline and post-restoration conditions at each site with a reference site $(\mathrm{KR})$.

\begin{tabular}{cccccc}
\hline & SSE & SSW & SSE & SSW & KR \\
& 2005 & 2005 & 2006 & 2006 & \\
\hline SSE 2005 & & 72.6 & 92.8 & - & 23.4 \\
SSW 2005 & & & - & 94.0 & 30.6 \\
SSE 2006 & & & & 86.3 & 23.4 \\
SSW 2006 & & & & & 53.2 \\
\hline
\end{tabular}

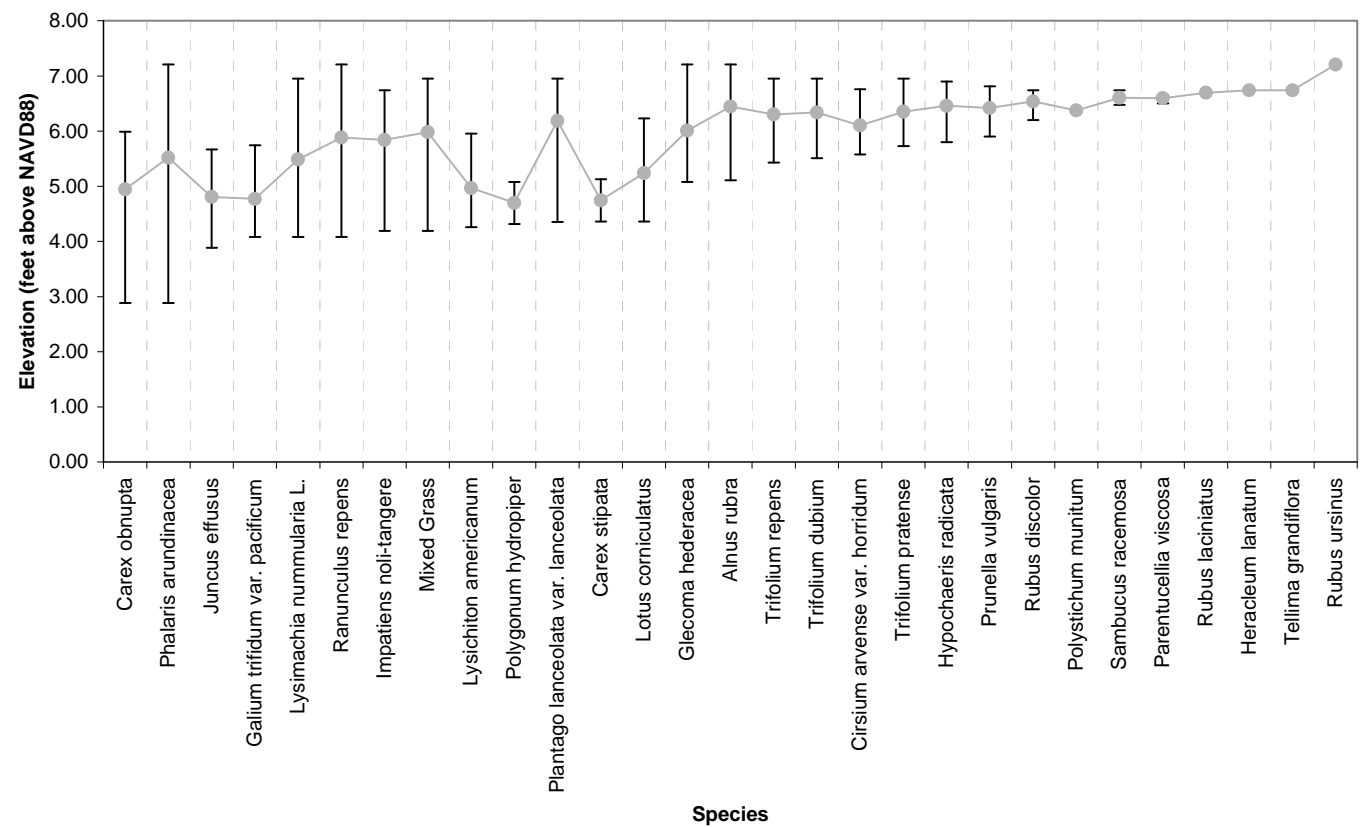

Figure 4.10. Percent Cover of Dominant Flora, Kandoll Farm 2005

\section{ADDITIONAL INFORMATION}

Cornu and Sadro (2002)

Frenkel and Morlan $(1990 ; 1991)$

Havens et al. (2003)

Leary et al. (2005)

Thom et al. (2002).

Useful plant identification books:

Cooke 1997

Pojar and MacKinnon 1994

Hitchcock and Cronquist 1973

Washington Department of Ecology 2001 


\subsection{Vegetation Plantings ${ }^{1}$ PURPOSE}

Vegetation planting can increase the rate at which desired species become established at a restoration site. Planting native vegetation can reduce erosion, increase cover and shade, and often reduce non-native invasive species (e.g., reed canary grass). To date, native vegetation plantings in the Columbia River estuary have been primarily trees and shrubs (woody species); however, this protocol outlines methods for monitoring woody species and herbaceous species (e.g., emergent wetland vegetation) to meet potential needs as restoration efforts increase in scope and diversity. The effectiveness of habitat vegetation plantings can be determined by assessing survival, overall health, and growth of the plantings through time. Often, invasive species management is a critical component to ensure the success of native species. It is important to determine a criterion for success when monitoring vegetation plantings to ensure that the project goals are being achieved and, if not, adaptive management corrections should be implemented. Examples of success criteria are 1) percentage or tree/shrub survival (stems per unit area) of initial planting stock, 2) amount of area covered by vegetation plantings, or 3) similarity to reference system within an established time period.

\section{GOAL}

Measure percent cover and density of vegetation pre- and post-restoration to determine whether a site is meeting success criteria and to identify any corrective actions needed.

\section{DESIGN}

The aim of the monitoring design is to capture the range of plantings that may occur in the Columbia River Estuary, including both herbaceous and woody vegetation. The sampling design is very similar to that described in Protocol 5: Plant Species Composition and Cover. Systematic sampling with a random start is recommended to achieve results that are representative of the conditions at the site. Transects are established at set intervals along an established 'baseline' with plots spaced equally on each transect with a randomly selected starting point (Figure 4.11). A subset of plots may be fixed (i.e., sampled repeatedly), to track trends, while others are randomized anew for each sampling event to assess status. The baseline remains the same each year. Photo points are also recommended to capture qualitative changes on the site over time (see Protocol 4: Landscape Features).

${ }^{1}$ Substantial elements of this protocol have been drawn directly from previously released methods developed and written by George Kral of Ash Creek Forest Management in Tigard, Oregon. While we have not field-tested this method, it is currently in use by others monitoring revegetation planting success in the lower Columbia River and estuary. 


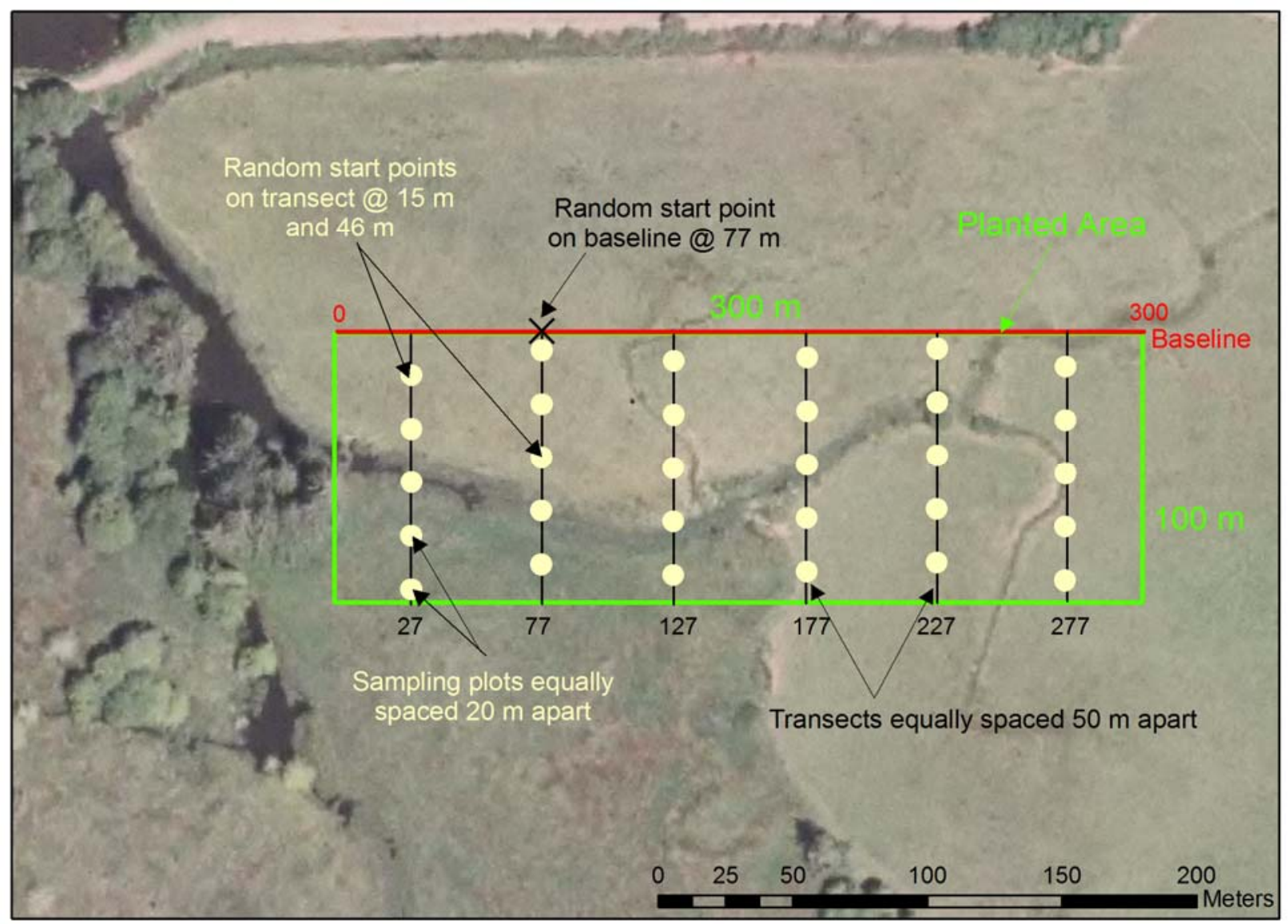

Figure 4.11. Example of a Woody Vegetation Planting Site Showing Location of Sample Area, Baseline, Transects, and Sample Plots. (Note: Example only not an actual planting site).

\section{EQUIPMENT}

Field: field notebook, meter tape s (100 $\mathrm{m}$ for baseline and transects, $10 \mathrm{~m}$ for tree/shrub plots), densiometer (for canopy cover measurements; see Additional Information below), rebar or PVC stakes, GPS, camera, one-meter square quadrats.

Lab: Aerial photos, GIS to assess GPS coordinates and make maps.

\section{SITE SELECTION}

A. General site selection considerations.

Using aerial photos or other site information stratify sites by vegetation community or potential planting areas. If the area has already been planted then identify the planted areas. If possible, a reference site with desired species composition should be identified. The reference site can be monitored using the methods outlined in Protocol 5: Plant Species Composition and Cover or an existing reference site can be used (e.g., Lower Columbia River Estuary Partnership Reference Site Study or City of Portland, Bureau of Environmental Services, Watershed Revegetation Program Reference Sites). 
B. Determine location of baseline, transects, and sample plots.

The location of the sample plots can be determined in the office, based on the aerial photos or site maps as follows.

For each area to be monitored (e.g., potential or existing planting site) determine the dimensions and area of the site. The recommended number of sample plots per site is as follows:

\begin{tabular}{|l|l|l|}
\hline Size & Woody Plots & Herbaceous Plots \\
\hline$<0.1$ ha $\left(1000 \mathrm{~m}^{2}\right)$ & 3 & 10 \\
\hline $0.1-1.0$ ha & 10 & 20 \\
\hline $1-5$ ha & 10 per ha & 20 per ha \\
\hline
\end{tabular}

For sites greater then 5 ha, a portion of the site that is representative of the whole area should be sampled, with a maximum of 50 woody plots and 100 herbaceous plots.

The size of the area will determine how many sample plots are needed, while the dimensions will influence the length of the baseline, number and length of transects, and placement of the plots. For the following discussion assume the area of a site is $3 \mathrm{ha}, 300 \mathrm{~m}$ by $100 \mathrm{~m}$ and therefore requires 30 woody plots or 60 herbaceous plots (Figure 4.11).

Determine the length and width of the site and establish a baseline along the longest part of the planted area. In our example, the baseline would be $300 \mathrm{~m}$.

Transects: Transects should encompass the width of the planted area (e.g. $100 \mathrm{~m}$ ) and should be spaced to cover the entire monitoring site. The spacing between transects and sample plots does not need to be equal and can be closer within transects then between transects. The main factor to consider is the distribution throughout the site. At an irregularly shaped site, the length of transects will need to be adjusted to stay within the site boundaries. In the above example, 6 transects would be spaced $50 \mathrm{~m}$ apart along the baseline.

To determine the location of transects, choose a random number between 0 and the length of the baseline and place a cross transect perpendicular to the baseline, at the location of the random number. Remaining cross transects are located parallel to the first and systematically spaced. In the example above, if the baseline baseline random number was 77 then cross transects would be set at 27, 77, 127, 177, 227, and 257 meters.

Sample Plots: Plots (8-m diameter circles for woody species and $1 \mathrm{~m} 2$ quadrats for herbaceous species) are located at equally spaced intervals along each transect, with the start point chosen randomly for each cross transect. In the example above, 5 plots per transect on 6 transects yields 30 plots with the plots spaced $20 \mathrm{~m}$ apart. For herbaceous vegetation monitoring, 10 plots per transect at $10 \mathrm{~m}$ spacing would be needed to yield 60 plots. 


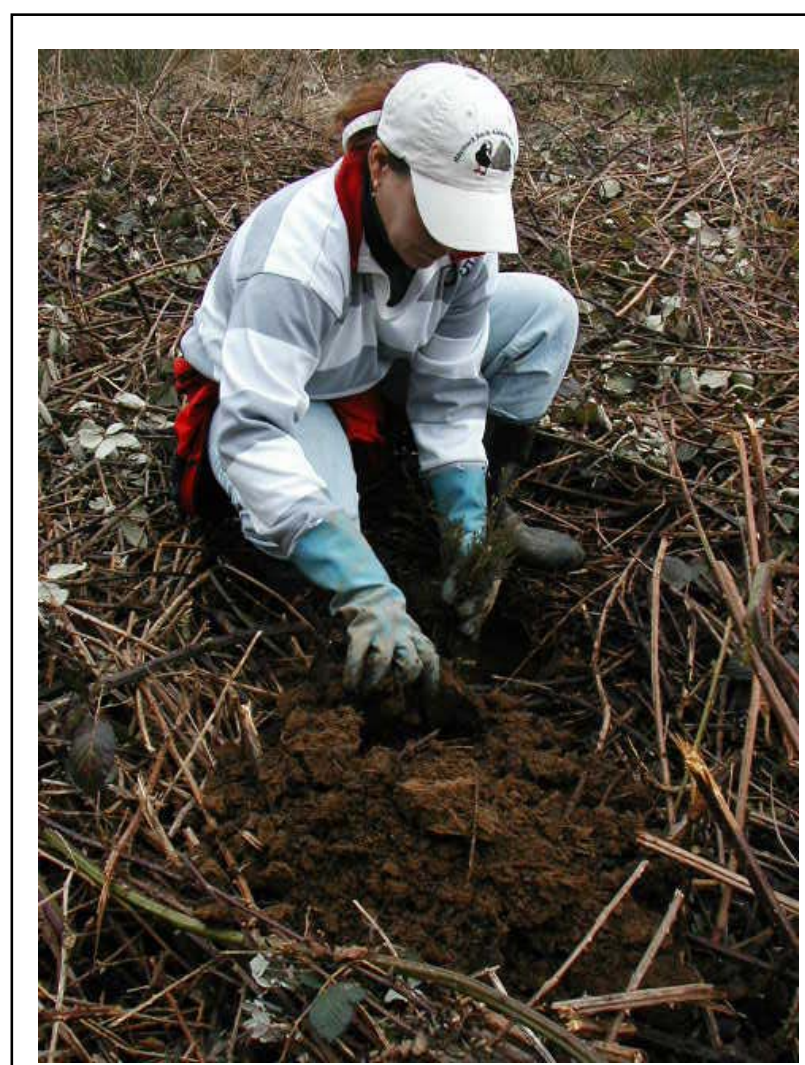

Replanting at a restoration site. Credit: North Coast Watershed Council, Clatsop County, Oregon

\section{SAMPLING PERIODICITY:}

A pre-restoration assessment is recommended to determine existing stems per area, canopy cover, and herbaceous cover. Sites will also be stratified into vegetation communities at this time.

Comprehensive monitoring for woody species will occur the first year after planting then every five years (at least years 1, 5, and 10) and for herbaceous wetland species every 2 years (at least years 1, 3, and 5) until the project can be evaluated for relative success.

Rapid monitoring is also recommended for monitoring vegetation planting success to ensure potential failure is noted so contingency management can be implemented if needed. Rapid monitoring would be conducted every year for the duration of the project, including comprehensive monitoring years.

Monitoring should be conducted at the end of the growing season before leaves begin to fall to capture maximum growth for the season.

\section{SAMPLING PROTOCOL}

\section{Pre-Restoration Assessment}

The pre-restoration assessment should happen as soon as the site is accessible and cleared of any restrictive vegetation (e.g. dense blackberries).

Step 1. Define the study area boundaries (see example above) based on extent of expected restoration.

Step 2. Use aerial photos (Protocol 4: Landscape Features) to broadly characterize existing plant communities (e.g., herbaceous, shrub/scrub, forested).

Step 3. Assess sites in the field prior to restoration to verify existing vegetation communities, size, soil characteristics, and topography.

Step 4. Establish baseline(s) based on broad plant communities and elevation strata. Mark baseline endpoints with permanent stakes (e.g., rebar or PVC) and record GPS positions.

During this assessment at least two sample plots ( $8 \mathrm{~m}$ diameter) should be sampled per existing vegetation strata, with plots located to best represent the strata. A list of common species for each strata can be developed from the sampling and observations at the site. Recommended measurements in the plots are 1) tree and shrub density, 2) canopy cover (using a densiometer), and 3) an estimate of 
herbaceous cover by species. The herbaceous and canopy cover data can be collected using cover classes such as outlined in Daubenmire (1959) as follows:

\begin{tabular}{|c|c|}
\hline Class & Cover (\%) \\
\hline 1 & $0-5$ \\
2 & $6-25$ \\
3 & $26-50$ \\
4 & $51-75$ \\
5 & $76-95$ \\
6 & $96-100$ \\
\hline
\end{tabular}

The information collected during this assessment is useful for determining a treatment plan if necessary and the planting scheme.

\section{Comprehensive Monitoring}

\section{A. Woody Plants}

Step 1. Establish overall size of the planting area and mark boundaries with GPS (all four corners of site).

Step 2. Select sample plots throughout the site as described in the Site Selection above, record each with GPS, and establish an 8-m-diameter circular plot by laying an 8-m tape perpendicular to the transect tape to delineate the 8-m-diameter tree plot with "crosshairs."

Step 3. To monitor trends at the site, choose a randomly selected subset of approximately one-third of the total number of plots to be permanent plots. These plots will be resampled each year. Mark the center of the plot with rebar or a PVC stake and record the GPS position. Note: if a subset is chosen as permanent plots then in future years, the number of sample plots monitored will increase to include the randomly selected plots and the permanent plots.

Step 4. Identify and count all woody plants in all plots by species and record the following:
a. Live or dead
b. Natural or planted
c. Plant vigor as defined in Table 4.3.

This measurement yields plant density (plantings/19.1 $\mathrm{m}^{2}$ ) as discussed in Calculations below.

Step 5. For sites 5 or 10 years old, record diameter at breast height ( $\mathrm{dbh}$ is recorded at $1.4 \mathrm{~m}$ ) for the stem closest to the center of the plot (must be at least 2 meters tall).

Step 6. Take four densiometer readings using Daubenmire Cover Classes described above, at 1.4 meters above the ground and 2 meters from the plot center, facing N, E, S, and W. Record average measurement.

Step 7. Estimate herbaceous cover by estimating the percentage of plot occupied by all species using Daubenmire Cover Classes described above. Note: this is the herbaceous cover within an area planted with woody species, not to be confused with the section below describing monitoring methods for 
herbaceous plantings. The information gathered in this step is important in identifying potentially competing vegetation.

Step 8. Record observations on causes of plant mortality, animal activity, and any other significant natural resource occurrences.

Step 9. Establish permanent photo points of area planted as described in Protocol 4: Landscape Features.

Table 4.3. Plant Vigor Categories

$\begin{array}{ll}\text { High: } & \text { Plants exhibiting remarkable growth and vigor } \\ \text { Medium: } & \begin{array}{l}\text { Plants exhibiting moderate growth and vigor and expected to } \\ \text { live beyond the immediate growing season }\end{array} \\ \text { Low: } & \text { Plants expected to die within the year }\end{array}$

\section{B. Herbaceous Plants}

Step 1. Establish overall size of planting area or seeded area and mark boundaries with GPS (all four corners of site).

Step 2. Select sample plots throughout the site as described in the Site Selection above, record each with GPS, and center $1 \mathrm{~m}^{2}$ quadrat on cross transect meter tape, so tape acts to divide the quadrat in two halves (this aids in estimating cover classes).

Step 3. Estimate herbaceous cover by percentage of plot occupied by all species using Daubenmire Cover Classes described above.

\section{Rapid Monitoring}

At each site establish the location of sample plots as described in the Site Selection section above using the previously established baseline. The sample plots should be established using a new random start point along the baseline and new random start points on each transect.

A. Identify and list native and non-native species at the site.

B. If woody species were planted, count the number of stems per plot as outlined above, but not by species. Calculate average number of trees and shrubs per acre (see below).

C. Estimate percentage cover within the plot of non-native weedy species.

D. Recommend maintenance treatments such as removal of invasive species, additional planting, seeding, and animal damage control.

\section{CALCULATIONS \& ANALYSIS}

A. Calculate average planting density (APD) in the sample plots $\left(8 \mathrm{~m}\right.$ diameter $\left.=19.1 \mathrm{~m}^{2}\right)$, 


$$
\mathrm{APD}=\text { Average plantings } / 19.1 \mathrm{~m}^{2} .
$$

B. Convert to density planting/ha $=\mathrm{APD} * 523.6 \mathrm{plots} / \mathrm{ha}$.

C. Assess success rate: $50 \%$ tree and $40 \%$ shrub survival of initial planting stock by year 5 as percentage of planting stock and/or as compared to reference site.

\section{ADDITIONAL INFORMATION}

A densiometer is small hand-held curved mirror grid. The canopy cover can be estimated by estimating the percent of the grid that are covered by the image of the canopy.

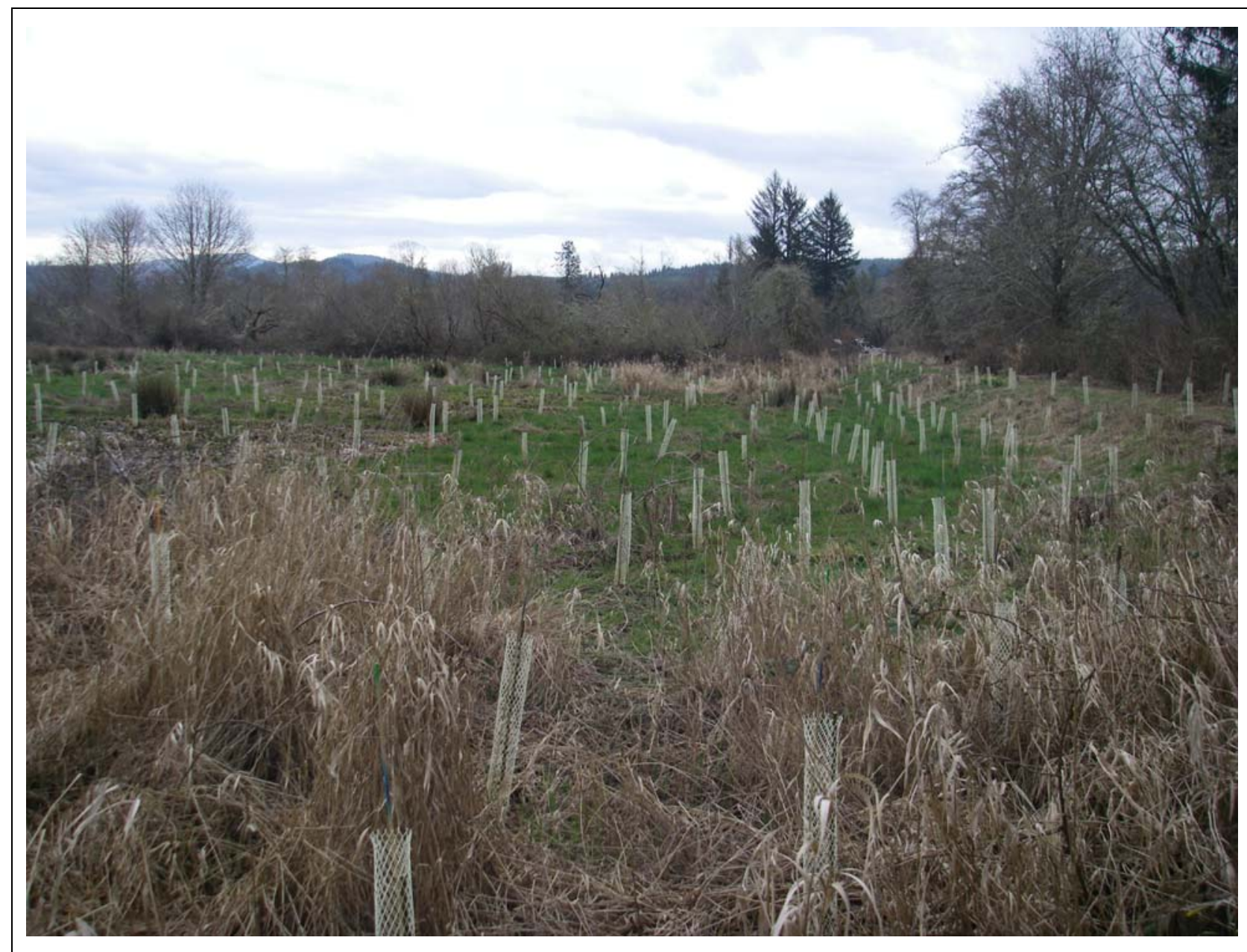

Replanting with native species at a restoration site. 


\subsection{Fish Community PURPOSE}

The incentive for many restoration activities in the CRE is to increase habitat available for rearing and migrating juvenile salmonid ESUs listed as threatened or endangered under ESA. One measure of success in effectiveness evaluations is a demonstration of increased habitat use by salmonids at restored locations relative to reference habitat. The minimum protocols for fish monitoring include abundance and size measurements of species at each site. From these basic data, species composition and size-frequency histograms can be produced.

However, we advocate higher order measurements for quantitative assessment of habitat utilization by different salmon stocks and life history types, which require analysis of, for instance, genetics, marks and tags, and prey availability and consumption (see Additional Measurements below). Ultimately, relation of fish habitat use to physical conditions such as water quality (Protocols $1 \& 2$ : Hydrology \& Water Quality) will be important for evaluating and predicting restoration success in the CRE.

\section{GOAL}

Evaluate species composition (lowest practical taxon), temporal abundance patterns (catch per unit effort by date), and fish size (fork length or total length) in pre-restoration habitat, post-restoration habitat, and reference sites.

\section{DESIGN}

The BACIPS/Recovery survey design with pre-restoration measurements should be utilized whenever possible to establish baseline community structure (see Statistical Design above). However, fish presence/absence in restored versus reference sites is the minimal metric for comparing habitat use. Repeated sampling allows a time series of abundance to be generated, information that is used to calculate migration timing and overall habitat use for juvenile salmonids. Fish lengths are used to construct sizefrequency histograms that help determine which life-history stages are utilizing the various habitats (e.g. fry, smolt-sized subyearling, or yearling salmon). Standard indices of community structure (catch, number of species, diversity) provide an assessment of the recovery trajectory of restoration relative to reference sites. Fish community metrics can be correlated with physical (Protocols $1 \& 2$ : Hydrology \& Water Quality) and biological (Protocol 3 \& 4: Landscape \& Vegetation) features to characterize habitat opportunity and capacity.

\section{EQUIPMENT}

There are a variety of gear types used for sampling juvenile salmon and other fish in the CRE, including seines, fyke (trap) nets, barrier nets, and pit traps; discussed in detail below. Particular gear choices depend largely on the physical conditions and constraints at the sites. Terrain, bottom contour, hydrography, and debris load will influence the gear type as well as the sampling location at a given site. For comparative purposes, it is highly desirable to utilize the same gear type throughout the monitoring program: however, the varied topography of wetland habitats may render this impossible, and often more than one gear type will be required to sample all sites of interest. 
Ancillary Hardware \& Materials - Plastic buckets or garbage cans for holding containers (with $3 / 16$ " holes drilled in side for water overflow), battery-powered aerators, plastic dish pan for anesthetic bath, buffered anesthetic solution (MS 222 solution at a concentration of about $50 \mathrm{mg} / \mathrm{l}$ ), dip nets, measuring boards, portable scale for weights, and standardized waterproof data forms.

Permits - Annually, a state fish sampling permit must be obtained from the Oregon Department of Fish and Wildlife or Washington Department of Fish and Wildlife to conduct sampling in the Columbia River and its tributaries. An Endangered Species Act permit from NOAA Fisheries must also be obtained because of the likelihood that threatened or endangered Chinook and chum salmon and steelhead will be captured. Naturally spawned coho salmon may soon be listed.

\section{SITE SELECTION}

Sampling site selection depends on the physical conditions necessary for the available sampling gear. Sites should be selected in each habitat type of the restoration area. Sites within the reference area should be as similar as possible to those of the restoration area. Fixed or random stations can be established. Fixed sites offer the benefit of generating time series measurements at locations where other monitoring metrics are being collected (e.g., data logging instruments or vegetation plots). Randomizing sampling sites allows measurement of sample variability across habitats.

\section{SAMPLING PERIODICITY}

The minimum sampling frequency is 1 day/month at each selected site during the March thru October time period that encompasses the period most salmonids are residing in or passing through the lower river and estuary. To the degree possible, the tide cycle and time of day for all samples should be standardized.

\section{SAMPLING PROTOCOL}

Seines and nets of various shapes, sizes, and methods of deployment are used to sample fish community structure. Net type and size are dependent on the width, breadth, and depth of the water body. Ideally, catch measurements should be standardized to density (fish $/ \mathrm{m}^{2}$ ), although accurate determination of area swept may not be possible due to variability between sets. Abundances expressed as catch per unit effort (CPUE) are therefore often reported, and it is important to be cognizant that CPUE values are not strictly comparable between different gear types. Below we discuss protocols for commonly used net types.

\section{Beach Seines}

Beach seines require a shoreline area with sloping beach for ease of collection. The length of the seine depends on the area to be sampled. General dimensions are: 10 to $30 \mathrm{~m}$ long x $2 \mathrm{~m}$ deep using 1 - to $2-\mathrm{cm}$

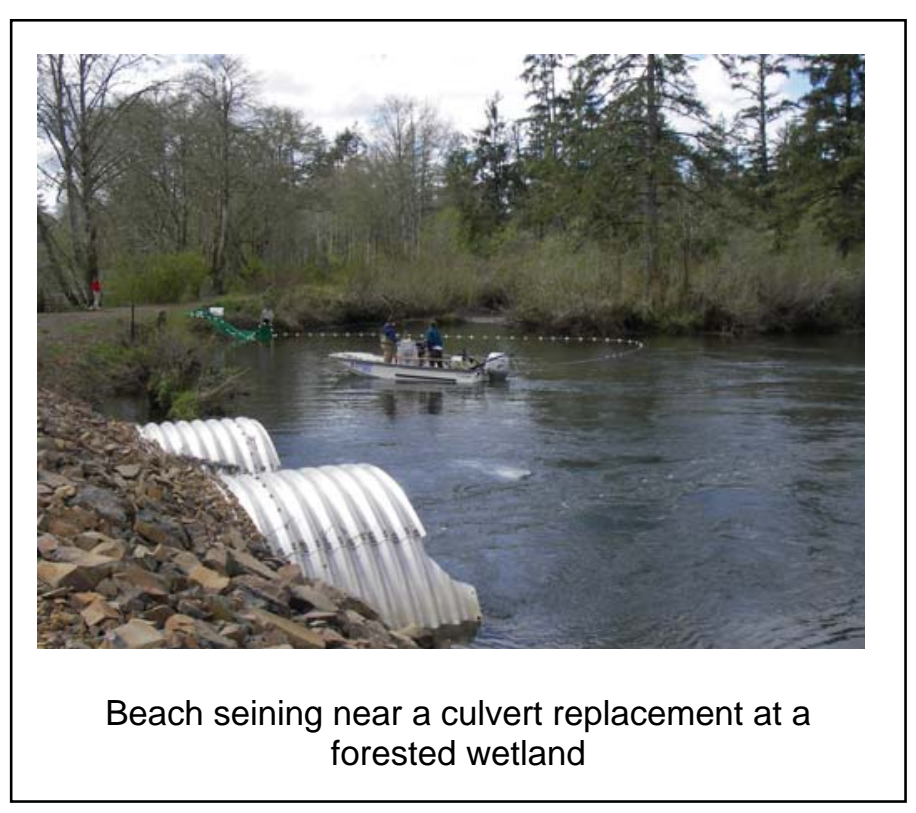


(stretch measure) webbing and $0.6 \mathrm{~cm}$ mesh bunt in the middle. Two methods can be used to fish a beach seine; 1) pullto-shore and 2) semicircular hauls.

A. Pull-to shore haul: For smaller tidal channels

Step 1. Deploy the seine on the bank parallel to the channel and situate personnel on opposite shore.

Step 2. Retrieve net by pulling the two wings simultaneously to shore, being careful to maintain the leadline at the bottom. Crowd fish into the center bunt for capture, and transfer fish with a dip net to holding containers for measurement.

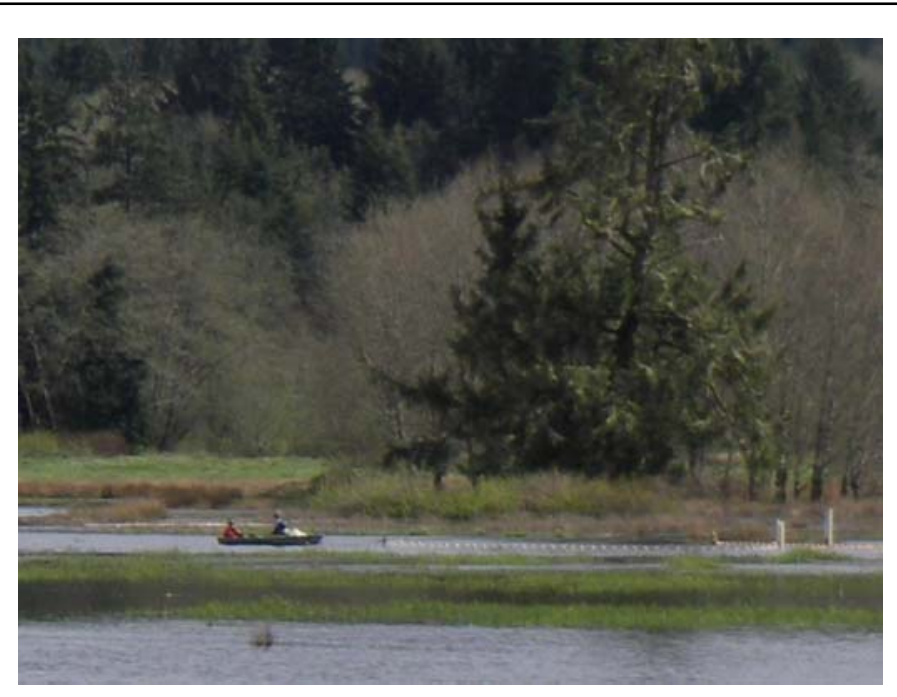

Trap netting after culvert replacement in a restoration site

Step 3. Area sampled is net length $x$ channel width, $A=L * W$. Density $=$ CPUE $/ A$

B. Semicircular haul: Larger channels or unenclosed habitats

Step 1. Anchor one end of seine at the beach, and deploy net either in a pile or stretched along shore.

Step 2. Using skiff, tow net in semicircular pattern back to shore. Haul net in from free end to anchor end, forcing fish into the bunt for capture. Use a dip net to transfer fish to holding containers for measurement.

Step 3. Area sampled is a half circle with radius equal to the net length, $\mathrm{A}=0.25 \pi \mathrm{r}^{2}$. Density $=$ CPUE / A

\section{Pole Seines}

Pole seines are usually smaller nets that can be fished in areas of topographic complexity that would foul larger nets. General dimensions are: up to $10 \mathrm{~m}$ in length (but often smaller) and $1.5 \mathrm{~m}$ depth (1-2$\mathrm{cm}$ stretch measure with $0.6 \mathrm{~cm}$ mesh bunt in the middle). The fishing procedure is similar to seine nets. These versatile nets are easily adjustable for size of area, and so can be utilized in many locations. However, CPUE may be correspondingly small.

\section{Fyke Trap Nets}

Fyke trap nets provide a method for sampling shallow, low-velocity tidal channels. This gear type works best in blind tidal channels, but can also be used in conjunction with barrier nets (described in the following section) in open ended tidal systems. The general trap design consists of a cylindrical trap tunnel ending in a sanctuary area which is positioned in the main section of the tidal channel. For fish retrieval, it is convenient to have the cod end of the fyke constructed into a live floating box. Net wings stretch from either side of the trap mouth to the shoreline. As the tide ebbs, water and fish are funneled 
into the trap, where they are periodically recovered and measured. This gear is dependent on volitional entry and water current for entrapment, and works best in sections of tidal channel that drain completely, thus providing good estimates of fish utilization upstream of the trap. Sufficient depth for sanctuary of captive fish during low water periods is necessary. This method is useful for time series measures of fish habitat use.

Step 1. Set net tunnels ( 2 × $2 \times 2 \mathrm{~m}$ long, 0.6-cm nylon mesh, with an attached fyke tunnel) at high slack tide a point above which the marsh channel system completely dewaters on a sampling tide.

Step 2. Attach upstream facing net wings of appropriate length with $0.6-\mathrm{cm}$ mesh to act as a barrier net to deflect fish into the fyke tunnel during ebb current.

Step 3. Periodically empty the trap and process catch. After the tidal channel has drained, continue sampling in the remaining upstream pools, if any, with pole seines and dip nets.

Step 4. Density of fish is a function of wetted surface area, which is dependent on tidal amplitude. Area is best estimated by linking the water level (Protocol 1: Hydrology) to marsh elevation (Protocol 3: Elevation). Fish Density $=$ CPUE /area.

\section{Barrier Nets or Screened Panels}

These nets are used in conjunction with traps and nets to close off all or portions of a sampling area to acquire greater precision of fish density calculations. Nets and panels are constructed of $1-$ to $2-\mathrm{cm}$ webbing (of sufficient length and depth for the site) bordered with corkline and leadline or solid framework of any desired construction materials. Use in conjunction with seines and fyke trap nets for sampling short reaches.

Step 1. Deploy panels to completely enclose up- and downstream ends of channel. Measure area of channel enclosed. $\mathrm{A}=\mathrm{L} * \mathrm{~W}$.

Step 2. Fish are collected within the blocked section with pole, pull- and/or beach seines. Continue seining until the catch approaches zero (depletion sampling). Catches should show an exponential decay pattern with increasing sweep number.

Step 3. This technique provides a direct measure of fish density in discrete areas: Density $\left(\mathrm{fish} / \mathrm{m}^{2}\right)=$ CPUE / area of channel.

\section{Pit Traps}

Pit traps can be employed in shallow water marsh areas where small fish may reside but that are not accessible by boats and are too shallow for seines. Brown plastic dish pans make an appropriate pit trap. The concept is to deploy the trap flush with the substrate during low tide. The trap samples over the next high water period and is recovered on the ensuing ebb tide. Fish are stranded or seek refuge in the waterfilled plastic dish-pan. The disadvantage with this technique is that it is behaviorally based and not quantitative; but it may provide qualitative data on small juvenile fish underrepresented by other methods. Natural impoundments may be analogously sampled.

Step 1. Bury traps flush with marsh surface at low water. 
Step 2. Allow tide to rise and fall. Fish are passively collected during ebb tides from pit traps.

\section{SAMPLE PROCESSING}

After collection of fish by the gear types described above, use a dip net to transfer the catch into a darkened and covered holding container (to diminish stress). Ensure that the water quality (especially temperature and dissolved oxygen) of the holding container is maintained near river conditions during processing. Portable air bubblers are useful. If the numbers of fish are too large and must be subsampled ( $>100$ salmon; $>30$ other species), ensure a random and unbiased subsample by crowding the fish together to limit stratification of different sizes and species.

It is crucial to anesthetize active and energetic fish (such as salmon) to minimize stress or physical damage during measurements. Place a few fish at a time into anesthetic solution (e.g., MS 222) until fish become lethargic and loose equilibrium. Identify species and individually measure fork-length of salmonids (tip of snout to center of fork in caudal fin) and fork- or total length (tip of snout to end of caudal fin) of other fish. After measurement, let the fish recover in a container of fresh river water, and maintain water quality prior to re-introducing the fish back to the river. For depletion sampling and trap nets, remember to release fish outside of area being sampled.

\section{ADDITIONAL MEASUREMENTS}

For restoration projects with extensive resources, increased sampling efforts and assessment protocols will provide estimates of enhanced fish production such as growth, residence time, feeding rate, and food resources. Some additional measurements commonly made during fish sampling surveys are presented below.

A. All marks and tags should be recorded. External marks include fin clips (especially adipose fin), latex beads, freeze branding, and variously colored paint marks. Internal tags require detection equipment and include Coded Wire Tags (CWT) and Passive Integrated Transponder (PIT) tags. CWT data requires sacrificing the animal to collect the tag; data from PIT tags can be deciphered in the field with the appropriate instrument.

B. Collection of genetic data. Small fin clips can be taken from anesthetized fish for subsequent analysis of stock identification. Clip tissue samples from a pelvic fin and preserve in separate plastic vials with 70\% ETOH, and labeled with date, time, location, species, and size.

C. Non-lethal collection of stomach contents by gastric lavage. This technique entails flushing a fish's stomach with a stream of water and collecting and preserving the contents for laboratory analysis. Gut contents should be preserved in the field using ETOH and stored in individual vials labeled with species and site-specific data.

D. Capture efficiencies can be determined by mark/recapture techniques. This requires releasing a known number of marked fish above a trap net or within a blocked barrier net section, and calculating the percent recaptured. 


\section{CALCULATIONS \& ANALYSIS}

A. Catch: Absence/presence is a minimum metric. Plot CPUE by time for a time series of abundance. To highlight timing of migration between sites and/or years, standardize CPUE by annual total (Figure 4.12). Wherever possible, report catch as density (fish $/ \mathrm{m}^{2}$ ) as described above.

B. Size frequency histograms are used to evaluate salmon life history categorization. Plot length in 5 $\mathrm{mm}$ increments. Columbia River stocks vary in their size-at-age characteristics. In general, salmon are categorized as fry when $<60 \mathrm{~mm}$ fork length and fingerlings between 60 and 130 $\mathrm{mm}$. Yearling salmon range in size from 90 to $>130 \mathrm{~mm}$ (Figure 4.13).

C. Time series of mean size. Compute mean and standard deviations by species for each date sampled. This data may be indicative of residence time and growth.

D. Compute standard measures of fish community structure (Figure 4.14).
a. Number of fish, $\mathrm{N}$
b. Number of species, $\mathrm{S}$
c. Shannon-Weiner diversity index $H^{\prime}=-p_{i} \ln \left(\Sigma p_{i}\right)$, where $p_{i}$ is the proportion of species $i$.

\section{ADDITIONAL INFORMATION}

Fish identification sources: McConnell and Snyder 1972; Scott and Crossman 1973; Carl et al. 1977; B.C. Ministry of Environment, Lands and Parks 1997.

Two-sweep depletion method: Seber and LeCren (1967).
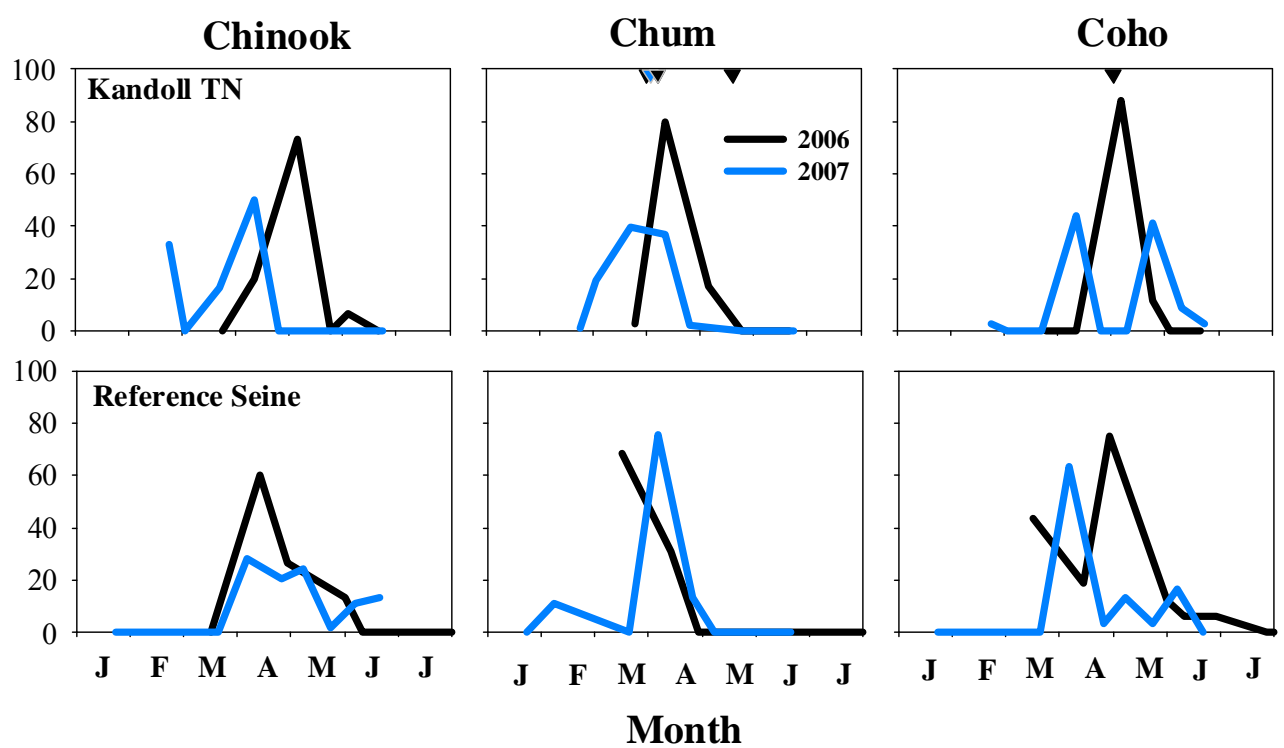

Figure 4.12. Time Series of Relative CPUE for Salmonids Sampled at Restoration and Reference Sites, Grays River System 2006 and 2007. This plot emphasizes migration timing. Upper row: Restoration trap net samples. Lower Row: Reference beach seine samples. 

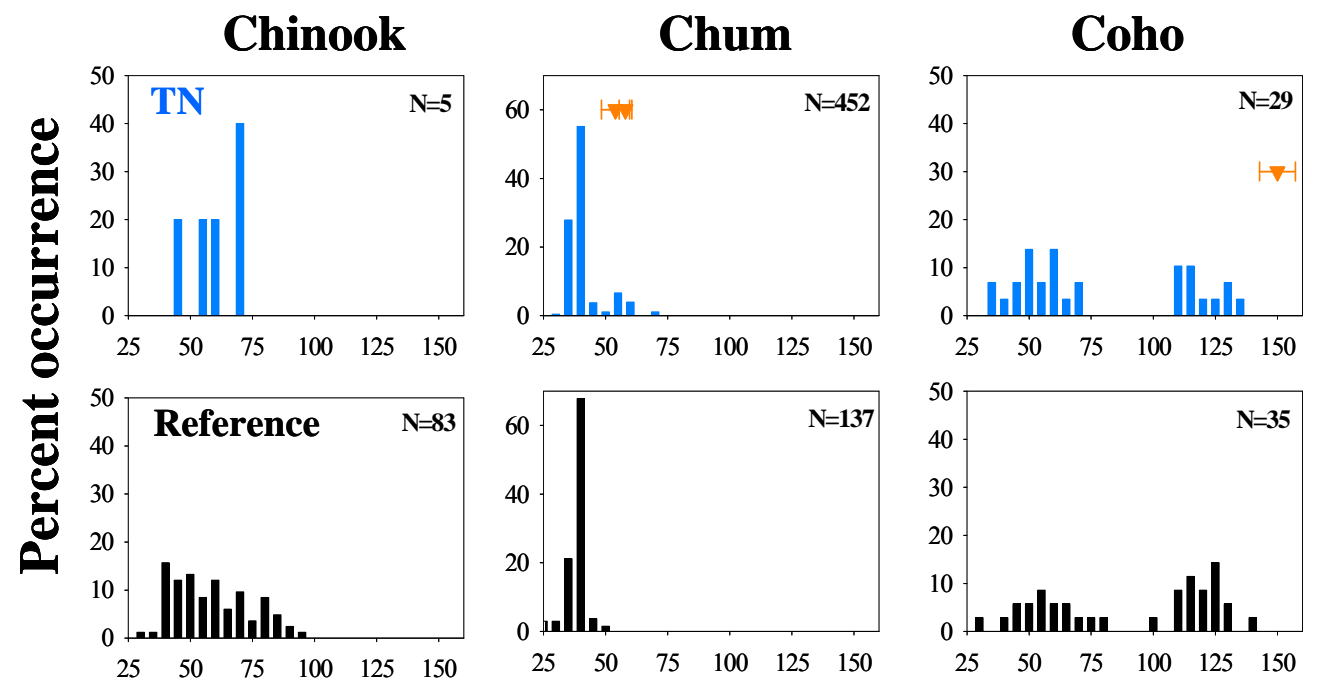

Fork length (mm)

Figure 4.13. Size-Frequency of Juvenile Salmonids Captured in Restoration and Reference Sites, Grays River system 2007. Upper row: Restoration trap net samples. Lower Row: Reference beach seine samples. Orange symbols are mean fork length $( \pm \mathrm{sd})$ of hatchery releases.
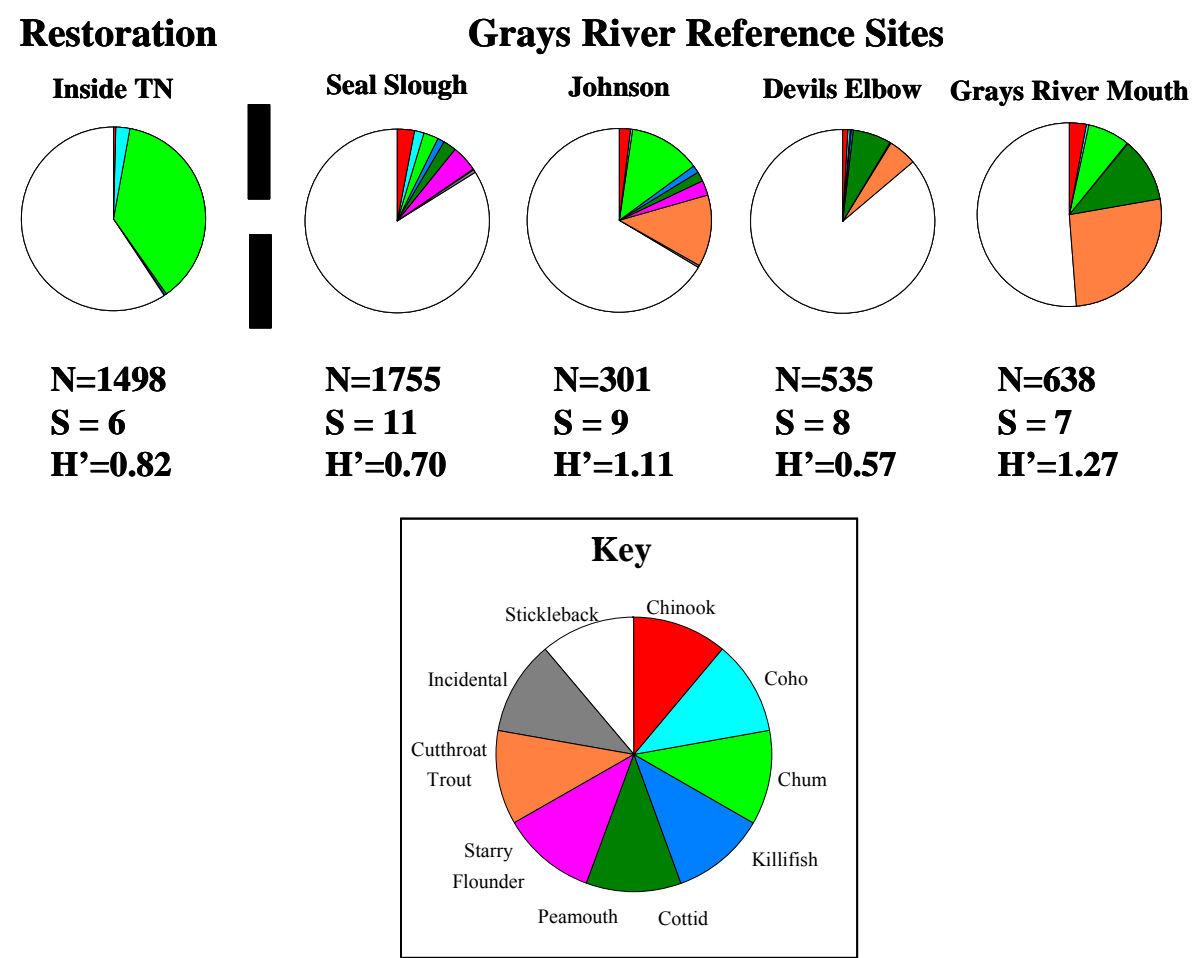

Figure 4.14. Fish Community Structure and Diversity Indices, Grays River System, 2007. N, catch; S, number of species; H', diversity. 


\subsection{References}

B.C. Ministry of Environment, Lands and Parks. 1997. Fish Collection Methods and Standards. Version 4.0. Available on the internet at http://www.for.gov.bc.ca/ric

Borde, A.B., R.M. Thom, H.L. Diefenderfer, K.L. Sobocinski, and S.A. Zimmerman. 2007. Lower Columbia River Reference Site Study: 2007 Progress Report. PNWD-3867. Prepared for the Lower Columbia River Estuary Partnership by the Pacific Northwest National Laboratory, Marine Sciences Laboratory, Sequim, Washington.

Borde, A.B., R.M. Thom, S. Rumrill, and L.M. Miller. 2003. Geospatial habitat change analysis in Pacific Northwest coastal estuaries. Estuaries 26(4B):1104-1116.

Bottom, D.L., C.A. Simenstad, A.M. Baptista, D.A. Jay, J. Burke, K.K. Jones, E. Casillas and M. Schiewe. 2005. Salmon at River's End: The Role of the Estuary in the Decline and Recovery of Columbia River Salmon. University of Washington Press and NOAA-National Marine Fisheries Service, Seattle, Washington.

Brophy, L.S. 2007. Estuary Assessment: Component XII of the Oregon Watershed Assessment Manual. Prepared by Green Point Consulting for the Oregon Department of Land Conservation and Development and the Oregon Watershed Enhancement Board, Salem, Oregon.

Burke, J.L. 2004. "Life Histories of Juvenile Chinook Salmon in Columbia River Estuary, 1916 to the Present." Master Thesis, Oregon State University, Corvallis, Oregon. August, 2004.

Callaway, J.C., G. Sullivan, J.S. Desmond, G.D. Williams, and J.B. Zedler. 2001. Assessment and monitoring. In J.B. Zedler (ed.) Handbook for Restoring Tidal Wetlands, pp.271-335, CRC Press, Boca Raton, Florida.

Carl, G.C., W.A. Clemens, and C.C. Lindsey. 1977. The Fresh-Water Fishes of British Columbia. British Columbia Provincial Museum, Victoria, Handbook No. 5.

Coats, R.N., P.B. Williams, C.K. Cuffe, J.B. Zedler, D. Reed, S.M. Watry and J.S. Noller. 1995. Design Guidelines for Tidal Channels in Coastal Wetlands. Report prepared for U.S. Army Corps of Engineers Waterways Experiment Station, Catalog. No. TA7W343.D47, Vicksburg, MS.

Cornu, C.E. and S. Sadro. 2002. Physical and functional responses to experimental marsh surface elevation manipulation in Coos Bays' South Slough. Res. Ecol. 10: 474-486.

Cooke, S.S. (ed). 1997. A Field Guide to the Common Wetland Plants of Western Washington \& Northwestern Oregon, Seattle Audubon Society.

Daubenmire, R.F. 1959. A canopy-coverage method. Northwest Science 33:43-64.

Dawley, E.M., R.D. Ledgerwood, T.H. Blahm, C.W. Sims, J.T. Durkin, R. A. Kirn, A.E. Rankis, G.E. Monan, and F.J. Ossiander. 1986. Migrational Characteristics, Biological Observations, and Relative Survival of Juvenile Salmonids Entering the Columbia River Estuary, 1966-1983. Report to Bonneville Power Admin., DACW57-85-F-0623, 256 p. (Available from Dick Ledgerwood, NMFS, P.O. Box 155 Hammond OR, 977121.)

Diefenderfer, H.L., R.M. Thom, and J.E. Adkins. 2003. Systematic Approach to Coastal Ecosystem Restoration. PNWD-3237. Report to the NOAA Coastal Services Center, by Battelle Marine Sciences Laboratory, Sequim, Washington. Available URL: http://www.csc.noaa.gov/coastal/expert/pdf/systematic.pdf 
Diefenderfer, H.L., G.C. Roegner, R.M. Thom, E.M. Dawley, A.H. Whiting, G.E. Johnson, K.L.Sobocinski, M.G. Anderson, and B.D. Ebberts. 2005ab. Evaluating Cumulative Ecosystem Response to Restoration Projects in the Columbia River Estuary, Annual Report 2004. PNNL15102. Report to the U.S. Army Corps of Engineers, Portland District, by Pacific Northwest National Laboratory, Richland, Washington.

Diefenderfer, H.L., R.M. Thom, and K.D. Hofseth. 2005b. A framework for risk analysis in ecological restoration projects. Pages 57-105 in RJF Bruins and MT Heberling, editors. Economics and Ecological Risk Assessment: Applications to Watershed Management. CRC Press, Boca Raton, Florida.

Diefenderfer, H.L., R.M. Thom, A.B. Borde, G.C. Roegner, A.H. Whiting, G.E. Johnson, E.M. Dawley, J.R. Skalski, J. Vavrinec, and B.D. Ebberts. 2006. Evaluating Cumulative Ecosystem Response to Restoration Projects in the Columbia River Estuary, Annual Report 2005. PNNL-15934. Report to the U.S. Army Corps of Engineers, Portland District, by Pacific Northwest National Laboratory, Richland, Washington.

Downes, B.J., L.A. Barmuta, P.G. Fairweather, D.P. Faith, M.J. Keough, P.S. Lake, B.D. Mapstone, G.P. Quinn. 2002. Monitoring Ecological Impacts: Concepts and Practice in Flowing Waters. Cambridge UP, Cambridge, UK.

Erwin, K.L. 1990. Wetland evaluation for restoration and creation. Pages 429-458, In J.A. Kusler and M.E. Kentula (eds.) Wetland Creation and Restoration: The Status of the Science, Island Press, Washington, D.C.

Estuary Restoration Act of 2000. Public Law 106-457, Nov. 7, 2000, 114 Stat. 1957, Title I-Estuary Restoration. Available URL: http://www.epa.gov/owow/oceans/habitat/index.html

Fischenich, J.C. 2008. The Application of Conceptual Models to Ecosystem Restoration. U.S. Army Corps of Engineers ERDC/EBA TN-08-1. ERDC Environmental Laboratory, Vicksburg, MS. Available URL: http://el.erdc.usace.army.mil/

Fox, D.S., S. Bell, W. Nehlsen, and J. Damron. 1984. The Columbia River Estuary: Atlas of Physical and Biological Characteristics. Columbia River Estuary Data Development Program, Astoria, Oregon.

Frenkel, R.E. and J.C. Morlan. 1990. Restoration of the Salmon River Salt Marshes: Retrospect and Prospect. Department of GeoSciences, Oregon State University. Final Report to the U.S. Environmental Protection Agency, Region 10.

Frenkel R.E. and J.C. Morlan 1991. Can we restore our salt marshes? Lessons from the Salmon River, Oregon. Northwest Environmental Journal 7:119-135.

Green, R.H. 1979. Sampling Design and Statistical Methods for Environmental Biologists. Wiley and Sons, New York, New York.

Hall, F.C. 2002. Photo Point Monitoring Handbook, Part A (Field Procedures), Part B (Concepts and Analysis). U.S. Department of Agriculture Forest Service General Technical Report PNW-GTR526.

Havens, K.J., D. O’Brien, D. Stanhope, R. Thomas, and G. Silberhorn. 2003. Initiating Development of a Forested Depressional Wetland HGM Model for Wetland Management in Virginia. Final report to U.S. Environmental Protection Agency, Region III, February 2003, by the Virginia Institute of Marine Science.

Healey, M.C. 1980. Utilization of the Nanaimo River estuary by juvenile Chinook salmon, Oncorhynchus tshawytscha. Fish. Bull. 77: 653-668. 
Hillman, T.W. 2004. Monitoring Strategy for the Upper Columbia Basin. Draft report prepared for the Upper Columbia Regional Technical Team of the Upper Columbia Salmon Recovery Board, Wenatchee, Washington, February 1, 2004.

Hitchcock, C. L., and A. Cronquist. 1973. Flora of the Pacific Northwest, University of Washington Press.

Hood, W.G. 2002a. Application of landscape allometry to restoration of tidal channels. Restoration Ecology 10(2):213-222.

Hood, W.G. 2002. Landscape allometry: from tidal channel hydraulic geometry to benthic ecology. Can. J. Fish. Aquat. Sci. 59: 1418-1427.

Hume, T.M. and R.G. Bell. 1993. Methods for Determining Tidal Fluxes and Material Fluxes in Estuarine Cross-Sections. Water Quality Centre Publication No. 22. Hamilton, New Zealand.

Johnson, G.E. (ed.) 2007. Evaluating Cumulative Ecosystem Response to Restoration Projects in the Columbia River Estuary, Annual Report 2006. PNNL-16561. Report to the U.S. Army Corps of Engineers, Portland District, by Pacific Northwest National Laboratory, Richland, Washington.

Johnson, G.E. and H.L. Diefenderfer (eds.). 2008. Evaluating Cumulative Ecosystem Response to Restoration Projects in the Columbia River Estuary, Annual Report 2007. PNNL-17437. Report to the U.S. Army Corps of Engineers, Portland District, by Pacific Northwest National Laboratory, Richland, Washington.

Johnson, G.E., H.L., Diefenderfer, T.J., Berquam, B.D., Ebberts, C., Tortorci, J.D., Wilcox. 2004. Plan for Research, Monitoring, and Evaluation of Salmon in the Columbia River. PNNL-14632. Date final draft, August 10, 2004. Pacific Northwest National Laboratory, Richland, WA.

Johnson, G.E., H.L. Diefenderfer, B.D. Ebberts, C. Tortorici, T. Yerxa, J. Leary, and J.R. Skalski. 2008. Federal Columbia River Estuary Research, Monitoring, and Evaluation Program. PNNL-14632. Prepared by the Pacific Northwest National Laboratory in conjunction with NOAA Fisheries and U.S. Army Corps of Engineers Portland District and collaboration from the Lower Columbia River Estuary Partnership for the Bonneville Power Administration, Portland, Oregon. Available URL: www.salmonrecovery.gov/research_reports_pubs/research/

Johnson G.E., R.M. Thom, A.H. Whiting, G.B. Sutherland, T. Berquam, B.D. Ebberts, N.M. Ricci, J.A. Southard, and J.D. Wilcox. 2003. An Ecosystem-Based Approach to Habitat Restoration Projects with Emphasis on Salmonids in the Columbia River Estuary. PNNL-14412, Prepared for Bonneville Power Administration, Portland, Oregon, Pacific Northwest National Laboratory, Richland, WA.

Kentula, M.E., R.P. Brooks, S.E. Gwin, C.C. Holland, A.D. Sherman and J.C. Sifneos. 1992. An Approach to Improving Decision Making in Wetland Restoration and Creation. EPA/600/R92/150, U.S. Environmental Protection Agency Environmental Research Laboratory, Corvallis, Oregon.

Kukulka, T. and D.A. Jay, 2003a. Impacts of Columbia River discharge on salmonid habitat: 1. a nonstationary fluvial tide model. Journal of Geophysical Research 108(C9):3293.

Kukulka, T. and D.A. Jay, 2003b. Impacts of Columbia River discharge on salmonid habitat: 2. changes in shallow-water habitat. Journal of Geophysical Research 108(C9):3294.

Larsen D.P., P.R. Kaufmann, T.M. Kincaid, N.S. Urguhart. 2003. Detecting persistent change in the habitat of salmon-bearing streams in the Pacific Northwest. Can. J. Fish. Aquat. Sci. 61: 283-291. 
Leary, J.C, J.L. Morace, C.A. Simenstad, J.L. Burke, T.D. Counihan, J.R. Hatten, I.R. Waite, K.L. Sobocinski, J. Dietrich, J. Spromberg, L. Johnson, G. Ylitalo. 2005. Lower Columbia River Ecosystem Monitoring Project Annual Report for Year 3. Draft Report Prepared by the Lower Columbia River Estuary Partnership for Bonneville Power Administration, Portland, Oregon.

Levings, C.D. 1994. Feeding behavior of juvenile salmon and significance of habitat during estuary and early sea phase. Nordic J. Freshw. Res, 69: 7-16.

Levings, C.D, K. Conlin, B. Raymond. 1991. Intertidal habitats used by juvenile Chinook salmon (Oncorhynchus tshawytscha) rearing in the North Arm of the Fraser River estuary. Mar. Pollution Bull. 22: 20-26.

Levy, D.A. and T.G. Northcote. 1982. Juvenile salmon residency in a marsh area of the Fraser River estuary. Can. J. Fish. Aquat. Sci. 39: 270-276.

Lichatowich, J.A. and L.E. Mobrand. 1995. Analysis of Chinook Salmon in the Columbia River from an ecosystem perspective. Research Report, Mobrand Biometrics, Vashon, Washington.

McConnell, R.J. and G.R. Snyder. 1972. Key to Field Identification of Anadromous Juvenile Salmonids in the Pacific Northwest. U.S. Dep.Commer., Natl. Ocean. Atmos. Admin., Natl. Mar. Fish. Serv., GPO 1979 690-465. 6p.

Miller, J.A. and C.A. Simenstad, 1997. A comparative assessment of a natural and created estuarine slough as rearing habitat for juvenile Chinook and Coho salmon. Estuaries 20(4):792-806.

Naiman, R.J., H. Décamps, and M.E. McClain. 2005. Riparia: Ecology, Conservation, and Management of Streamside Communities. Elsevier Academic Press, Amsterdam.

National Oceanic and Atmospheric Administration (NOAA). 2004. Monitoring Requirements under the Estuary Restoration Act. Available URL: http:/era.noaa.gov/htmls/era/era monitoring.html.

National Oceanic and Atmospheric Administration (NOAA). 2007. Biological Opinion - Remand Draft. Consultation on Remand for Operation of the Federal Columbia River Power System, 11 Bureau of Reclamation Projects in the Columbia Basin and ESA Section 10(a)(1)(A) Permit for Juvenile Fish Transportation Program (Revised and reissued pursuant to court order, NWF v. NMFS, Civ. No. CV 01-640-RE (D. Oregon)). National Marine Fisheries Service (NOAA Fisheries) Northwest Region, Seattle, Washington. October 2007. Available at http://www.salmonrecovery.gov/implementation.

National Research Council. 1992. Restoration of Aquatic Ecosystems: Science, Technology, and Public Policy, National Academic Press, Washington DC.

Neckles, H.A., M. Dionne, D.M. Burdick, C.T. Roman, R. Buchsbaum, E. Hutchins. 2002. A monitoring protocol to assess tidal restoration of salt marshes on local and regional scales. Rest. Eco. Vol. 10 (3) pp. 556-563.

Osenberg, C.W., B.M. Bolker, J.S.S. White, C.M. St. Mary, and J.S. Shima. 2006. Statistical issues and study design in ecological restorations: lessons learned from marine reserves. Pages 280-302 In, DA Falk, MA Palmer, and JB Zedler (eds.). Foundations of Restoration Ecology, Society for Ecological Restoration International and Island Press, Washington DC.

Osenberg, G.W., R.J. Schmitt, S.J. Holbrook, K.E. Abu-Sara, and A.R. Flegal. 1994. Detection of environmental impacts: Natural variability, effect size, and power analysis. Ecol. App. 4: 16-30.

OWEB (Oregon Watershed Enhancement Board). 1999. Water Quality Monitoring Guidebook. Salem, OR. 
Peet, R.K., T.R. Wentworth, and P.S. White. 1998. A flexible, multipurpose method for recording vegetation composition and structure. Castaneo 63:262-274.

Pojar, J. and A. MacKinnon (eds). 1994. Plants of the Pacific Northwest Coast: Washington, Oregon, British Columbia \& Alaska, B.C. Ministry of Forests and Lone Pine Publishing.

Raposa, K. 2002. Early responses of fishes and crustaceans to restoration of a tidally restricted New England salt marsh. Rest. Ecol. 10: 665-676.

Reimers, P.E. and R.E. Loeffel. 1967. The length of residence of residence of juvenile fall Chinook salmon in selected Columbia River tributaries. Res. Briefs, Fish Comm. Oreg. 13(1):5-19

Rice, C.A., L.L. Johnson, P. Roni, B.E. Feist, W.G. Hood, L.M. Tear, C.A. Simenstad, and G.D. Williams, 2005. Monitoring rehabilitation in temperate North American estuaries. In: P. Roni (ed.), Monitoring Stream and Watershed Restoration. American Fisheries Society, Bethesda, Maryland, pp. 165-204.

Rich, W.H. 1920. Early history and seaward migration of Chinook salmon in the Columbia and Sacramento Rivers. U.S. Bur. Fish. Bull. 37:2-73.

Roegner G.C. 1998. Hydrodynamic control of the supply of suspended chlorophyll a to estuarine infaunal bivalves. Est. Coast. Shelf Sci. 47: 319-331.

Roegner, G.C, A. Baptista, D.L. Bottom, J. Burke, L. Campbell, C. Elliot, S. Hinton, D. Jay, M.A. Lott, T. Lundrigan, R. McNatt, P. Moran, C.A. Simenstad, D. Teel, E. Volk, J. Zamon, and E. Casillas. 2005. Estuarine habitat and juvenile salmon - current and historical linkages in the lower Columbia River and estuary, 2002-2004. Report of Research by Fish Ecology Division, NOAA Fisheries to Portland District, U.S. Army Corps of Engineers.

Roman, C.T., K.B. Raposa, S.C. Adamowicz, M.J. James-Pirri, and J.G. Catena. 2002. Quantifying vegetation and nekton response to tidal restoration of a New England saltmarsh. Res. Ecol. 10: 450-460.

Roni, P., T.J. Beechie, R.E. Bilby, F.E. Leonetti, M.M.Pollock, and G.R. Pess. 2002. A review of stream restoration techniques and a hierarchical strategy for prioritizing restoration in Pacific Northwest watersheds. North American J. Fish. Mgmt. 22: 1-20.

Sanderson, E.W., W.L. Ustin, T.C. Foin. 2000. The influence of tidal channels on the distribution of salt marsh plant species in Petaluma Marsh, CA, USA. Plant Ecology 146:29-41.

Scott, W. B. and E.J. Crossman. 1973. Freshwater Fishes of Canada. Fisheries Res. Bd. Of Canada. Bulletin 184.

Seber, G.A.F. and E.D. Le Cren. 1967. Estimating population parameters from catches large relative to the population. Journal of Animal Ecology 36: 631-643

Shreffler, D.K., C.A. Simenstad, and R.M. Thom. 1990. Temporary residence of juvenile salmon n in a restored estuarine wetland. Can. J. Fish. Aquat. Sci. 47: 2079-2084.

Shreffler, D.K., C.A. Simenstad, R.M. Thom. 1992. Foraging by juvenile salmon in a restored estuarine wetland. Estuaries 15: 204-213.

Simenstad, C.A. and J.R. Cordell. 2000. Ecological assessment criteria for restoring anadromous salmonid habitat in Pacific Northwest estuaries. Ecological Engineering 15:283-302. 
Simenstad, C.A., D.A. Jay, and C.R. Sherwood, 1992. Impacts of watershed management on land-margin ecosystems: the Columbia River estuary as a case study. In: R.J. Naiman (ed.), Watershed Management: Balancing Sustainability and Environmental Change, Springer-Verlag, New York, pp. 266-306.

Simenstad, C.A., C.D. Tanner, R.M. Thom and L.L. Conquest. 1991. Estuarine habitat assessment protocol. EPA 910/9-91-037. Prepared for U.S. EPA, Region 10 Office, Puget Sound, Seattle, WA.

Simenstad, C.A. and R.M. Thom. 1996. Functional equivalency trajectories of the restored Gog-Le-Hi-Te estuarine wetland. Ecological Applications 6:38-56.

Skalski, J.R., D.A. Coats, and A.K. Fukuyama. 2001. Criteria for oil spill recovery: a case study of the intertidal community of Prince William Sound, Alaska, following the Exxon Valdez oil spill. Env. Man. 28(1):9-18.

Small, LF, CD McIntire, KB MacDonald, JR Lara-Lara, BE Frey, MC Amspoker, and T Winfield. 1990. Primary production, plant and detrital biomass, and particle transport in the Columbia River Estuary. L.F. Small, L.F. editor. Columbia River: Estuarine System. Progress in Oceanography 25:1-4.

Sommer, T.R., M.L. Nobriga, W.C. Harrell, W. Batham, and W.J. Kimmerer. 2001. Floodplain rearing of juvenile Chinook salmon: evidence of enhanced growth and survival. Can. J. Fish. Aquat. Sci. 58:325-333.

Steyer, G.D., C.E. Sasser, J.M. Visser, E.M. Swenson, J.A. Nyman, and R.C. Raynie. 2003. A proposed coast-wide reference monitoring system for evaluating wetland restoration trajectories in Louisiana. Environmental Monitoring and Assessment 81: 107-117.

Stolz, A, C. Martin, and C. Wong. 2005. Vertical control in a tidally influenced complex river system with a fixed low water datum. Presented at Hydrographic Society of America Meeting (US Hydro 2005), March 20-31, 2005 San Diego, California. Available at: http://www.thsoa.org/hy05/09_1.pdf

Tanner, C.D., J.R. Cordell, J. Rubey, L.M. Tear. 2002. Restoration of freshwater intertidal habitat functions at Spencer Is., Everett, Washington. Res. Ecol. 10: 564-576.

Tegler, B., M. Sharp, M.A. Johnson. 2001. Ecological monitoring and assessment network's proposed core monitoring variables: an early warning of environmental change. Environ. Monitor. Assess. 67: 29-56.

Thom, R.M. 1997. System-development matrix for adaptive management of coastal ecosystem restoration projects. Ecological Engineering 8:219-232.

Thom, R.M. 2000. Adaptive management of coastal ecosystem restoration projects. Ecological Engineering 15:365-372.

Thom, R.M., A.B. Borde, N.R. Evans, C.W. May, G.E. Johnson, and J.A. Ward. 2004. A Conceptual Model for the Lower Columbia River Estuary. Final report to the U. S. Army Corps of Engineers by Pacific Northwest National Laboratory, Richland, WA.

Thom, R.M. and K.F. Wellman, 1996. Planning aquatic ecosystem restoration monitoring programs. IWR Report 96-R-23, prepared for Institute for Water Resources, U.S. Army Corps of Engineers, Alexandria, VA and Waterways Experimental Station, U.S. Army Corps of Engineers, Vicksburg, MS. 
Thom, R.M., G.W. Williams, H.L. Diefenderfer. 2005. Balancing the need to develop coastal areas with the desire for an ecologically functioning coastal environment: Is net ecosystem improvement possible? Res. Ecol 13:193-203.

Thom, R.M., R. Zeigler and A.B. Borde. 2002. Floristic development patterns in a restored Elk River estuarine marsh, Grays Harbor, Washington. Rest. Ecol. 10(3): 487-496.

Thomas, D.W. 1983. Changes in the Columbia River estuary habitat types over the past century. Columbia River Estuary Data Development Program. 51 (Available from Columbia River Estuary Study Taskforce. P.O. Box 175, Astoria, OR 97103).

Trexler, J.C. and D.E. Busch. 2003. Monitoring, assessment, and ecoregional initiatives: a synthesis. Pages 405-424 In D.E. Busch and J.C. Trexler, eds. Monitoring Ecosystems: Interdisciplinary Approaches for Evaluating Ecoregional Initiatives, Island Press, Washington DC.

Waples, R. S. 1991. Pacific salmon, Oncorhynchus spp., and the definition of "species" under the Endangered Species Act. U.S. Natl. Mar. Fish. Serv., Mar. Fish. Rev. 53(3):11-22.

Washington Salmon Recovery Funding Board. 2004. Protocol for monitoring effectiveness of riparian planting projects. MC-3. April, 2004.

Washington State Department of Ecology. 2001. An Aquatic Plant Identification Manual for Washington's Freshwater Plants, Washington State Department of Printing.

Weitkamp, L.A. 1994. A review of the effects of dams on the Columbia River estuarine environment, with special reference to salmonids. Report to US Department of Energy, BPA. 120 pages. Available from National Marine Fisheries Service, 2725 Montlake Blvd. E., Seattle WA, 98112.

Williams, P.B. and M.K. Orr. 2002. Physical evolution of restored breached levee salt marshes in the San Francisco Bay estuary. Res. Ecol. 10: 527-537.

Wright, A., W.A. Marcus, and R. Aspinall. 2000. Evaluation of multispectral, fine scale digital imagery as a tool for mapping stream morphology. Geomorphology 22: 107-120.

Zedler, J.B. 1988. Salt Marsh restoration: lessons from California. Pages 123-138 in J. Caines, ed. Rehabilitating Damaged Ecosystems. Volume 1. CRC Press, Boca Raton, Florida.

Zedler, J.B., editor. 2001. Handbook for Restoring Tidal Wetlands. CRC Press, Boca Raton, Florida. 
